Florida International University FIU Digital Commons

5-15-2018

\title{
Three Essays on the Behavioral Responses to Coastal Hazards and Vulnerability
}

Fan Jiang

fian003@fiu.edu

DOI: $10.25148 /$ etd.FIDC006598

Follow this and additional works at: https://digitalcommons.fiu.edu/etd

Part of the Economics Commons

\section{Recommended Citation}

Jiang, Fan, "Three Essays on the Behavioral Responses to Coastal Hazards and Vulnerability" (2018). FIU Electronic Theses and Dissertations. 3759.

https://digitalcommons.fiu.edu/etd/3759

This work is brought to you for free and open access by the University Graduate School at FIU Digital Commons. It has been accepted for inclusion in FIU Electronic Theses and Dissertations by an authorized administrator of FIU Digital Commons. For more information, please contact dcc@fiu.edu. 


\title{
FLORIDA INTERNATIONAL UNIVERSITY
}

Miami, Florida

THREE ESSAYS ON THE BEHAVIORAL RESPONSES TO COASTAL HAZARDS

AND VULNERABILITY

\author{
A dissertation submitted in partial fulfillment of \\ the requirements for the degree of \\ DOCTOR OF PHILOSOPHY \\ in \\ ECONOMICS \\ by
}

Fan Jiang

2018 
To: Dean John F. Stack, Jr.

Green School of International and Public Affairs

This dissertation, written by Fan Jiang, and entitled Three Essays on the Behavioral Responses to Coastal Hazards and Vulnerability, having been approved in respect to style and intellectual content, is referred to you for judgment.

We have read this dissertation and recommend that it be approved.

Mahadev Bhat

Jesse Bull

B M Golam Kibria

Pallab Mozumder, Major Professor

Date of Defense: May 15, 2018

The dissertation of Fan Jiang is approved.

Dean John F. Stack, Jr. Green School of International and Public Affairs

Andrés G. Gil

Vice President for Research and Economic Development and Dean of the University Graduate School

Florida International University, 2018 
(C) Copyright 2018 by Fan Jiang

All rights reserved. 


\section{DEDICATION}

To my beloved parents, I could not finish my dissertation without your support and encouragement. 


\section{ACKNOWLEDGMENTS}

I wish to express my deep appreciation and sincere gratitude to my major advisor, Dr. Pallab Mozumder, for his mentorship and guidance in helping me navigate through this degree program and pursue my academic goal. I would also like to thank all the members of my committee, Dr. Mahadev Bhat, Dr. Jesse Bull, and Dr. B M Golam Kibria, for their insightful comments and support.

I am also grateful to Dr. Cem Karayalcin and Dr. Mihaela Pintea and the other faculty members from the Economics Department and the Statistics Department for their dedication during my Master's and Ph.D. studies at Florida International University. I would also like to thank the following staff at the Department of Economics for their generous support during my graduate studies: Maria Cossio, Mariela Delgado, Lorette Garcia, and Mayte Rodriguez.

Finally, I want to acknowledge the research guidance and support from my coauthors, Dr. Chiradip Chatterjee, Dr. Xiaoquan Jiang, Dr. Qiang Kang, and Dr. Bakhtear Talukdar. 
ABSTRACT OF THE DISSERTATION

THREE ESSAYS ON THE BEHAVIORAL RESPONSES TO COASTAL HAZARDS

AND VULNERABILITY

by

Fan Jiang

Florida International University, 2018

Miami, Florida

Professor Pallab Mozumder, Major Professor

This dissertation consists of three papers in environmental and natural resource economics. The first paper estimates the value of statistical lives (VSL) from hurricane evacuation behavior through an empirical analysis. I present empirical models that predict individuals' willingness to pay (WTP) for avoiding hurricane risks revealed through their evacuation behavior. Using survey data from Texas residents (who were affected by Hurricane Ike), I analyze the individuals' hurricane evacuation decisions and their corresponding WTP for evacuation. I also estimate the individuals' WTP for avoiding hurricane risks under both voluntary and mandatory evacuation orders and calculate the associated VSL. The findings can be useful to emergency management agencies for evacuation planning.

In the second paper, I study market responses to multiple hurricanes based on evidence from real estate sales data. Unlike earlier studies that examined the effect of hurricane 
exposures on property value, the present study considers how multiple hurricane hits affect the home value. I use repeat sales data from three counties in Florida from 2000 to 2010 and develop a hedonic price model. The findings identify the determinants that influence the property value and provide valuable insights for homebuyers and sellers. The study also provides useful insights regarding the benefits of hurricane mitigations to Florida residents and beyond.

The third paper investigates the time preference and the dynamics of evacuation behavior based on evidence from Hurricane Ike and Hurricane Sandy. This paper contributes to the literature on households' evacuation timing decisions by investigating the factors influencing people's time preference for evacuation behavior. Unlike other studies, I examine the residents' evacuation behavior across the Gulf coast as well as the Northeast and Mid-Atlantic coasts from a comparative perspective. I use one survey dataset from Texas residents who experienced Hurricane Ike and another survey dataset from the Northeastern and Mid-Atlantic US states that were affected by Hurricane Sandy. The results provide insights for future hurricane evacuation planning and emergency management. 
CHAPTER 1 ESTIMATING THE VALUE OF STATISTICAL LIVES FROM HURRICANE EVACUATION BEHAVIOR: AN EMPIRICAL ANALYSIS .1

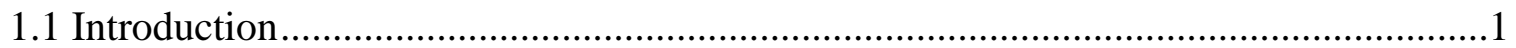

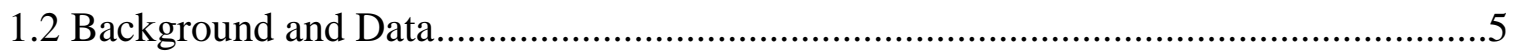

1.3 Analytical Framework and Empirical Analyses ....................................................

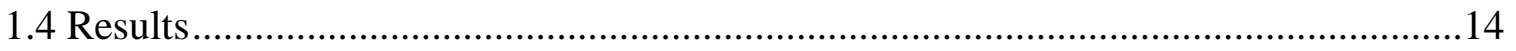

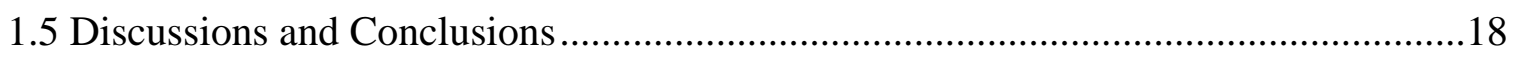

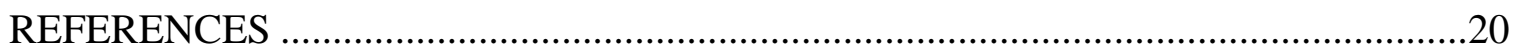

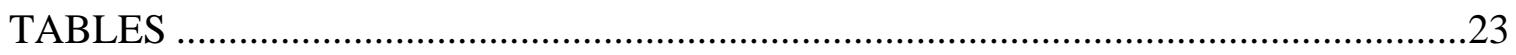

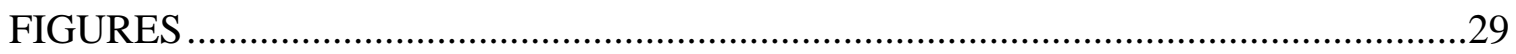

CHAPTER 2 MARKET RESPONSES TO MULTIPLE HURRICANE EXPOSURES IN FLORIDA： EVIDENCE FROM REAL ESTATE SALES DATA …...........................33

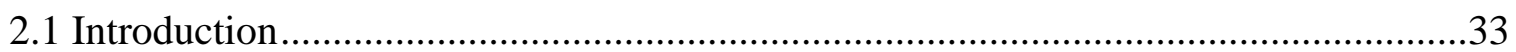

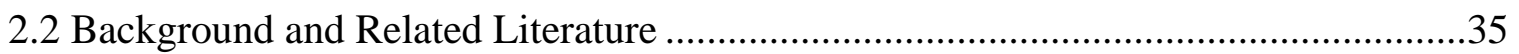

2.3 Analytical Framework and Empirical Modeling ……................................................37

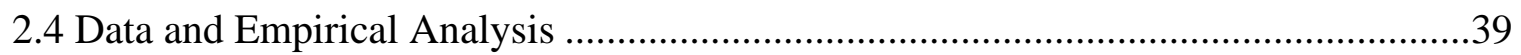

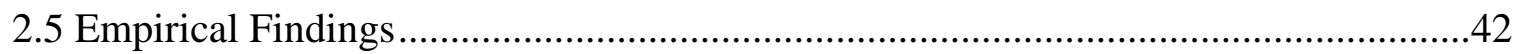

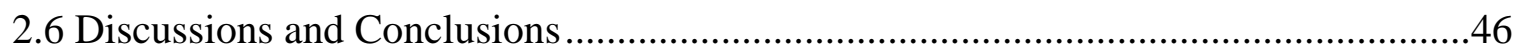

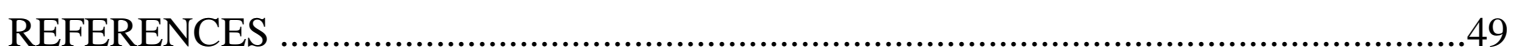

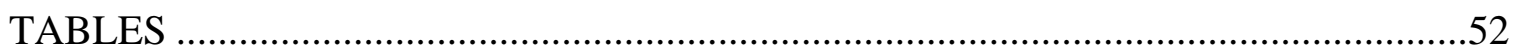

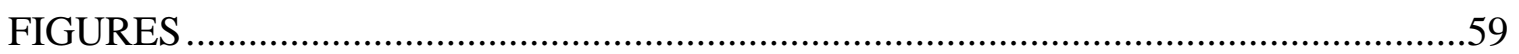

CHAPTER 3 TIME PREFERENCE AND THE DYNAMICS OF EVACUATION BEHAVIOR: EVIDENCE FROM HURRICANE IKE AND HURRICANE SANDY....62

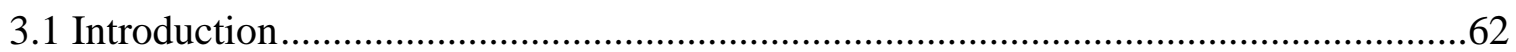

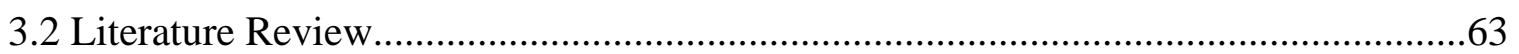

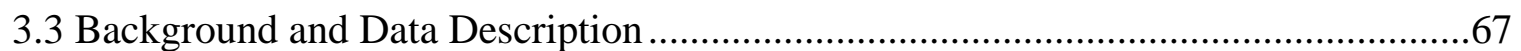

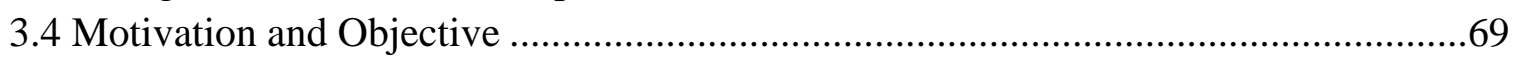

3.5 Analytical Framework and Empirical Modeling ...................................................69

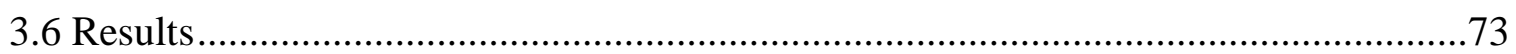

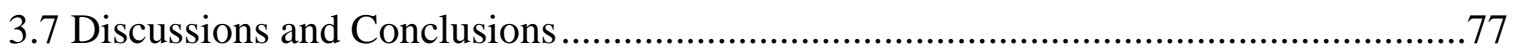

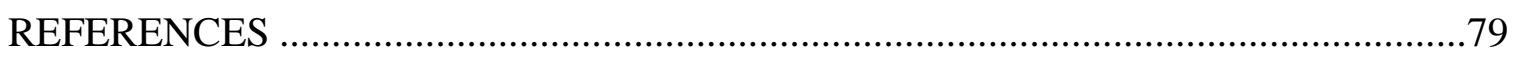

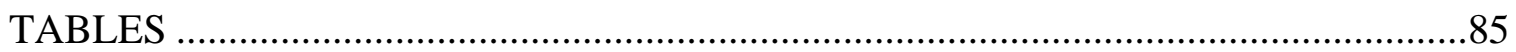




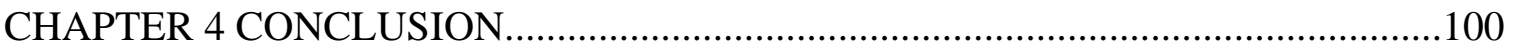

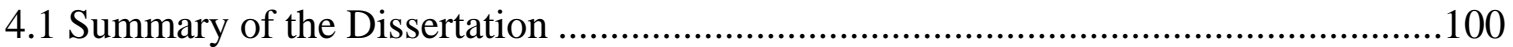

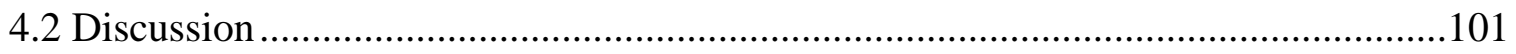

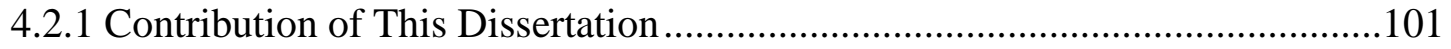

4.2.2 Limitations and Scope for Future Research …………....................................103

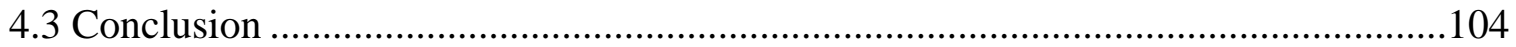

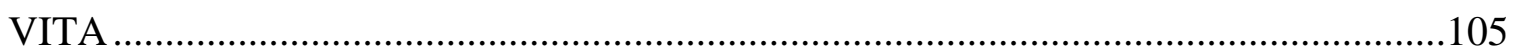




\section{LIST OF TABLES}

$\begin{array}{lll}\text { TABLE } & \text { PAGE }\end{array}$

1.1 Variable Definitions and Descriptive Statistics ....................................................23

1.2 Revealed and Stated Preference: Evacuations by Scenario ...................................24

1.3 Revealed and Stated Preference: Individual Evacuation Expenditure........................24

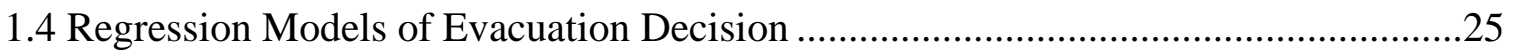

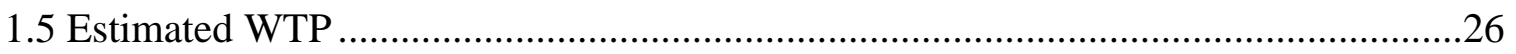

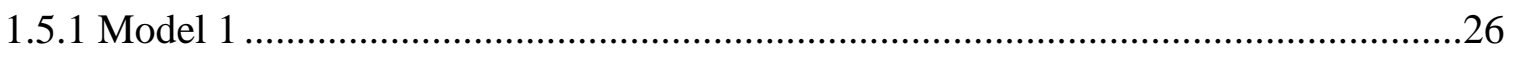

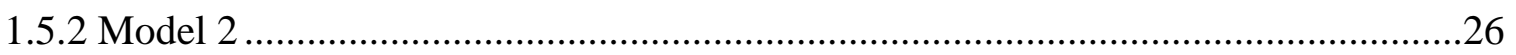

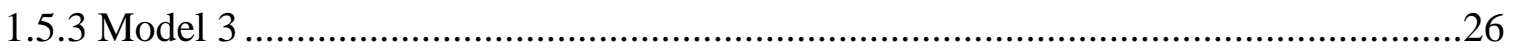

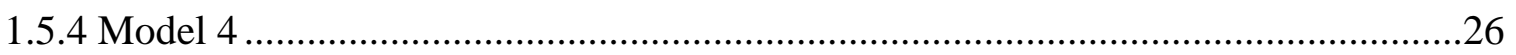

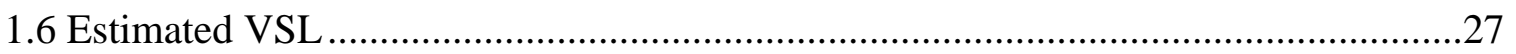

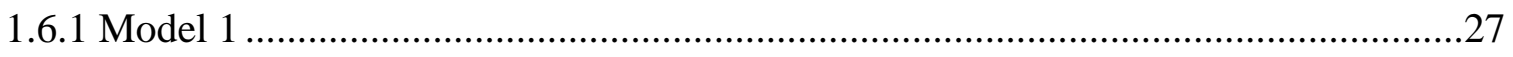

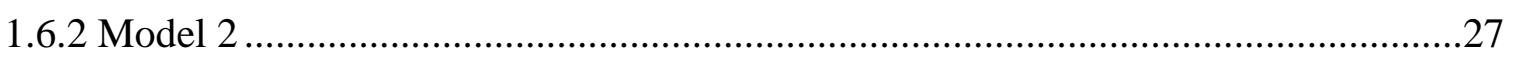

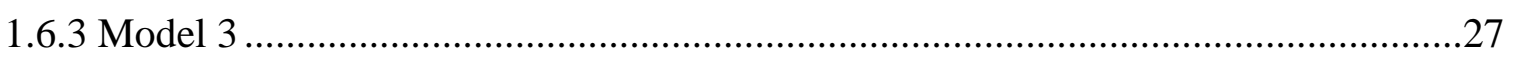

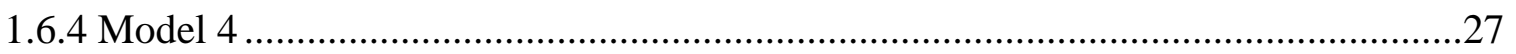

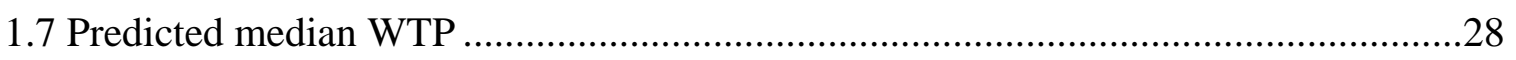

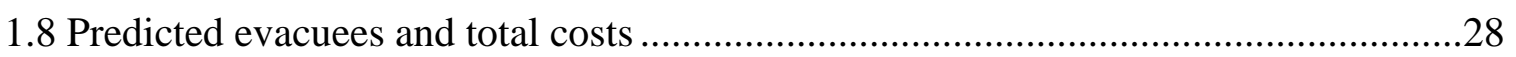

2.1 Variable Definitions and Descriptive Statistics ................................................52

2.2 Spatial/temporal decomposition of sale prices in Martin County ..............................53 
2.4 Variations in Property Values for Totalhit.

2.5 Hedonic Model Estimation of Real Estate Sales for Totalhit with Hurricane

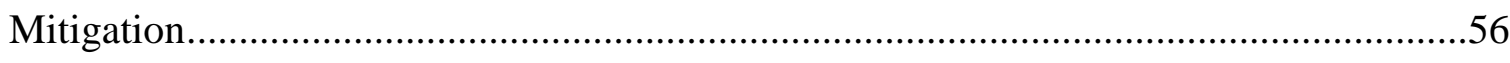

2.6 Variations in Property Values for Totalhit with Hurricane Mitigation........................58

3.1 Variable Definitions and Descriptive Statistics for Analyzing Evacuation

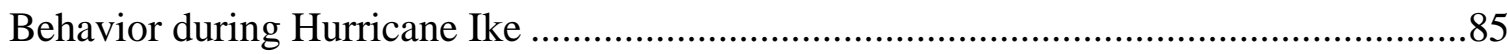

3.2 Variable Definitions and Descriptive Statistics for Analyzing Evacuation

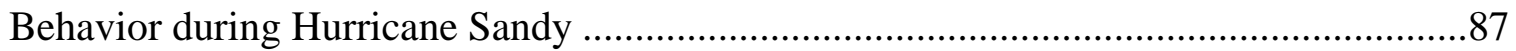

3.3 Selection Models of Evacuation Time Decision for Hurricane Ike ...........................89

3.4 Robustness Analysis for Hurricane Ike..........................................................91

3.5 Selection Models of Evacuation Time Decision for Hurricane Sandy ......................92

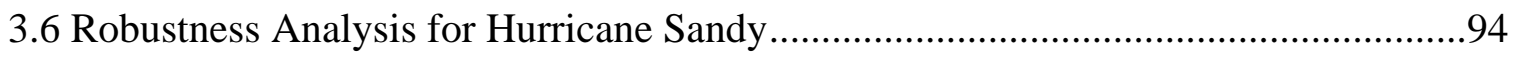




\section{LIST OF FIGURES}

FIGURE

PAGE

1.1 Hurricane Ike track

1.2 Geo-coded location of respondents participated in the survey and their evacuation decision during Hurricane Ike .29

1.3 Process for determining the individual's WTP for hurricane risks

1.4 Evacuation order received by respondents during Hurricane Ike 30

1.5 Respondents who had prior hurricane experience

1.6 Predicted WTP by Evacuation orders

1.7 Predicted VSL by Evacuation orders.

2.1 Percentages of Total Sales with Property Value Appreciation from the Year 2000-2010 in Martin County

2.2 Location of St. Lucie, Martin and Palm Beach County with Hurricane Tracks of

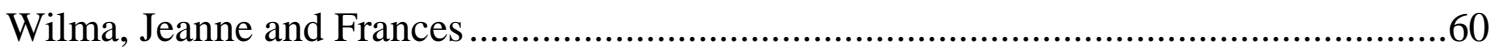

2.3 Variations in Property Values for Totalhit and Other Characteristics .........................61

2.4 Variations in Property Values for Totalhit with Hurricane Mitigation and Other

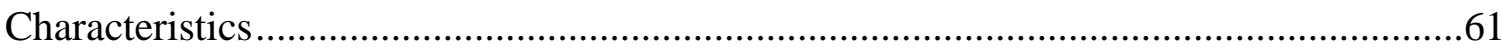

3.1 Respondents who have hurricane experience before for Ike ………..........................95

3.2 Respondents who have hurricane experience before for Sandy .................................95

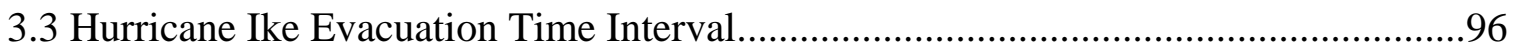

3.4 Hurricane Sandy Evacuation Time Interval.............................................................96

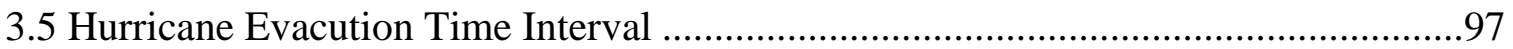

3.6 Reference Point with Hurricane Experience.............................................................98 


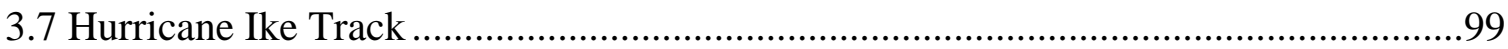

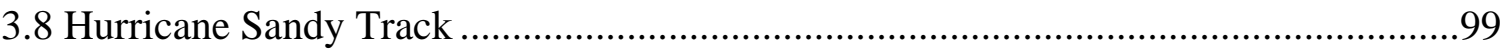




\section{CHAPTER 1}

\section{ESTIMATING THE VALUE OF STATISTICAL LIVES FROM HURRICANE EVACUATION BEHAVIOR: AN EMPIRICAL ANALYSIS}

\subsection{Introduction}

Hurricanes are among of the most destructive natural disasters affecting coastal areas. Hurricanes cause fatalities and severe property damage due to the massive rain and damaging winds. Despite considerable increases in forecast accuracy, many casualties due to hurricanes continue to occur in the US and worldwide. Texas is one of the most vulnerable states and has experienced many hurricane events in its history due to the long coastlines of the Gulf of Mexico (Roth 2010). In 2017, Hurricane Harvey made landfall in Texas and caused at least 104 deaths and USD \$125 billion in damage, which tied with Hurricane Katrina as the costliest hurricane on US record (NOAA 2018).

In any natural disaster, the first priority of policymakers is to prevent immaterial damages, such as human deaths. Evacuation is considered an effective option for reducing hurricane-related fatalities and property damage. Social scientists and community planners have found that evacuation orders are a useful policy tool in hurricane-prone areas. Emergency management policies such as mandatory or voluntary evacuation orders are often used to evacuate a large number of people in a timely fashion during a hurricane event. 
Although evacuation orders benefit public safety, they impose unexpected costs on the evacuees in the path of the storm. Whitehead (2005) argued that policymakers should consider both the costs and benefits when issuing evacuation orders before a hurricane makes landfall. However, little information is available on individual or household evacuation expenditures for a hurricane event. In one of the few studies focused on estimating expenditures, Czajkowski (2011) found that the overtime total evacuation costs initially increase and then decrease after a peak. Czajkowski (2011) also argued that the 'expected costs of evacuating' are lower than the 'expected costs of not evacuating.' Mozumder and Vasuez (2015) used survey data to estimate the average household evacuation expenditures under different hurricane evacuation orders. The previous literature implies that it is crucial to evaluate evacuation expenditures precisely to enable emergency managers to adopt effective evacuation policies.

Different types of life-saving policies reduce mortality risks through changing the level of risk for affected people (Robinson 2007). Economists have developed a method for aggregating these changes in risk exposures by using the concept of value of statistical life (VSL) in a wide range of contexts. VSL is a concept developed to estimate the economic value placed on changes in people's death risk. Specifically, VSL reflects the aggregation of people's WTP for avoiding premature death risks. For instance, if the members of a population of one million were willing to pay USD $\$ 100$ on average for a mortality risk of one in one million, the corresponding VSL would be USD\$100 million. 
Several empirical VSL studies have been conducted. For instance, research on the use of bicycle safety helmets estimated the VSL in three age categories, with values ranging from USD\$1.1 to USD\$4 million (Jenkins et al. 2001). Rheinberger (2011) used a mixed logit model and obtained estimations of the VSL related to fatal accidents on Alpine roads, with values ranging from USD\$6.0 to USD\$7.8 million. The VSL estimated for automobile accident risk reduction is in the range of USD\$2.6 to USD\$3.7 million (Dreyfus and Viscusi 1995). Mrozek and Taylor (2002) conducted a meta-analysis of VSL studies and estimated a range of VSL from USD \$1.5 to USD \$2.5 million. Viscusi and Aldy (2003) found a range of VSL from USD\$4 to USD\$9 million by using labor market data.

Although studies related to VSL can be found in a wide range of contexts, surprisingly, very few reviews are available for natural disasters, particularly for hurricanes. Among closely related studies, Cropper (2009) provided a theoretical framework and estimated the VSL for mortality and morbidity from disaster risks. Blomquist (2004) also reviewed the VSL literature focusing on environmental policies and estimated the range of VSL values from labor and construction markets. Viscusi (2009) found that the VSL estimate for preventing terrorism deaths, which are close to the VSL estimates for preventing deaths from traffic accidents, are twice that of the VSL estimate for preventing natural disaster-induced deaths. 
In the literature related to the present study, Whitehead (2003) applied a joint probit model to survey data from North Carolina and calculated the difference in total expenditures for different types of evacuation orders under different storm categories. By using the VSL approach (based on Mrozek and Taylor, 2002), Whitehead estimated approximately how many lives can be saved if the government were to change from a voluntary evacuation order to a mandatory order for different hurricane categories. Bockarjova and Verhoef (2012) estimated the VSL ( $€ 6.3$ to $€ 7.2$ million), the value of statistical evacuation ( $€ 2,300$ to $€ 2,500$ ), and the value of statistical injury ( $€ 91,000$ to $€ 102,000)$ in flooding events.

My objective in this paper is to make a further contribution to the literature on VSL regarding hurricane evacuation to provide insights into the design of emergency management policies. I use both revealed and stated preference evacuation expenditure data from households who experienced Hurricane Ike. The estimated mean evacuation expenditure is then used to calculate the VSL under different evacuation orders. In contrast to Whitehead (2003), I use my VSL estimates to calculate the lives saved under different emergency policies. I also examine these estimates with the notion of 'USD $\$ 1,000,000$ per mile,' which is often used by emergency management agencies for justifying evacuation orders. 
Another outstanding contribution of this paper is that I estimate the WTP from modeling and calculate the associate VSL, which is not based on the labor market. The results indicate that an individual's marginal WTP is approximately USD $\$ 904$ to USD\$5,545 under a voluntary evacuation order and approximately USD\$1,857 to USD $\$ 7,621$ when the evacuation order is mandatory. Depending on the type of evacuation orders, the VSL estimates range from USD\$0.5 to USD\$3.8 million. When using the lower bound of USD\$0.5 million of VSL, 22 lives can be saved if the government changes a voluntary evacuation order to a mandatory order.

\subsection{Background and Data}

On September 13, 2008, Hurricane Ike hit Galveston Island with damaging winds of 110 miles per hour, 22-foot storm surges and coastal flooding (Hurricane Ike track, Figure 1.1). Hurricane Ike primarily affected Texas, Louisiana, and Arkansas and caused at least 84 deaths in these three states, with insured damage of approximately USD\$19.3 billion. The total property damage was approximately USD $\$ 24.9$ billion. Hurricane Ike was the sixth costliest of any Atlantic hurricane and the second costliest hurricane in Texas (NHC 2018).

Furthermore, over 140,000 residents who lived in Hurricane Ike-affected areas failed to evacuate. Many residents who experienced heavy traffic jams during Hurricane Rita chose not to leave. Some people could not evacuate due to flooding. Approximately 100,000 houses were flooded in Texas during Hurricane Ike. Approximately 3,000 
people were rescued during that flooding and thereafter. During that time, Galveston was announced as not suitable for living and Houston experienced a one-week curfew due to the shortage of electric power. More than 50,000 residents of Galveston were in a mandatory evacuation zone; unfortunately, approximately only $60 \%$ evacuated. More than 140,000 people lived in the death zone, but only approximately $70 \%$ were able to leave.

To investigate people's WTP for evacuation to avoid hurricane risks, researchers at Florida International University conducted a survey in which they interviewed 1,099 households from Texas by phone (Figure 1.2). The survey questionnaire asked the residents to report their hurricane-related experiences and the behaviors they adopted to reduce the risk during Hurricane Ike. Evacuees were asked how much they spent during evacuation for transportation, food, and lodging. Conversely, those residents who did not evacuate were asked to estimate their evacuation expenditures had they decided to leave.

To estimate the wage loss of residents during a hurricane evacuation, the respondents were asked to report their annual income. The survey also gathered other socioeconomic characteristics of respondents (i.e., gender, marital status, age, and family size). To calculate the VSL under different evacuation orders, the survey asked whether respondents received an evacuation order during Hurricane Ike and the voluntary or mandatory order they received. Respondents also reported whether or not they conducted any hurricane preparedness or mitigation measures before this hurricane event (such as 
elevating their housing unit and installing shutters or window protection). With the data collected through this survey in the aftermath of Hurricane Ike, I attempt to estimate the individuals' mean WTP for evacuation to avoid hurricane risks and calculate the corresponding VSL.

For empirical analyses, I combine the revealed preference (RP) data and the stated preference (SP) data (Louviere 1996). A strong correlation always exists between variables for RP data, and the hypothetical nature limits SP data. I can control for these limitations by combining the RP and SP data and proposing different hypothetical scenarios (Whitehead et al. 2001). Whitehead (2005) predicted the validity by combining the RP and SP behavior data from a survey of North Carolina's coastal area. Smith (1999) estimated the hurricane evacuation expenditures using combined RP and SP data. Price (1999) conducted an RP and SP analysis and estimated individuals' WTP in decision-making. Using the combined RP and SP data, I predict the individual's marginal WTP and compare the individual' marginal WTP ( $\mathrm{SP}=$ mean) and the revealed WTP $(\mathrm{SP}=0)$.

\subsection{Analytical Framework and Empirical Analyses}

This section describes the theoretical framework of VSL associated with an individual's WTP for evacuation to avoid hurricane risks. The theoretical framework is based on the lifecycle consumption model of Yaari (1965). Cropper and Sussman (1990) utilized the lifecycle consumption model to derive an individual's WTP for death risk reduction. 
Shepard and Zeckhauser (1982) analyzed the lifecycle consumption model and derived the WTP for an increment in survival rate. The lifecycle consumption model can also be applied to investigate the effects of health status and age on the WTP for fatality risk reduction (Cropper et al. 2002). The theoretical framework of VSL used here is based on the lifecycle model. At age $\mathrm{i}$, individuals choose future consumption streams to maximize expected utilities:

$V_{i}=\sum_{i=t}^{T} p_{i, t}(1+\theta)^{i-t} U_{t}\left(C_{t}\right)$

where $V_{i}$ is the expected utility of consumption in each period i, $U_{t}\left(C_{t}\right)$ is the expected utility of consumption in time $t, p_{i, t}$ is the probability of an individual surviving from age i to age $t$, and $\theta$ is the discount rate of time preference. Yaari (1965) calculated the budget constraint that people could borrow and lend at rate $r$ :

$$
\sum_{t=i}^{T} p_{i, t}(1+r)^{i-t} C_{t}=\sum_{t=i}^{T} p_{i, t}(1+r)^{i-t} Y_{t}+W_{i}
$$

The present value of expected incomes plus initial wealth equals the present value of expected consumption. If the probability that an individual will die during the current period is $D_{i}$ and $p_{i, t}$ is the product of the individual's survival probabilities in all periods, then

$$
p_{i, t}=\left(1-D_{i}\right)\left(1-D_{i+1}\right) \ldots\left(1-D_{t-1}\right)
$$

The VSL can be expressed as follows: 
$W T P_{i, j}=-\frac{d V_{i} / d D_{j}}{d V_{i} / d W_{j}} d D_{j} \equiv V S L_{i, j}$

For the empirical approach, I use a methodology similar to that used for the labor market (Viscusi 1993). Controlling for other factors of the evacuation, I estimate the individual's WTP for avoiding hurricane risks. The production possibility frontier (PPF) curves of voluntary and mandatory evacuation orders are shown in Figure 1.3 as green lines. $q$ is the probability that an individual experiences hurricane risks under different evacuation orders, and $w(q)$ is the WTP under different evacuation orders. For an individual who receives the evacuation orders in Figure 1.3, the optimal WTP is the point at which the individual's constant expected utility locus $E U$ (the red lines) is tangent to PPF.

The observed points $(q, w)$ reflect the influence of both supply and demand on the market equilibrium for the entire set of individuals; all points $(q, w)$ compose the blue line $\mathrm{T}$. The estimated rate of tradeoff $\frac{\partial w}{\partial q}$ equals the slope of T, providing a local measure of the WTP-risk tradeoff for marginal changes in risk. For any given individual located along T, the estimated slope simultaneously reflects the marginal willingness to accept the risk and the marginal WTP for greater safety.

Suppose that $H(w)$ denotes the utility of being healthy if respondents evacuate for the hurricane and $I(w)$ denotes the utility of being injured if respondents do not evacuate. The 
WTP-risk combinations that maintain an individual's constant expected utility level consist of the points that satisfy

$T=(1-q) H(w)+q I(w)$

The WTP-risk tradeoff along this curve is given by

$\frac{d w}{d q}=-\frac{T_{q}}{T_{w}}=\frac{H(w)-I(w)}{(1-q) H^{\prime}(w)-q I^{\prime}(w)}>0$

or the WTP amount increases with the risk level.

In the empirical analysis, I use an unbalanced panel of revealed and SP data and utilize an ordinary least squares (OLS) regression model to analyze the evacuation decision as described below:

$y=\alpha+\beta X+\gamma_{i} Z_{i}+\varepsilon$

( $i=1$ for voluntary evacuation, and $\mathrm{i}=2$ for mandatory evacuation)

Here, $y=1$ if the individual chooses to evacuate and 0 otherwise, $\alpha$ is the intercept of the regression model, $X$ represents independent variables including individual characteristics and respondents' attitudes toward Hurricane Ike, and $\beta$ is the coefficient to be estimated. $Z_{i}=1$ if the respondents received an evacuation order and 0 otherwise, $\gamma_{i}$ is the coefficient of $Z_{i}$, and $\varepsilon$ is the error term of the regression, which is assumed to follow a normal distribution. 
Table 1.1 displays the definitions and descriptive statistics. First, I summarize the information regarding the dependent variable EVAC (the evacuation decision). Approximately half of the respondents evacuated for Hurricane Ike. The INDEXP (individual expenditure) is included, as is the RPINDEXP (revealed preference expenditure). The average INDEXP is USD $\$ 322$, and the average RPINDEXP is USD $\$ 259$ (Table 1.3). The variable INCOME (households' annual income in intervals of USD $\$ 10,000)$ is used to determine the relationship between evacuation behavior and individual income. The dummy variables VOLUNTARY and MANDATORY represent voluntary and mandatory evacuation orders received. Figure 1.4 shows that approximately $25 \%$ of respondents received voluntary evacuation orders and $30 \%$ of respondents received mandatory orders.

EXPERIENCE represents whether the respondent evacuated for Hurricane Rita. Figure 1.5 shows that approximately $59 \%$ of respondents evacuated for Hurricane Rita. Individual characteristics and the binary variables IMPSURGE (the respondents considered the possibility of flooding to be important) and IMPCRIME (the respondents considered that being able to protect the home from crime is important) are included as control variables to investigate the individuals' attitudes toward hurricane risks and evacuation behavior. Finally, the binary variable WINDOWPREP (if the respondent was prepared to protect windows against hurricanes) is included as a control variable for other hurricane risk mitigation behavior (Solís et al., 2010). 
In the empirical analysis, I address the following specific research questions: Is the VSL for a mandatory order larger than the VSL for a voluntary order? How many lives would be saved if the government were to change a voluntary evacuation order to a mandatory one? Are VSL estimations for hurricanes significantly different from those of other risky events? Based on these questions, I test the following hypotheses:

$\mathrm{H} 1: \beta_{\text {INDEXP }}<0$

$\mathrm{H} 2: \beta_{\text {MANDATORY }}>\beta_{\text {VOLUNTARY }}>0$

$\mathrm{H} 3: \beta_{\text {EXPERIENCE }}>0$

The first hypothesis (H1) is based on the fundamental intuition that the evacuation probability of an individual decreases in tandem with expenditures incurred in the process of evacuation. According to the second hypothesis (H2), individuals who received a voluntary evacuation order have a higher likelihood of evacuation than those who received no evacuation order. Moreover, individuals who received a mandatory evacuation order have a higher probability of evacuation than those who received a voluntary evacuation order. The last hypothesis (H3) indicates that individuals who previously experienced a hurricane are more likely to evacuate than those who did not have a similar experience.

From the regression results, I calculate the individuals' WTP for different evacuation orders by using the following formula (Cameron 1988): 
$W T P=\left|\frac{\alpha+\gamma_{i}}{\beta_{\exp }}\right|$

where $\beta_{\exp }$ is the coefficient of the individual evacuation expenditure. Using this formula, I obtain four different estimates of WTP for each evacuation order from four empirical models. To improve the estimates, I apply additional information about the WTP distributions. Rheinberger (2011) used the mixed logit model to simulate the WTP distributions and the associated VSL distributions and estimated the confidence intervals, median, quartile, and mean of WTP and VSL. I use the same approach and find the upper limit, lower limit, and mean of WTP and VSL for my estimates. Based on the OLS model, I use the nonlinear transformations of the estimated parameter vectors from the fitted models and apply the delta method to calculate the variance and standard error. I assume that the WTP follows a normal distribution with the estimated mean equal to one and standard deviation equal to two; then, the WTP N [1,4]. Since the coefficient follows a normal distribution, by using $z=(x-\mu) / \sigma$, I calculate the corresponding Q1 (lower quartile), median (mean for normal case), Q3 (upper quartile), and confidence interval. From the above WTP space, I use these estimates to calculate the corresponding VSL by using the following formula (Viscusi 1993):

$V S L=\frac{W T P}{D}$

where $\mathrm{D}$ is the probability of death due to Hurricane Ike. Finally, I obtain the aggregation estimated evacuation cost as follows: 
Total expenditure $=$ mean evacuation expenditure $\times$ population $\times$ percentage of evacuation

\subsection{Results}

Table 1.1 presents the definitions and descriptive statistics of variables used in the empirical analysis. Approximately $88 \%$ of respondents owned their house, and the average household size was 2.65 . The average household income was between USD $\$ 60,000$ and USD $\$ 70,000$. Approximately $52 \%$ of respondents graduated with a college degree. Approximately $16 \%$ of respondents identified themselves as black. Approximately $32 \%$ of respondents were male, and the average age of respondents was 59 years. Approximately $38 \%$ of respondents believed that their house could be affected by flooding, a factor that was very important in evacuation decision making when a hurricane was approaching. Approximately $42 \%$ of respondents believed protecting their home from crime was very important, and $51 \%$ of respondents did use window protection to mitigate hurricane risks to their house.

Table 1.2 classifies hurricane evacuation by scenarios, evacuation orders (voluntary or mandatory), and data type (RP or SP). Table 1.3 categorizes individuals' evacuation expenditures in the same way as Table 1.2. Table 1.4 displays four models to investigate individuals' evacuation behaviors. In all models, I assume that error terms follow a standard normal distribution. Model 1 includes evacuation order, hurricane experience variables, and individuals' demographic information. Model 2 adds INCOME and 
INCOMESQ to extend the empirical specification. Model 3 and Model 4 include additional individuals' characteristics to improve the results and check the robustness of the findings from Model 1 and 2.

Models 1, 2, 3, and 4 in Table 1.4 indicate that three factors have a statistically significant impact on individuals' evacuation decision: evacuation expenditure, hurricane experience, and evacuation orders received. These results support H1 that an increase in evacuation costs will decrease the probability of evacuation. The estimations also verify $\mathrm{H} 2$, as all coefficients on hurricane evacuation orders are positive and significant in models 1, 2, 3, and 4 in Table 1.4. Furthermore, the estimated coefficients for a mandatory order are larger than those for a voluntary evacuation. These results indicate that individuals who were given evacuation orders are more likely to evacuate, and the mandatory evacuation order induced evacuation more than the voluntary order.

Whitehead (2003) stated that respondents who received a mandatory hurricane evacuation order had a higher likelihood of evacuation than those who received no order. However, contrary to my results, Whitehead found that voluntary hurricane evacuation orders did not affect people's evacuation decisions. Regarding hurricane experience, I found that individuals who evacuated for the previous hurricane (Rita) were more likely to evacuate since all coefficients of hurricane experience are positive and significant in models 1, 2, 3, and 4 in Table 1.4, which is also consistent with $\mathrm{H} 3$. 
Table 1.5 displays the estimated WTP. Using Equation 1.8, I apply the nonlinear transformations of the estimated parameter vector, constant term, coefficient of individual expenditure, and coefficients of evacuation order received (mandatory or voluntary order) to obtain the mean and standard deviation of the estimated WTP. The Model 2 is the best model in all models since only the constant term in Model 2 is significant. Based on Model 2, the marginal WTP is USD\$3,225 (Figure 1.6); the 95\% confidence interval of WTP ranges from USD\$904 to USD\$5,545 for respondents who have received voluntary evacuation orders. The marginal WTP is USD $\$ 4,739$; the 95\% confidence interval of WTP ranges from USD $\$ 1,857$ to USD $\$ 7,621$ for those who have received mandatory evacuation orders. These results also verify Equation 1.6; the WTP amount increases with the change in risk level from voluntary to mandatory evacuation received.

Using Equation 1.9, I calculate the corresponding VSL. Cropper (2009) reported that the value of statistical life is equal to the sum of reductions in the death risk multiplied by the total population. According to the National Weather Service office report, approximately 500,000 residents of Galveston were in an evacuation zone when Hurricane Ike landed. From officials' statements, the population of the Harris County evacuation zone is nearly 245,000 . I add these numbers and use the combined 745,000 people as my total population. Hurricane Ike caused 84 fatalities, and approximately 140,000 individuals were in the specific death zone. Approximately $30 \%$ residents who 
lived in that zone did not evacuate, which means nearly 42,000 people remained home and lived with the worst risk of the storm surges. I calculate the probability of death by using the 84 fatalities divided by 42,000 . Figure 1.4 shows that approximately $25 \%$ of respondents received a voluntary evacuation order, while $30 \%$ of respondents received a mandatory evacuation order. The results from models $1,2,3$, and 4 in Table 1.5 provide a range of WTP, and Table 1.6 shows the corresponding VSL. Model 2 in Table 1.6.2 shows the range of VSL from USD\$0.5 to USD\$2.8 million for the voluntary evacuation order and USD\$0.9 to USD\$3.8 million for the mandatory evacuation order.

Table 1.7 displays the individual's marginal WTP and the revealed WTP under voluntary and mandatory evacuation orders. For any given evacuation order, the individual's marginal WTP ( $\mathrm{SP}=$ mean) is always higher than the revealed WTP $(\mathrm{SP}=0)$. Figure 1.4 shows the predicted evacuation probabilities under different evacuation orders. Multiplying these evacuation probabilities to the total population, I calculate the number of total predicted evacuees. Multiplying the entire predicted evacuees by the estimated individual evacuation cost provides an estimation of the total hurricane evacuation expenditures. The total evacuation expenditures of different types of evacuation orders range from approximately USD\$61 to USD\$72 million, as presented in Table 1.8.

This empirical analysis of evacuation behavior and related hurricane evacuation expenditures provides useful insights applicable for emergency management in the 
future. The total expenditures of mandatory evacuation are approximately USD \$11 million more than the total cost of the voluntary evacuation order; the tradeoff of changing a mandatory evacuation order from a voluntary order is how many lives could be saved. The VSL estimate from Model 2 based on the marginal WTP (Table 1.6) is between USD\$0.5 million and USD\$3.8 million (Figure 1.7). Applying the VSL of USD\$0.5 million, approximately 22 lives could be saved if the government were to change a voluntary evacuation order to a mandatory order. Using the VSL of USD\$3.8 million, approximately 3 lives could be saved if the government were to change a voluntary evacuation order to a mandatory order.

\subsection{Discussions and Conclusions}

In this study, I conduct an empirical exercise for analyzing individuals' evacuation behaviors under a hurricane risk. I use individuals' evacuation expenditures and the intensity of hurricane risks (evacuation orders) to obtain individuals' attitudes toward mitigating risk. The findings indicate that the average cost of an individual's hurricane evacuation is USD\$321, and the total expenditures for coastal communities in Texas range from approximately USD\$61 million (Voluntary) to USD\$72 million (Mandatory) (Table 1.8). The approach presented here is useful because hurricane evacuation costs are difficult to measure; the often-quoted estimate of hurricane evacuation expenditure is 'one million dollars per mile' (Coudriet 1998). Whitehead (2003) argued that 'one million dollars per mile' is a gross overestimate of the opportunity costs of evacuation. In 
this study, I estimate the total expenditure as USD\$72 million. Considering that Galveston Island and Texas's coastal counties have much more than 92 miles of coastline, the opportunity costs of evacuation is 0.78 million dollars per mile. Therefore, I conclude that 'one million dollars per mile' is not a correct estimation of the hurricane evacuation expenditures.

In closing, this study utilized the RP data (respondents' actual evacuation costs) and the SP data (respondents' estimated evacuation costs had they chosen to evacuate) on the evacuation cost and the evacuation decision during Hurricane Ike. The findings from the estimated OLS models reveal identified three primary sets of determinants of evacuation decisions: 1) evacuation expenditures, 2) evacuation orders, and 3) hurricane experience. These results suggest that as the evacuation costs increase, the probability of evacuation decreases; respondents who receive evacuation orders are more likely to leave; and individuals who have experienced a hurricane are more likely to evacuate than their counterparts.

In this research, I estimate the individuals' WTP for an evacuation to mitigate hurricane risks. I apply the OLS model to estimate the individual's WTP for avoiding hurricane risks under voluntary and mandatory evacuation orders and calculate the associated VSL. The same methodology could also be applied to different hurricane events and combined with additional survey datasets to obtain the VSL estimates in other regional contexts. The results provide insight for emergency management agencies such 
that they can issue appropriate evacuation orders before a hurricane hits. Moreover, this paper indicates that more lives could be saved if governments issued a mandatory evacuation order instead of a voluntary evacuation order. Thus, the findings of this study may be useful for emergency management agencies and community planners in Texas.

\section{REFERENCES}

Blomquist, G.C., 2004. Self-protection and averting behavior, values of statistical lives, and benefit cost analysis of environmental policy. Review of Economics of the Household, 2(1), pp.89-110.

Bockarjova, M. and Verhoef, E.T., 2012. Composite valuation of immaterial damage in flooding: value of statistical life, value of statistical evacuation and value of statistical injury.

Cameron, T.A., 1988. A new paradigm for valuing non-market goods using referendum data: maximum likelihood estimation by censored logistic regression. Journal of environmental economics and management, 15(3), pp.355-379.

Coudriet, C., 1998. Personal communication.

Cropper, M.L. and Sussman, F.G., 1990. Valuing future risks to life. Journal of environmental economics and management, 19(2), pp.160-174.

Cropper, M., Krupnick, A. and Simon, N.B., 2002. Does the Value of a Statistical Life Vary with Age and Health Status? Evidence from the United States and Canada. Washington, DC: Resources for the Future.

Cropper, M., \& Sahin, S., 2009. Valuing mortality and morbidity in the context of disaster risks. World Bank Policy Research Working Paper Series, Vol.

Czajkowski, J., 2011. Is it time to go yet? Understanding household hurricane evacuation decisions from a dynamic perspective. Natural Hazards Review, 12(2), pp.72-84. 
Dreyfus, M.K. and Viscusi, W.K., 1995. Rates of time preference and consumer valuations of automobile safety and fuel efficiency. Journal of Law and Economics, pp.79-105.

Jenkins, R.R., Owens, N. and Wiggins, L.B., 2001. Valuing reduced risks to children: the case of bicycle safety helmets. Contemporary Economic Policy, 19(4), pp.397-408.

Louviere, J., 1996, June. Combining revealed and stated preference data: the rescaling revolution. In AERE conference.

Mozumder, P. and Vásquez, W.F., 2015. An empirical analysis of hurricane evacuation expenditures. Natural Hazards, 79(1), pp.81-92.

Mrozek, J.R. and Taylor, L.O., 2002. What determines the value of life? A meta analysis. Journal of Policy analysis and Management, 21(2), pp.253-270.

National Oceanic and Atmospheric Administration. January 8, 2018. Billion-Dollar Weather and Climate Disasters: Table of Events (Report).

"NHC Data Archive". www.nhc.NOAA.gov. Retrieved April 2018.

Price, C., 1999. Stated and Revealed Preference Analysis: Cost-Benefit Analysis, Democracy and Multiple-Objective Decision-Making. In Multiple Use of Forests and Other Natural Resources (pp. 46-65). Springer, Dordrecht.

Rheinberger, C.M., 2011. A mixed logit approach to study preferences for safety on alpine roads. Environmental and Resource Economics, 49(1), pp.121-146.

Robinson, L.A., 2007. Policy Monitor: How US Government Agencies Value Mortality Risk Reductions. Review of Environmental Economics and Policy, 1(2), pp.283-299.

Roth, D., 2010. Texas hurricane history. National Weather Service, Camp Springs, MD.

Shepard, D.S. and Zeckhauser, R., 1982. Life-cycle consumption and willingness to pay for increased survival. Institute for Research on Poverty. University of Wisconsin, Madison, WI.

Smith, K.T., 1999. Estimating the costs of hurricane evacuation. Manuscript. East Carolina University. Greenville, NC, 27858. 
Solís, D., Thomas, M. and Letson, D., 2010. An empirical evaluation of the determinants of household hurricane evacuation choice. Journal of Development and Agricultural Economics, 2(3), pp.188-196.

United States National Hurricane Center. January 12, 2018. Costliest U.S. tropical cyclones tables update (Report).

Viscusi, W.K., 1993. The value of risks to life and health. Journal of economic literature, 31(4), pp.1912-1946.

Viscusi, W.K. and Aldy, J.E., 2003. The value of a statistical life: a critical review of market estimates throughout the world. Journal of risk and uncertainty, 27(1), pp.5-76.

Viscusi, W.K., 2009. Valuing risks of death from terrorism and natural disasters. Journal of Risk and Uncertainty, 38(3), pp.191-213.

Whitehead, J.C., 2003. One million dollars per mile? The opportunity costs of hurricane evacuation. Ocean \& coastal management, 46(11), pp.1069-1083.

Whitehead, J.C., 2005. Environmental risk and averting behavior: Predictive validity of jointly estimated revealed and stated behavior data. Environmental and Resource Economics, 32(3), pp.301-316.

Whitehead, J.C., Haab, T.C. and Huang, J.C., 2000. Measuring recreation benefits of quality improvements with revealed and stated behavior data. Resource and energy economics, 22(4), pp.339-354.

Yaari, M.E., 1965. Uncertain lifetime, life insurance, and the theory of the consumer. The Review of Economic Studies, 32(2), pp.137-150. 


\section{TABLES}

Table 1.1 Variable Definitions and Descriptive Statistics

\begin{tabular}{|c|c|c|c|c|}
\hline Variable & Description & $\mathrm{N}$ & Mean & SD \\
\hline EVAC & $\begin{array}{l}\text { If the respondent evacuated for } \\
\text { Hurricane Ike } \\
(1=\text { Yes, } 0=\text { Otherwise })\end{array}$ & 1093 & 0.50 & 0.50 \\
\hline$I N D E X P$ & $\begin{array}{l}\text { Mean evacuation expenditures of all } \\
\text { respondents }\end{array}$ & 688 & $\begin{array}{l}321.8 \\
8\end{array}$ & 764.95 \\
\hline RPINDEXP & $\begin{array}{l}\text { Mean evacuation expenditures of } \\
\text { respondents who evacuated for } \\
\text { Hurricane Ike }\end{array}$ & 387 & $\begin{array}{l}258.8 \\
8\end{array}$ & 706.76 \\
\hline INCOME & $\begin{array}{l}\text { Households' annual income in } \\
\text { intervals } \text { of } \text { USD } \$ 10,000 \\
(1=\text { USD } \$ 10,000 \text { or less } \ldots . .11=\text { over } \\
\text { USD } \$ 100,000)\end{array}$ & 616 & 6.29 & 3.52 \\
\hline INCOMESQ & $\begin{array}{l}\text { Households' annual income } \\
\text { intervals squared }\end{array}$ & 616 & 51.88 & 46.17 \\
\hline VOLUNTARY & $\begin{array}{l}\text { If the respondent received a } \\
\text { voluntary order to evacuate }(1=\text { Yes, } \\
0=\text { Otherwise })\end{array}$ & 981 & 0.25 & 0.43 \\
\hline MANDATORY & $\begin{array}{l}\text { If the respondent received a } \\
\text { mandatory order to evacuate } \\
\text { ( } 1=\text { Yes, } 0=\text { Otherwise) }\end{array}$ & 981 & 0.30 & 0.46 \\
\hline EXPERIENCE & $\begin{array}{l}\text { If the respondent evacuated for } \\
\text { Hurricane Rita before ( } 1=\text { Yes, } \\
0=\text { Otherwise })\end{array}$ & 899 & 0.60 & 0.49 \\
\hline HHSIZE & $\begin{array}{l}\text { The number of individuals lived in } \\
\text { the respondent's household }\end{array}$ & 1056 & 2.65 & 1.56 \\
\hline$E D U C$ & $\begin{array}{l}\text { If the respondent had a college } \\
\text { degree }(1=\text { Yes, } 0=\text { Otherwise })\end{array}$ & 1013 & 0.52 & 0.50 \\
\hline$A G E$ & The respondent's age (in years) & 1031 & 59.10 & 15.73 \\
\hline OWNER & $\begin{array}{l}\text { If the respondent owned of the } \\
\text { house ( } 1=\text { Yes, } 0=\text { Otherwise })\end{array}$ & 1051 & 0.88 & 0.32 \\
\hline$B L A C K$ & $\begin{array}{l}\text { If the respondent identified } \\
\text { themselves as black (1=Yes, } \\
\text { 0=Otherwise) }\end{array}$ & 992 & 0.16 & 0.36 \\
\hline IMPSURGE & $\begin{array}{l}\text { If the respondents considered the } \\
\text { possibility of flooding to be }\end{array}$ & 816 & 0.38 & 0.49 \\
\hline
\end{tabular}


important ( $1=$ Yes, $0=$ Otherwise $)$

\begin{tabular}{|c|c|c|c|c|}
\hline IMPCRIME & $\begin{array}{l}\text { If the respondents considered that } \\
\text { being able to protect the home from } \\
\text { crime is important ( } 1=\text { Yes, } \\
0=\text { Otherwise) }\end{array}$ & 815 & 0.42 & 0.49 \\
\hline GENDER & 1 if male, 0 if female & 1096 & 0.32 & 0.47 \\
\hline $\begin{array}{l}\text { WINDOWPRE } \\
P\end{array}$ & $\begin{array}{l}\text { If the respondent was prepared to } \\
\text { protect windows against hurricanes } \\
\text { ( } 1=\text { Yes, } 0=\text { Otherwise })\end{array}$ & 1050 & 0.51 & 0.50 \\
\hline
\end{tabular}

Table 1.2 Revealed and Stated Preference: Evacuations by Scenario

\begin{tabular}{lllllll}
\hline Types & Revealed & \multicolumn{3}{c}{ Stated } & All & \\
\hline Scenario & Cases & Percent & Cases & Percent & Cases & Percent \\
\hline Voluntary & 129 & 27.6 & 119 & 23.3 & 248 & 25.3 \\
Mandatory & 251 & 53.6 & 43 & 8.4 & 296 & 30.2 \\
No order & 88 & 18.8 & 349 & 68.3 & 437 & 44.5 \\
Total & 468 & 100 & 511 & 100 & 981 & 100 \\
\hline
\end{tabular}

Table 1.3 Revealed and Stated Preference: Individual Evacuation Expenditure

\begin{tabular}{lllllll}
\hline Types & Revealed & \multicolumn{3}{l}{ Stated } & All & \\
\hline Scenario & Cases & $\begin{array}{l}\text { Mean } \\
\text { Expenditure } \\
\text { (USD\$) }\end{array}$ & Cases & $\begin{array}{l}\text { Mean } \\
\text { Expenditure }\end{array}$ & Cases & $\begin{array}{l}\text { Mean } \\
\text { Expenditure } \\
\text { (USD\$) }\end{array}$ \\
\hline Voluntary & 98 & 146 & 69 & 558 & 167 & 316 \\
Mandatory & 187 & 296 & 24 & 289 & 212 & 295 \\
No order & 62 & 144 & 189 & 363 & 251 & 309 \\
Total & 387 & 259 & 200 & 403 & 688 & 322 \\
\hline
\end{tabular}


Table 1.4 Regression Models of Evacuation Decision

\begin{tabular}{|c|c|c|c|c|}
\hline EVAC & Model 1 & Model 2 & Model 3 & Model 4 \\
\hline INDEXP & $\begin{array}{l}-0.00017 * * * \\
(3.19 \mathrm{E}-05)\end{array}$ & $\begin{array}{l}-0.00016 \text { *** } \\
(4.01 \mathrm{E}-05)\end{array}$ & $\begin{array}{l}-0.00016 * * * \\
(4.04 \mathrm{E}-05)\end{array}$ & $\begin{array}{l}-0.00015 * * * \\
(4.04 \mathrm{E}-05)\end{array}$ \\
\hline RPINDEXP & $\begin{array}{l}0.00055^{* * *} \\
(7.66 \mathrm{E}-05)\end{array}$ & $\begin{array}{l}0.00048 * * * \\
(8.48 \mathrm{E}-05)\end{array}$ & $\begin{array}{l}0.00048 * * * \\
(8.42 \mathrm{E}-05)\end{array}$ & $\begin{array}{l}0.00047 * * * \\
(8.34 \mathrm{E}-05)\end{array}$ \\
\hline INCOME & & $\begin{array}{l}-0.045 \\
(0.034)\end{array}$ & $\begin{array}{l}-0.031 \\
(0.034)\end{array}$ & $\begin{array}{l}-0.035 \\
(0.035)\end{array}$ \\
\hline INCOMESQ & & $\begin{array}{l}0.003 \\
(0.003)\end{array}$ & $\begin{array}{l}0.002 \\
(0.003)\end{array}$ & $\begin{array}{l}0.002 \\
(0.003)\end{array}$ \\
\hline VOLUNTARY & $\begin{array}{l}0.282^{* * * *} \\
(0.049)\end{array}$ & $\begin{array}{l}0.259 * * * \\
(0.059)\end{array}$ & $\begin{array}{l}0.262 * * * \\
(0.060)\end{array}$ & $\begin{array}{l}0.264 * * * \\
(0.06)\end{array}$ \\
\hline MANDATORY & $\begin{array}{l}0.478^{* * *} \\
(0.051)\end{array}$ & $\begin{array}{l}0.503 * * * \\
(0.060)\end{array}$ & $\begin{array}{l}0.508 * * * \\
(0.061)\end{array}$ & $\begin{array}{l}0.514 * * * \\
(0.061)\end{array}$ \\
\hline EXPERIENCE & $\begin{array}{l}0.100 * * \\
(0.043)\end{array}$ & $\begin{array}{l}0.101 * \\
(0.052)\end{array}$ & $\begin{array}{l}0.118 * * \\
(0.052)\end{array}$ & $\begin{array}{l}0.114 * * \\
(0.052)\end{array}$ \\
\hline$A G E$ & $\begin{array}{l}0.003^{*} \\
(0.002)\end{array}$ & $\begin{array}{l}3.2 \mathrm{E}-04 \\
(0.002)\end{array}$ & $\begin{array}{l}0.001 \\
(0.002)\end{array}$ & $\begin{array}{l}0.001 \\
(0.002)\end{array}$ \\
\hline$B L A C K$ & $\begin{array}{l}0.085 \\
(0.056)\end{array}$ & & $\begin{array}{l}0.101 \\
(0.066)\end{array}$ & $\begin{array}{l}0.097 \\
(0.066)\end{array}$ \\
\hline HHSIZE & $\begin{array}{l}0.032 * * \\
(0.014)\end{array}$ & & $\begin{array}{l}0.025 \\
(0.017)\end{array}$ & $\begin{array}{l}0.03^{*} \\
(0.017)\end{array}$ \\
\hline OWNER & $\begin{array}{l}-0.009 \\
(0.062)\end{array}$ & $\begin{array}{l}0.080 \\
(0.073)\end{array}$ & $\begin{array}{l}0.044 \\
(0.075)\end{array}$ & $\begin{array}{l}0.048 \\
(0.075)\end{array}$ \\
\hline IMPCRIME & $\begin{array}{l}-0.091 * * \\
(0.042)\end{array}$ & $\begin{array}{l}-0.091 * \\
(0.052)\end{array}$ & $\begin{array}{l}-0.110^{* *} \\
(0.053)\end{array}$ & $\begin{array}{l}-0.116^{* *} \\
(0.052)\end{array}$ \\
\hline IMPSURGE & $\begin{array}{l}0.081^{*} \\
(0.042)\end{array}$ & $\begin{array}{l}0.064 \\
(0.051)\end{array}$ & $\begin{array}{l}0.069 \\
(0.052)\end{array}$ & $\begin{array}{l}0.066 \\
(0.052)\end{array}$ \\
\hline WINDOWPREP & $\begin{array}{l}0.07^{*} \\
(0.039)\end{array}$ & $\begin{array}{l}0.073 \\
(0.047)\end{array}$ & $\begin{array}{l}0.079 \\
(0.048)\end{array}$ & $\begin{array}{l}0.073 \\
(0.047)\end{array}$ \\
\hline GENDER & & & & $\begin{array}{l}-0.080 \\
(0.050)\end{array}$ \\
\hline$E D U C$ & & & & $\begin{array}{l}0.053 \\
(0.051)\end{array}$ \\
\hline Constant & $\begin{array}{l}-0.063 \\
(0.12)\end{array}$ & $\begin{array}{l}0.261 * \\
(0.146)\end{array}$ & $\begin{array}{l}0.091 \\
(0.173)\end{array}$ & $\begin{array}{l}0.083 \\
(0.174)\end{array}$ \\
\hline$N$ & 400 & 284 & 273 & 272 \\
\hline$R^{2}$ & 0.4436 & 0.4466 & 0.4648 & 0.4796 \\
\hline$A I C$ & 369.24 & 269.53 & 254.80 & 250.23 \\
\hline$B I C$ & 421.13 & 316.96 & 308.94 & 311.53 \\
\hline
\end{tabular}


Notes: $* * *, * *, *$ imply significance at $1 \%, 5 \%$, and $10 \%$ levels respectively; numbers in parentheses are corresponding standard errors.

Table 1.5 Estimated WTP

Table 1.5.1 Model 1

\begin{tabular}{lllll}
\hline Estimation & $\begin{array}{l}\text { Evacuation } \\
\text { order }\end{array}$ & $\begin{array}{l}95 \% \text { Lower } \\
\text { limit }\end{array}$ & Median & $\begin{array}{l}95 \% \\
\text { Upper limit }\end{array}$ \\
\hline WTP & Voluntary & -181 & 1,267 & 2,714 \\
& Mandatory & 812 & 2,398 & 3,985 \\
\hline
\end{tabular}

Table 1.5.2 Model 2

\begin{tabular}{|c|c|c|c|c|}
\hline Estimation & $\begin{array}{l}\text { Evacuation } \\
\text { order }\end{array}$ & $\begin{array}{l}95 \% \text { Lower } \\
\text { limit }\end{array}$ & Median & $\begin{array}{l}95 \% \\
\text { Upper limit }\end{array}$ \\
\hline \multirow[t]{2}{*}{ WTP } & Voluntary & 904 & 3,225 & 5,545 \\
\hline & Mandatory & 1,857 & 4,739 & 7,621 \\
\hline
\end{tabular}

Table 1.5.3 Model 3

\begin{tabular}{lllll}
\hline Estimation & $\begin{array}{l}\text { Evacuation } \\
\text { order }\end{array}$ & $\begin{array}{l}95 \% \text { Lower } \\
\text { limit }\end{array}$ & Median & $\begin{array}{l}95 \% \\
\text { Upper limit }\end{array}$ \\
\hline \multirow{2}{*}{ WTP } & Voluntary & -104 & 2,247 & 4,599 \\
& Mandatory & 1,049 & 3,814 & 6,580 \\
\hline
\end{tabular}

Table 1.5.4 Model 4

\begin{tabular}{lllll}
\hline Estimation & $\begin{array}{l}\text { Evacuation } \\
\text { order }\end{array}$ & $\begin{array}{l}95 \% \text { Lower } \\
\text { limit }\end{array}$ & Median & $\begin{array}{l}95 \% \\
\text { Upper limit }\end{array}$ \\
\hline WTP & Voluntary & -142 & 2,251 & 4,644 \\
& Mandatory & 1,032 & 3,871 & 6,709 \\
\hline
\end{tabular}


Table 1.6 Estimated VSL

Table 1.6.1 Model 1

\begin{tabular}{lllll}
\hline Estimation & $\begin{array}{l}\text { Evacuation } \\
\text { order }\end{array}$ & $\begin{array}{l}\text { 95\% Lower } \\
\text { limit }\end{array}$ & Median & $\begin{array}{l}95 \% \\
\text { Upper limit }\end{array}$ \\
\hline VSL & $\begin{array}{l}\text { Voluntary } \\
\text { evacuation } \\
\text { order }\end{array}$ & & 633,330 & $1,357,167$ \\
& $\begin{array}{l}\text { Mandatory } \\
\text { evacuation } \\
\text { order }\end{array}$ & 405,788 & $1,199,048$ & $1,992,307$ \\
& & & \\
\hline
\end{tabular}

Table 1.6.2 Model 2

\begin{tabular}{lllll}
\hline Estimation & $\begin{array}{l}\text { Evacuation } \\
\text { order }\end{array}$ & $\begin{array}{l}\text { 95\% Lower } \\
\text { limit }\end{array}$ & Median & $\begin{array}{l}95 \% \\
\text { Upper limit }\end{array}$ \\
\hline VSL & $\begin{array}{l}\text { Voluntary } \\
\text { evacuation } \\
\text { order }\end{array}$ & 452,245 & $1,612,413$ & $2,772,579$ \\
& & & \\
& $\begin{array}{l}\text { Mandatory } \\
\text { evacuation } \\
\text { order }\end{array}$ & 928,288 & $2,369,417$ & $3,810,546$ \\
& & & \\
\hline
\end{tabular}

Table 1.6.3 Model 3

\begin{tabular}{lllll}
\hline Estimation & $\begin{array}{l}\text { Evacuation } \\
\text { order }\end{array}$ & $\begin{array}{l}\text { 95\% Lower } \\
\text { limit }\end{array}$ & Median & $\begin{array}{l}95 \% \\
\text { Upper limit }\end{array}$ \\
\hline VSL & $\begin{array}{l}\text { Voluntary } \\
\text { evacuation } \\
\text { order }\end{array}$ & & $1,123,685$ & $2,299,346$ \\
& $\begin{array}{l}\text { Mandatory } \\
\text { evacuation } \\
\text { order }\end{array}$ & 524,546 & $1,907,242$ & $3,289,938$ \\
& & & \\
\hline
\end{tabular}

Table 1.6.4 Model 4

\begin{tabular}{lllll}
\hline Estimation & $\begin{array}{l}\text { Evacuation } \\
\text { order }\end{array}$ & $\begin{array}{l}\text { 95\% Lower } \\
\text { limit }\end{array}$ & Median & $\begin{array}{l}95 \% \\
\text { Upper limit }\end{array}$ \\
\hline VSL & $\begin{array}{l}\text { Voluntary } \\
\text { evacuation } \\
\text { order }\end{array}$ & & $1,125,531$ & $2,322,123$ \\
& $\begin{array}{l}\text { Mandatory } \\
\text { evacuation } \\
\text { order }\end{array}$ & 516,139 & $1,935,396$ & $3,354,652$ \\
& & & \\
\hline
\end{tabular}


Table 1.7 Predicted median WTP

\begin{tabular}{llllll}
\hline $\begin{array}{l}\text { Evacuation } \\
\text { order }\end{array}$ & & Model 1 & Model 2 & Model 3 & Model 4 \\
\hline Voluntary & $\mathrm{SP}=$ mean & 1,267 & 3,225 & 2,247 & 2,251 \\
& $\mathrm{SP}=0$ & 398 & 1,079 & 740 & 737 \\
Mandatory & $\mathrm{SP}=$ mean & 2,398 & 4,739 & 3,814 & 3,871 \\
& $\mathrm{SP}=0$ & 753 & 1,585 & 1,256 & 1,267 \\
\hline
\end{tabular}

Table 1.8 Predicted evacuees and total costs

\begin{tabular}{llll}
\hline \multicolumn{2}{l}{ Voluntary evacuation order } & \multicolumn{2}{l}{ Mandatory evacuation order } \\
\hline Evacuees & Total costs & Evacuees & Total costs \\
\hline 188,336 & $60,621,403$ & 224,766 & $72,347,616$ \\
\hline
\end{tabular}




\section{FIGURES}

Figure 1.1 Hurricane Ike track

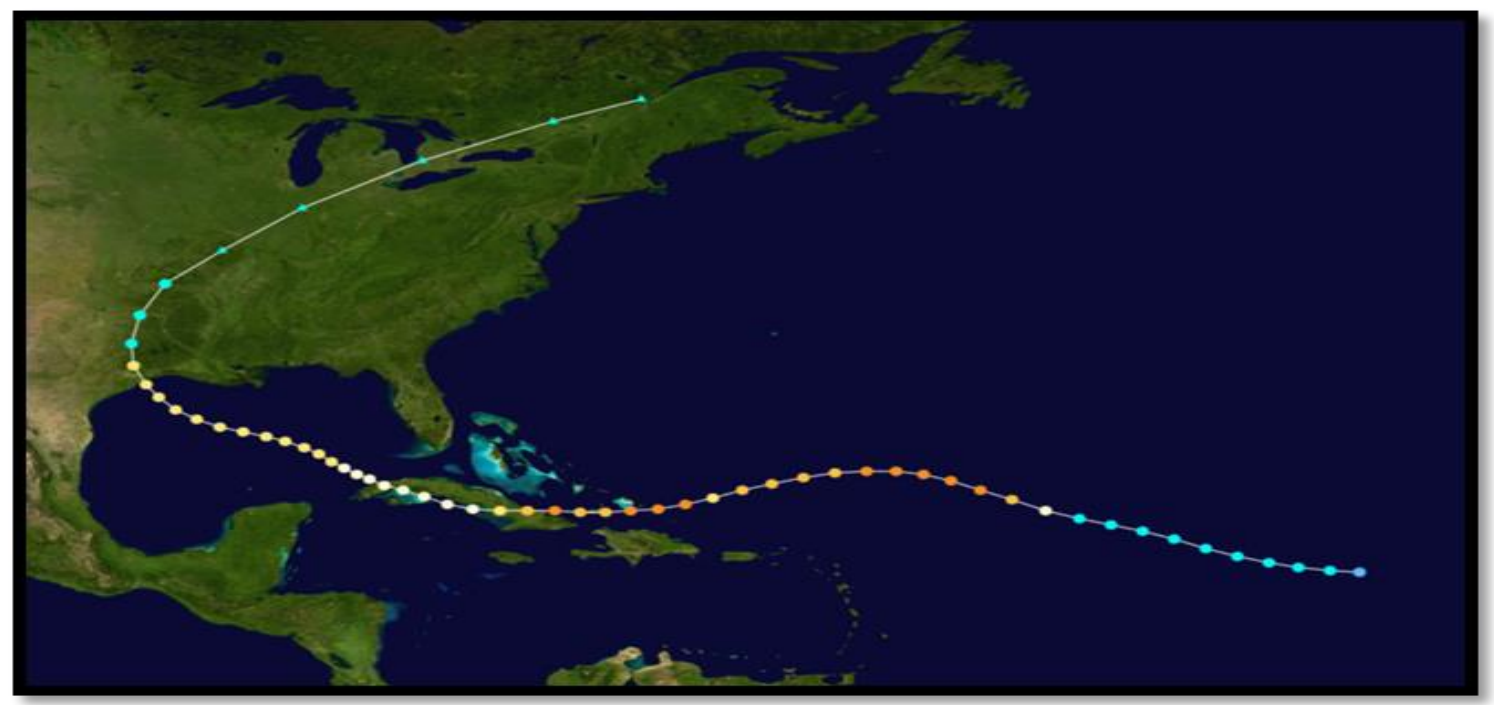

Figure 1.2 Geo-coded location of respondents participated in the survey and their evacuation decision during Hurricane Ike

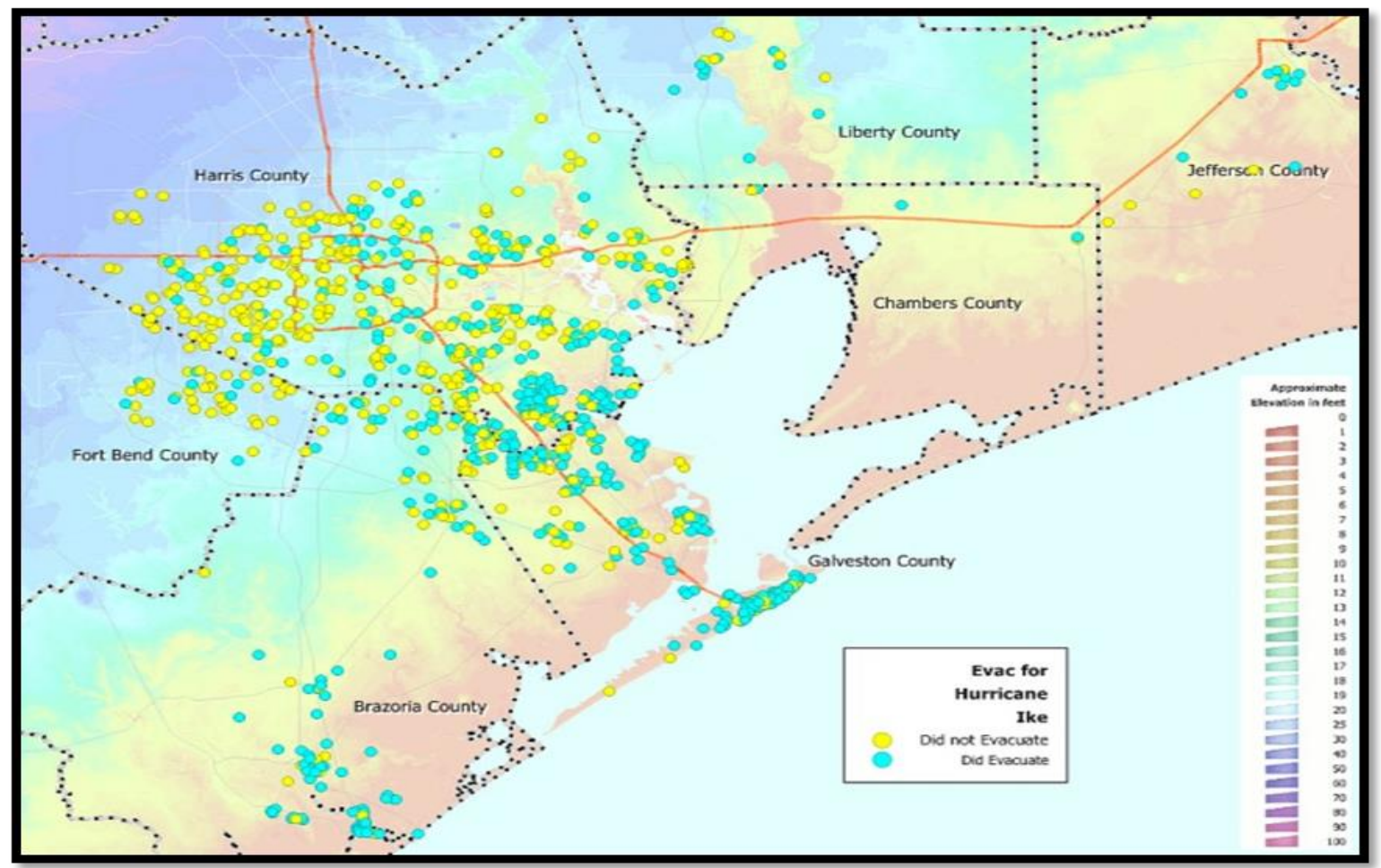


Figure 1.3 Process for determining the individual's WTP for hurricane risks

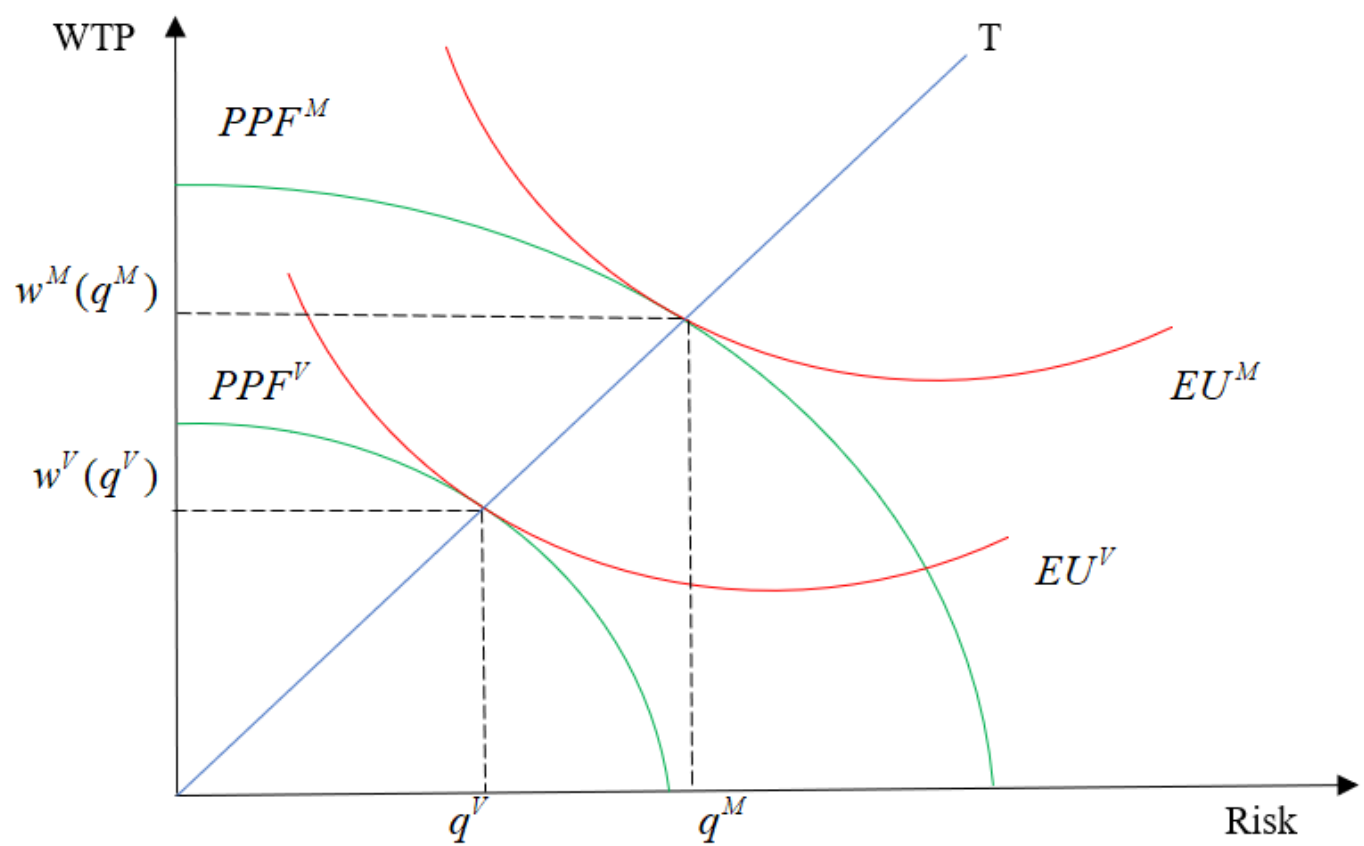

Figure 1.4 Evacuation order received by respondents during Hurricane Ike

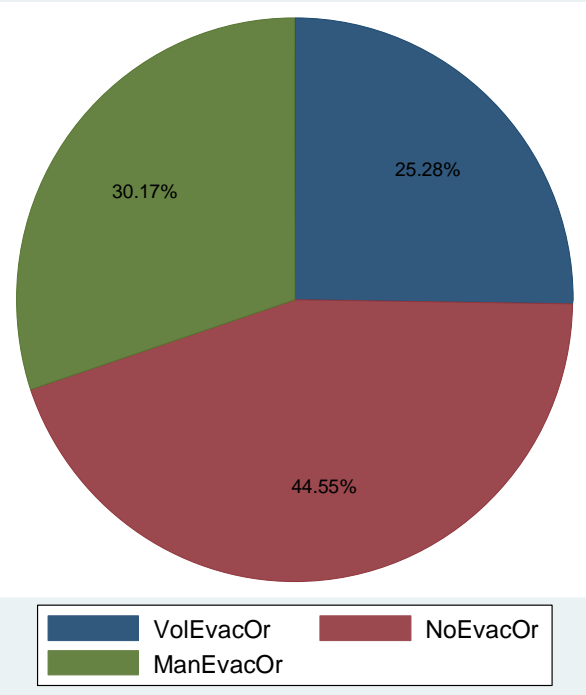


Figure 1.5 Respondents who had prior hurricane experience

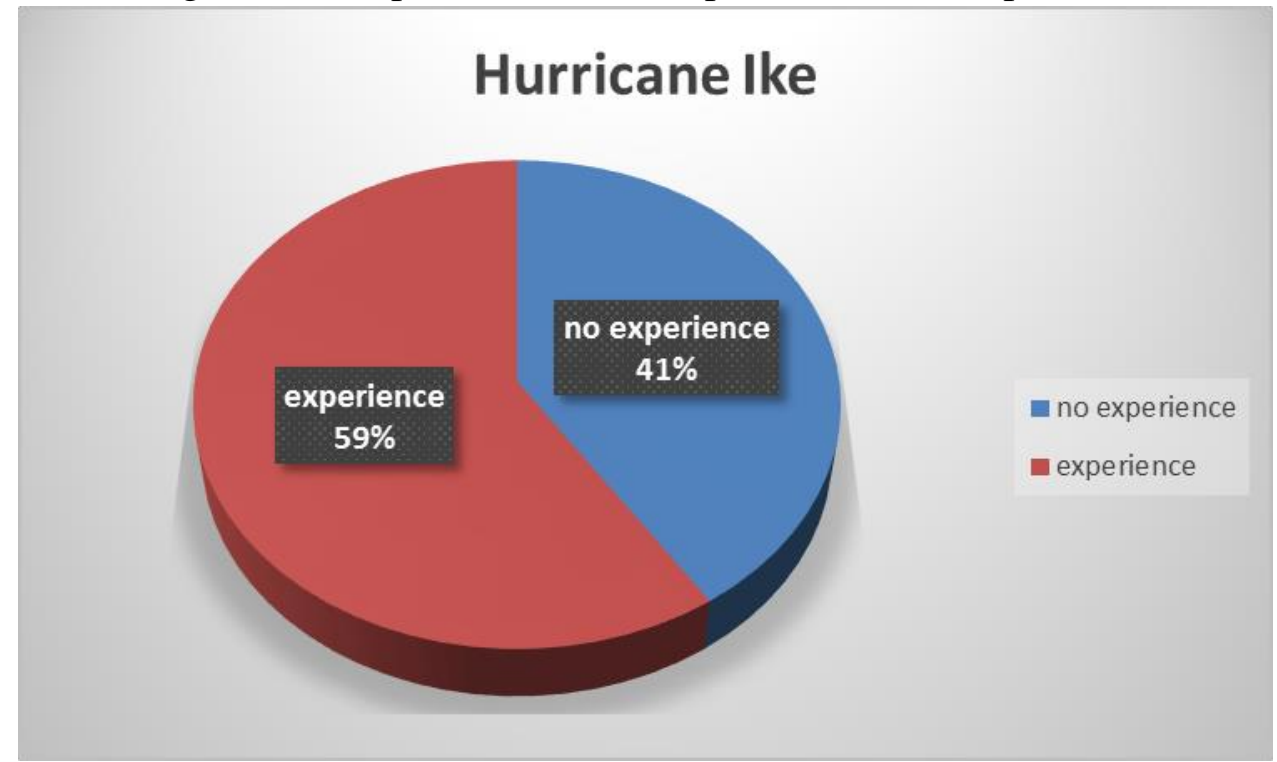

Figure 1.6 Predicted WTP by Evacuation orders

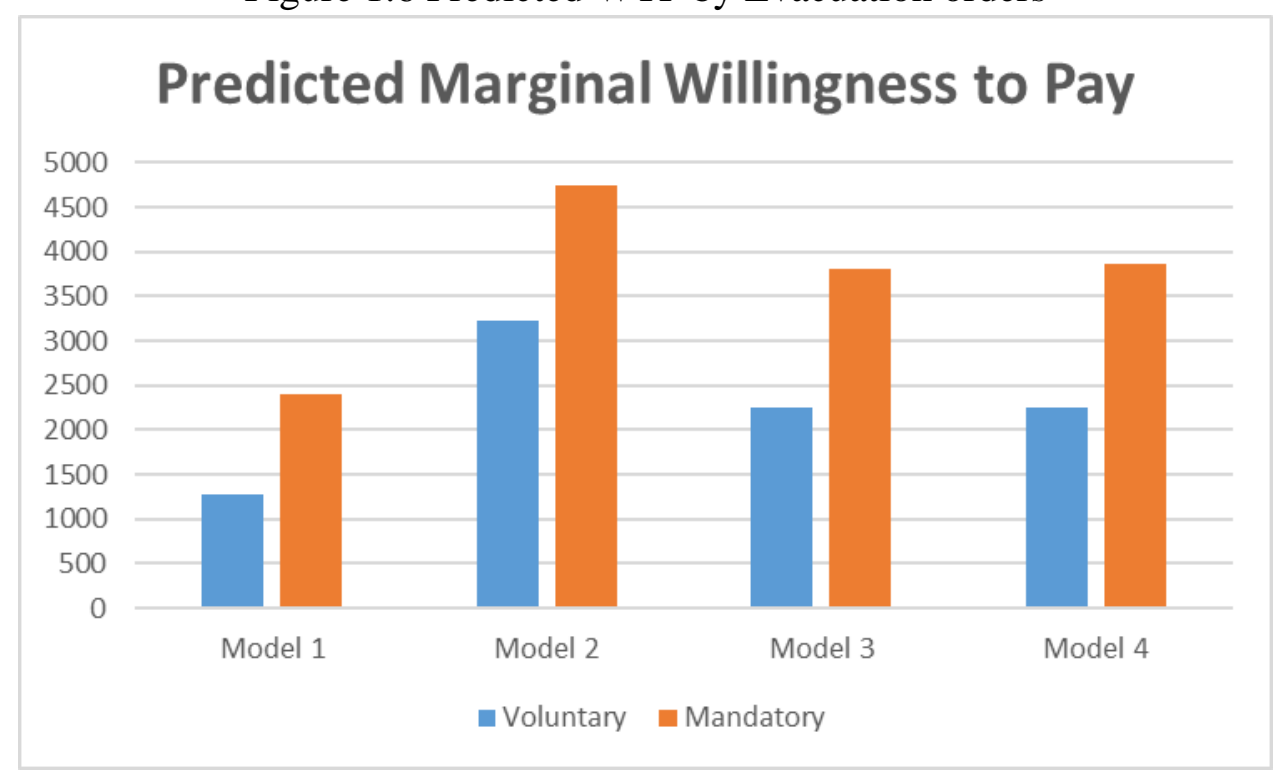


Figure 1. 7 Predicted VSL by Evacuation orders

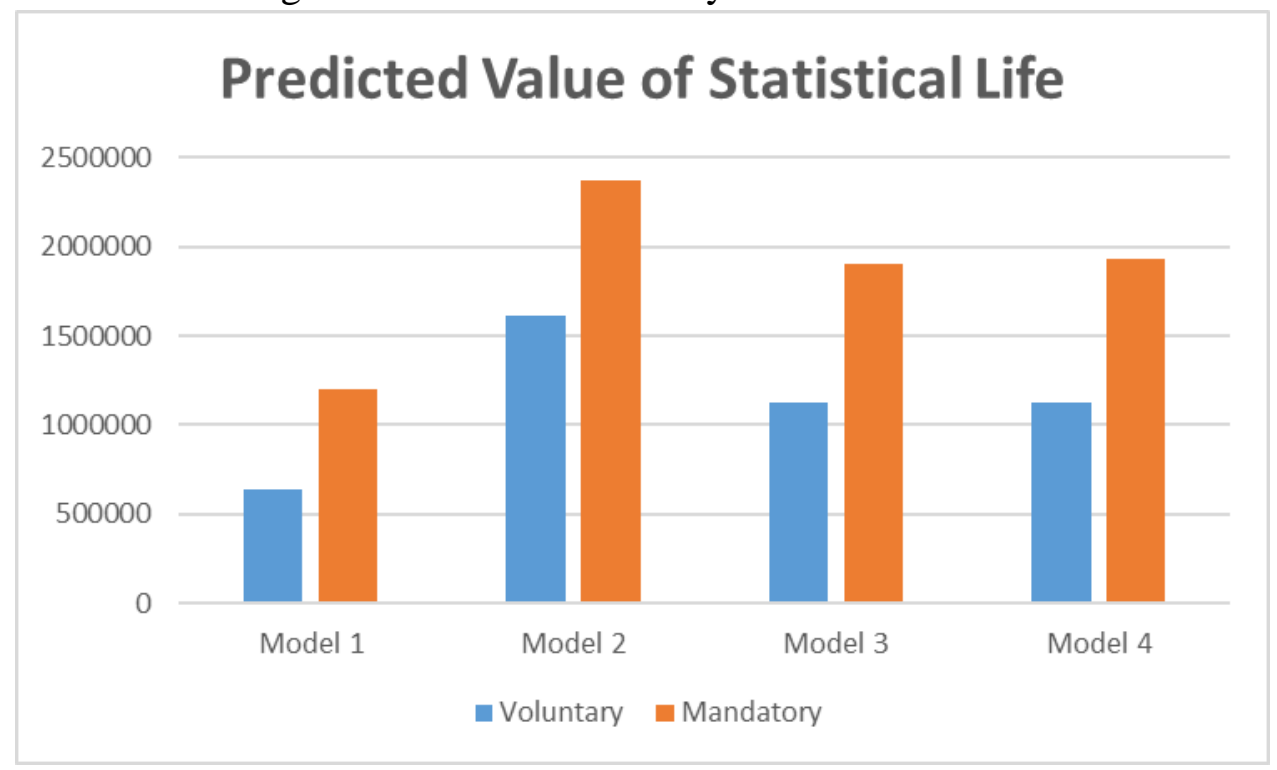




\section{CHAPTER 2}

\section{MARKET RESPONSES TO MULTIPLE HURRICANE EXPOSURES IN FLORIDA： EVIDENCE FROM REAL ESTATE SALES DATA}

\subsection{Introduction}

Hurricanes are among the most destructive natural disasters and are characterized by heavy rain, damaging winds, and inundation with storm surges. Between 1988 and 2017, hurricanes caused an average of 1,127 fatalities per year globally (NHC 2018). Furthermore, in the last 30 years, hurricanes have caused USD\$821 billion in damages worldwide. In the 2017 hurricane season, ten hurricanes formed in the Atlantic Basin, 6 of which were major hurricanes (Category 3 or higher on the Saffir-Simpson scale). That season is the most destructive season on record, with a total of over USD\$317 billion in damages and 434 fatalities, nearly all of which were due to three major hurricanes (Harvey, Irma, and Maria).

In the past decade, the 2004-2005 hurricane seasons were the most destructive consecutive hurricane seasons on record. The 2004 Atlantic hurricane season was the costliest Atlantic hurricane season on record until it was surpassed the following year. The death toll was at least 3,270, and the total damages exceeded USD $\$ 57$ billion. The 2005 hurricane season is the second costliest tropical cyclone season on record, with an estimated 3,913 deaths and damage of approximately USD\$159 billion. Florida is one of the most vulnerable states regarding hurricane exposures. During the 2004-2005 
hurricane seasons, Florida was exposed to three major storms (Wilma, Frances, and Jeanne). The estimates of the insured losses from these storms was approximately USD\$19 billion.

Previous literature has identified the effect of hurricane exposures on property values and found an associated declining trend in property values. Using a difference-in-difference framework, Hallstrom and Smith (2005) analyzed real estate sales data in Florida after Hurricane Andrew (1992) and provided evidence that hurricane exposure has a negative impact on property values. The researchers found a $19 \%$ depreciation in housing prices due to Hurricane Andrew in special flood hazard areas (SFHAs). Bin and Polasky (2004) examined flood effects on property values in North Carolina after Hurricane Floyd (1999) and found that property values depreciated more after the hurricane hit than before. Although studies have focused on how multiple hurricanes affect the ecosystems, few have considered the economic impacts, and even fewer works have examined how multiple hurricanes affect property values (Burkholder et al., 2004, Greening et al. 2006).

My objective in this paper is to analyze how multiple hurricane hits affect property values. I examine the real estate market responses from three counties in Florida (Martin, Okeechobee, and Palm Beach) for the period of 2000-2010, when these counties experienced multiple hurricane hits. I use the repeat sales data and estimate a hedonic price model with a semilog transformation approach. I use a set of regression models to 
predict the marginal effects of hurricane-related and other pertinent variables on property values. My findings indicate that the appreciation of property values is approximately $10 \%$ lower for each successive hurricane hit, and the market values of houses located in the SFHA zone appreciate by nearly $55 \%$ less. I also find that location-related variables (distance to shoreline and waterfront) and hurricane mitigation measures (shutters and metal roof) and other home characteristics (garage and pool) significantly affect the appreciation of property values.

\subsection{Background and Related Literature}

The real estate market exhibits price volatility when it encounters natural hazard risks. Th previous literature has shown that natural hazards impact property values. For instance, Murdoch et al. (1993) found that earthquakes have a negative effect on housing values. Mueller et al. (2009) reported that repeated wildfires have a negative correlation with house prices for houses near forest fires. Bin and Kruse (2006) reported that, on average, housing values are 5-10\% lower if the house is located within a flood zone. Studies have also focused on the relationship between hurricane risks and market responses. Hallstrom and Smith (2005) used the difference in differences framework and showed that property values exhibit a declining trend due to hurricane risks. Bin and Polasky (2004) used a hedonic model and found that, after a hurricane, house price discounts within flood zones are significantly greater than before. 
Many papers have used geographic information system (GIS) and hedonic price models to investigate the dynamics of real estate prices. Atreya and Czajkowski (2014) investigated the real estate market's response to coastal amenities and flood risks in Galveston County, Texas. Kong et al. (2007) conducted a case study on the amenity value of urban green space using GIS and landscape metrics and employed hedonic price modeling. Hindsley et al. (2013) utilized light detection and ranging (LIDAR) data in hedonic property models and found that property values have a positive correlation with the property's viewsheds. Bin et al. (2008) examined the flood risk in properties with a view and investigated the coastal real estate market's response to flooding risk and amenities within the hedonic framework.

Most previous studies have identified the effect of a single hurricane event on property values in areas that experienced substantial storm damage and found a decline in property values (Morgan 2007, Vigdor 2008). During the 2004-2005 hurricane seasons, three major hurricanes_-Wilma, Frances, and Jeanne—made landfall in Florida. The estimates of the insured losses suggest approximately USD $\$ 19$ billion in damage from these three hurricanes. In this study, I analyze the real estate market's responses to hurricane impacts in three counties in Florida that experienced a varying number of hurricanes-Martin, Okeechobee, and Palm Beach—for the period of 2000-2010. In total, there were six major hurricane events in Florida in the period of 2000-2010. 
Florida is one of the most vulnerable states in terms of hurricane exposure, and the real estate market is heavily influenced by hurricane events. Based on the data I analyze, the total sales after the 2004-2005 hurricane seasons experienced a sharp decline in Martin, Okeechobee, and Palm Beach Counties (Figure 2.1). Against this backdrop, I focus on understanding how the real estate market responds to multiple hurricane events in Florida.

\subsection{Analytical Framework and Empirical Modeling}

The hedonic price model uses data on prices and associated attributes of the good or service to obtain value estimates of those attributes using regression analysis (Rosen 1974). The hedonic price model has been widely used to estimate property value with various home characteristics and features that affect its prices (Malpezzi 2003). The analytical framework is based on an expected utility model, which assumes that households live in a hurricane-prone area and confront the risk of multiple hurricane hits. Considering the timeframe and the locational context, I limit the framework to three hurricane hits. Therefore, the households encounter four outcomes of hurricane risks (i.e., to be exposed to $0,1,2$ or 3 hurricane hits). I use a approach similar to that used by Hallstrom and Smith (2005) but consider multiple hurricane hits in this framework. The four outcomes are provided as the following utility function: 
$V=p_{1}(d, I) U_{H 1}\left(F(d, C, w)-E_{1}\left(d, C, r, p_{1}(d, I)\right)-L_{1}(d, C, r)\right)+$

$p_{2}(d, I) U_{H 2}\left(F(d, C, w)-E_{2}\left(d, C, r, p_{2}(d, I)\right)-L_{2}(d, C, r)\right)+$

$p_{3}(d, I) U_{H 3}\left(F(d, C, w)-E_{3}\left(d, C, r, p_{3}(d, I)\right)-L_{3}(d, C, r)\right)$

$+p_{0}(d, I) U_{H 0}\left(F(d, C, w)-E_{0}\left(d, C, r, p_{0}(d, I)\right)\right)$

where $V$ is the total utility of households in the real estate market, $p_{i}(d, I)(\mathrm{i}=0,1,2$,

3 ) is the probability of being hit by one or more hurricanes at a given location (a function

of $d$, the distance from hurricane tracks and coastlines) and with the information set

$I\left(\sum_{i=0}^{3} p_{i}(d, I)=1\right)$, and $U_{H i}$ is the utility for hurricane hits $(\mathrm{i}=0,1,2,3) . F($.$) is the$ property value function, where $C$ is the household characteristics and $w$ is the wealth portion that is less than the value under insurance. $E($.$) is the exogenous hedonic price$ function, $r$ is the net of insurance, and $L($.$) is the property loss function due to$ hurricane exposures.

Households want to maximize their expected utility by adjusting locational attributes $(d)$; this depends on hedonic price function $(E)$, insurance rate $(r)$, information set $(I)$ and their income $(w)$. In their home-buying decision, the households' marginal bid for an attribute is equal to its marginal price in equilibrium. A household's expected utility function indicates that it can be influenced by a change in $\mathrm{d}$ by three means:

$$
E_{i_{d}}=\frac{p_{i} U_{H i_{d}}+\left(p_{0}\right) U_{H 0_{d}}}{p_{i} U_{H i_{w}}+\left(p_{0}\right) U_{H 0_{w}}}-\frac{p_{i} U_{H i_{d}} L_{i_{d}}}{p_{i} U_{H i_{w}}+\left(p_{0}\right) U_{H 0_{w}}}+\frac{p_{i_{d}}\left(U_{H i}-U_{H 0}\right)}{p_{i} U_{H i_{w}}+\left(p_{0}\right) U_{H 0_{w}}}
$$


where $E_{i_{d}}$ is the marginal hedonic price with respect to locational attribute $d$ and $U_{H i_{d}}$ is the partial derivative of $U_{H i}$ with respect to $d$. In Equation 2.2, the first term on the right side is the expected amenity contribution. The second term is monetary losses (net of insurance) that are likely to change with distance in case of a hurricane event. The third term represents how the hurricane hits affect the property price, which is the primary focus of my research. This mechanism has two components: through a change in the probability of hurricane risks with respect to locational attribute $\left(p_{d}\right)$ and through the reduction in home value due to hurricane impacts $\left(\frac{U_{H i}-U_{H 0}}{p_{i} U_{H i_{w}}+\left(p_{0}\right) U_{H 0_{w}}}\right)$.

\subsection{Data and Empirical Analysis}

I analyze the real estate market responses from three counties in Florida-Martin, Okeechobee, and Palm Beach — for the period 2000-2010 by using the repeat sales data of detached family homes. The dataset has 36,204 observations, of which 21,613 are detached family homes. My data include detailed information on the time of sale and the price of each sale, the geographic location of each home and relevant home characteristics. Since $95 \%$ of the homes are concentrated in Martin County, this analysis focuses on Martin County and mainly on properties that appreciated in value after the 2004-2005 hurricane seasons. 
My analysis includes a set of temporal and spatial control variables to distinguish the effects of three major hurricanes that affected the area. For instance, the price difference between two sales (one is before and the other is after the 2004-2005 hurricane seasons) for homes located in the SFHA are assumed to capture how the storm-associated flood risk information is perceived by the households living in the area. If houses located in the SFHA had first and second sales after the storm, the information attributed to the storm would be known for both sales. Similarly, homes located outside the hurricane-affected area are assumed to consider the information as relevant only to the designated flood zone. Furthermore, I find the price differences or appreciation of values to be attributed to frequencies of hurricane hits from the repeat sales of properties. The geographic identification of each property also allows the calculation of the shortest distance of the property from the hurricane track, the coastline, and the proximity to the large water body.

Most hedonic models use the semilog form of price and regress it against unlogged explanatory variables (Sirmans et al. 2005). In my analysis, I initially calculate the first price differences and the percentage of price differences as the dependent variable. However, the distributions of these variables are right-skewed and nonnormal; therefore, I take the log of price differences of repeat sales and find that the price difference of properties follows a log-normal distribution. Thus, in my empirical specification, I use the $\log$ of price differences as the dependent variable (diffsale=the price differences of 
repeat sales of detached family homes before and after the 2004-2005 hurricane seasons), which is regressed against a set of explanatory variables, as listed in Equation 2.3.

$\log$ diffsale $=\gamma+\alpha X_{i}+\beta Z_{i}+\delta K_{i}+\varepsilon_{i}$

In Equation 2.3, $X_{i}$ is a vector of hurricane-related variables (e.g., number of hurricane hits and hurricane-induced damages); $Z_{i}$ is a vector representing location-specific variables such as flood zone and distance from shoreline and water bodies; and $K_{i}$ is a vector of home characteristics variables (e.g., finished area in square feet, lot size, number of bedrooms, and bathrooms). Among other notations, $\gamma$ is the intercept term; $\alpha, \beta, \delta$ are the corresponding coefficients to be estimated; and $\varepsilon$ is the error term that is assumed to follow a standard normal distribution.

Since my empirical approach uses the log of price differences of property sales (value appreciation) as the dependent variable, I can use $\log$ and exponential transformation to obtain the variation (marginal contribution) of property value appreciation for each explanatory variable. For instance, I assume the value appreciation of a home within the SFHA is $V_{1}$ and that outside the SFHA is $V_{0}$, and the coefficient of SFHA is $\beta_{S F H A}$. Then, I can perform the following transformation:

$$
\begin{aligned}
& \log \left(V_{1}\right)=\hat{\beta}_{0}+\hat{\beta}_{\text {SFHA }} \times 1+\hat{\beta}_{i} x_{i} \\
& \log \left(V_{0}\right)=\hat{\beta}_{0}+\hat{\beta}_{\text {SFHA }} \times 0+\hat{\beta}_{i} x_{i} \\
& \frac{V_{1}}{V_{0}}=\frac{e^{\hat{\beta}_{0}+\hat{\beta}_{S F H A} \times 1+\hat{\beta}_{i} x_{i}}}{e^{\hat{\beta}_{0}+\hat{\beta}_{\text {SFHA }} \times 0+\hat{\beta}_{i} x_{i}}}=e^{\hat{\beta}_{\text {SFHA }}}
\end{aligned}
$$


$\frac{V_{1}-V_{0}}{V_{0}}=e^{\hat{\beta}_{S F H A}}-1$

Equations 2.4 to 2.7 allow the marginal contribution of each explanatory variable to be calculated to value the appreciation variation for a home that is influenced by any factor.

\subsection{Empirical Findings}

The definitions and descriptive statistics of the variables are provided in Table 2.1. In my dataset, 5,250 properties experienced value appreciation after the 2004-2005 hurricane seasons, and the average value of the appreciation was approximately USD $158 \mathrm{~K}$. The sample mean of total hurricane hits is 2.49 , with maximum hits of 3 times, indicating that most of my sample properties experienced multiple hurricane hits. Approximately $29 \%$ of the properties in my data were marked as "damaged" by the hurricanes in 2004 and 2005 by the property tax authority. Approximately $11 \%$ of the properties are located in the SFHA, and $57 \%$ of properties have shutters installed. The average size of the parcel is 0.37 acres, and $27 \%$ have a pool. An average home in my sample has three bedrooms and two bathrooms; the average size of the attached garage is approximately 496 square feet. Approximately $9 \%$ of the home's exterior wall is made of wood, and $15 \%$ of the home's roof is made of metal. The mean distance from the shoreline of my sample properties is approximately 0.97 mile. Assuming 2013 as the base year (when the data were collected), the average age of the home is 32.42 years. 
Based on the Saffir-Simpson wind scale, I define a home as having experienced a hurricane hit if it was on the path of sustained wind of $74 \mathrm{mph}$ or higher. Figure 2.2 shows the hurricane tracks of Wilma, Jeanne, and Frances that affected Martin County in the 2004-2005 hurricane seasons. As shown in Table 2.1, most of the properties experienced two or three hurricane hits. Table 2.2 decomposes my sample based on how many times the property was hit by a hurricane and whether the home was in an SFHA zone. A total of 291 homes were exposed to two hurricane hits and were located in the SFHA, and 267 properties were exposed to three hurricane events and were located in the SFHA.

In Table 2.3, I report the estimated coefficients of the hedonic price model using the same sample of properties that have been sold more than once and that have appreciated in value in the time span considered. Four specifications are reported in Table 2.3, and the primary variable of interest, hurricane hit (Totalhit), is always significant and negative in all models, which implies that repeated hurricane exposures cause a cumulative decline in the appreciation of home values. The extent of hurricane damage also affects the appreciation of property values negatively, and it is significant in all models. It is logical that greater damage caused to a house by hurricanes leads to a greater loss of its value. The coefficients of the variable flood zone (SFHA) are significantly negative in all models, indicating that the value appreciation of properties located in the SFHA is much lower. These estimations also mean that buyers are willing 
to pay less for houses located in the SFHA as they are concerned about the inundation risk induced by hurricane hits.

In addition to hurricane-related variables, my results in Table 2.3 reveal that several home characteristics influence the appreciation of property values. Sirmans et al. (2006) used a meta-regression analysis and found that certain housing characteristics significantly affect the house price, including square footage, lot size, age, bathrooms, swimming pool, and air conditioning. My results indicate that the property value appreciates more if it has more acreage or a larger garage; however, it appreciates less if the house is older than other properties. A property with a pool and with more bedrooms and bathrooms appreciates more in value.

In addition to the effect of the flood zone, other location-related variables affect the appreciation of home value. Conroy and Milosch (2009) found that a one-mile increase in distance from the shoreline would reduce the house price by approximately USD\$8,680. My results reveal a negative sign of the coefficients of distance to shoreline, which indicates that a property close to the ocean appreciates in value more than those properties farther inland. Benson et al. (1998) reported that a lake frontage house with a boat dock has more value in its market price relative to a no-dock house. My results indicate that the waterfront properties with a dock experience greater appreciation of value. 
Table 2.4 displays the percentage changes of the appreciation of property values for each significant variable listed in Table 2.3. On average, a property that has experienced one more hurricane hit is subjected to a $10 \%$ decline (at most) in its value appreciation. A home marked as 'damaged' by a hurricane in 2004 and 2005 by the property tax authority appreciated in value $7 \%$ less than those homes with no hurricane damage. Properties located in the SFHA zone experienced the largest decline in value appreciation, nearly 55\%. Regarding distance from the shoreline, the home value appreciated $4 \%$ less with each mile farther inland, and it appreciated $1 \%$ less per year of home age. A waterfront property appreciated in value by as much as $99 \%$. A property with a larger land area (by one more acre) appreciated in value $9 \%$ more, and a property with a swimming pool appreciated in value by $12 \%$ more. The significant effects of these variables on the appreciation of property values are graphically displayed in Figure 2.3.

Table 2.5 provides results from a set of extended hedonic price models, which include variables related to hurricane mitigation measures. If a home had hurricane shutters, or the roof of the house was made of metal, the property values appreciated more. However, if the wall of the house was made of wood, the property value appreciation was lower. These results imply that, in making the purchase decision, homebuyers consider these structural features to mitigate hurricane risks substantially.

Table 2.6 shows the sole contribution of these variables in property value appreciation (calculated from models listed in Table 2.5). The sign of the coefficients in 
basic models (Table 2.3) and extended models (Table 2.5) are consistent, and corresponding effects reported in Table 2.4 and 2.6 are relatively close, with certain caveats, implying the robustness of my findings. For instance, based on the extended models indicated in Table 2.5, the appreciation of property value was $8 \%$ lower when the property experienced one more hurricane hit. This estimation is slightly lower than what I found in the first set of models (Table 2.3) without hurricane mitigation variables. These results imply that the value of houses with mitigation features appreciate more even when they are exposed to the same number of hurricane hits.

\subsection{Discussions and Conclusions}

In this study, I utilized the repeat sales data from three counties in Florida for the period 2000-2010, which experienced a varying number of hurricanes. I focused on Martin County, where $95 \%$ of the homes are concentrated, and mainly on properties that appreciated in value after the 2004-2005 hurricane seasons. My findings identified three sets of explanatory variables that influence the property value appreciation: (1) hurricane-related variables, (2) location-related variables, and (3) home characteristics. I used these variables to estimate the hedonic price model. The results indicate that the appreciation of property values declines when properties experience more hurricane hits.

I estimated the variations in appreciation of property values and found that the appreciation is $10 \%$ lower (at most) when a property encounters one more hurricane hit. 
The SFHA affects the value appreciation negatively, and the magnitude of the variation is at most $60 \%$. In an earlier study, Atreya and Czajkowski (2014) found that the property within a flood risk zone has a lower sales price (4-12\%) than an equivalent property outside of the SFHA. Bin and Kruse (2006) argued that the property values are $5-10 \%$ lower if the property is located within a flood risk zone. McKenzie and Levendis (2010) found that the property value increased $1.4 \%$ with an elevation increase of one foot in the SFHA before Hurricane Katrina; the premium rose to $4.6 \%$ per foot for the SFHA after Katrina. My results also confirm that buyers are concerned about the flood risk and are willing to pay less if the property is within the SFHA. My estimates also reflect that the number of hurricane hits has a positive correlation with the SFHA, since the coefficients of interaction term hits and the SFHA are positively significant in all specifications. Hurricanes often bring heavy rain, damaging winds, and inundation with storm surges, which lead to increasing flood risk in the SFHA and further impact the property values adversely.

I also investigated the effects of location-related variables such as distance to the shoreline from the property and the waterfront of a home. Cordes et al. (2001) used the repeat sales index to measure the property value appreciation rates with distance from the water's edge. Wyman et al. (2014) found that waterfront properties have a higher price premium, and the appreciation of waterfront properties increases more than properties without the waterfront. Properties with a dock appreciate nearly 99\% more than homes 
without a dock. Furthermore, Benson et al. (1998) found that a property with higher quality ocean views increases its market value by approximately $60 \%$; however, this number is only $8 \%$ for a property with lower quality ocean views. Consistent with this finding, my results indicate that property values appreciate $4 \%$ less if the property is located one more mile away from the shoreline.

My analysis also includes useful information regarding hurricane mitigation measures adopted by homeowners. Gatzlaff et al. (2017) found that visible hurricane mitigation features are positively correlated with house price increases. Dumm et al. (2011) argued that homebuyers recognize the hurricane risks and are willing to pay for hurricane mitigations. My results show that properties with hurricane shutters appreciate more than those without shutters. Furthermore, Simmons and Sutter (2007) analyzed the property sales data in tornado-prone areas and found that a property with an internal shelter had an increase in median sale price of USD\$4,200. I also find that the value of a home with a metal roof will appreciate more, whereas the value of a home with a wood exterior wall will appreciate less. These estimates indicate that homebuyers are concerned about the ability of their home's structure to withstand a hurricane. Thus, homeowners can strengthen their homes by investing in hurricane mitigation measures and can expect a return on their investment through a higher appreciation of property values. 
In closing, the real estate market exhibits price volatility when it encounters natural hazard risks, particularly an extreme weather event such as a hurricane. Understanding the real estate market responses to multiple hurricane hits is critical for both homebuyers and sellers in coastal areas. My findings not only provide reliable estimates on which factors significantly affect the appreciation of property values but also provide insights on the value of hurricane risk mitigations.

\section{REFERENCES}

Atreya, A., \& Czajkowski, J. (2014, November). Housing Price Response to the Interaction of Positive Coastal Amenities and Negative Flood Risks. In 2014 Annual Meeting, July 27-29, 2014, Minneapolis, Minnesota (No. 180098). Agricultural and Applied Economics Association.

Benson, E. D., Hansen, J. L., Schwartz Jr, A. L., \& Smersh, G. T. (1998). Pricing residential amenities: the value of a view. The Journal of Real Estate Finance and Economics, 16(1), 55-73.

Bin, O., Crawford, T., Kruse, J., \& Landry, C. (2008). Flood prone with a view: coastal housing market response to risk and amenity. Land Economics, 84, 434-48.

Bin, O., \& Kruse, J. B. (2006). Real estate market response to coastal flood hazards. Natural Hazards Review, 7(4), 137-144.

Bin, O., \& Polasky, S. (2004). Effects of flood hazards on property values: evidence before and after Hurricane Floyd. Land Economics, 80(4), 490-500.

Burkholder, J., Eggleston, D., Glasgow, H., Brownie, C., Reed, R., Janowitz, G., \& Toms, D. (2004). Comparative impacts of two major hurricane seasons on the Neuse River and western Pamlico Sound ecosystems. Proceedings of the National Academy of Sciences of the United States of America, 101(25), 9291-9296.

Conroy, S. J., \& Milosch, J. L. (2011). An estimation of the coastal premium for residential housing prices in San Diego County. The Journal of Real Estate Finance and Economics, 42(2), 211-228. 
Cordes, J. J., Gatzlaff, D. H., \& Yezer, A. M. (2001). To the Water's Edge, and Beyond: Effects of Shore Protection Projects on Beach Development. The Journal of Real Estate Finance and Economics, 22(2), 287-302.

Dumm, R. E., Sirmans, G. S., \& Smersh, G. (2011). The capitalization of building codes in house prices. The Journal of Real Estate Finance and Economics, 42(1), 30-50.

Gatzlaff, D., McCullough, K., Medders, L., \& Nyce, C. M. (2017). The impact of hurricane mitigation features and inspection information on house prices. The Journal of Real Estate Finance and Economics.

Greening, H., Doering, P., \& Corbett, C. (2006). Hurricane impacts on coastal ecosystems. Estuaries and Coasts, 29(6), 877-879.

Hallstrom, D. G., \& Smith, V. K. (2005). Market responses to hurricanes. Journal of Environmental Economics and Management, 50(3), 541-561.

Hindsley, P., Hamilton, S. E., \& Morgan, O. A. (2013). Gulf views: toward a better understanding of viewshed scope in hedonic property models. The Journal of Real Estate Finance and Economics, 47(3), 489-505.

Kong, F., Yin, H., \& Nakagoshi, N. (2007). Using GIS and landscape metrics in the hedonic price modeling of the amenity value of urban green space: A case study in Jinan City, China. Landscape and Urban Planning, 79(3), 240-252.

Malpezzi, S. (2003). Hedonic pricing models: a selective and applied review. Section in Housing Economics and Public Policy: Essays in Honor of Duncan Maclennan, 67-74.

McKenzie, R., \& Levendis, J. (2010). Flood hazards and urban housing markets: The effects of Katrina on New Orleans. The Journal of Real Estate Finance and Economics, 40(1), 62-76.

Morgan, A. (2007). The impact of Hurricane Ivan on expected flood losses, perceived flood risk, and property values. Journal of Housing Research,16(1), 47-60.

Mueller, J., Loomis, J., \& González-Cabán, A. (2009). Do repeated wildfires change homebuyers' demand for homes in high-risk areas? A hedonic analysis of the short and long-term effects of repeated wildfires on house prices in Southern California. The Journal of Real Estate Finance and Economics, 38(2), 155-172. 
Murdoch, J. C., Singh, H., \& Thayer, M. (1993). The impact of natural hazards on housing values: the Loma Prieta earthquake. Real Estate Economics, 21(2), 167-184.

"NHC Data Archive". www.nhc.NOAA.gov. Retrieved April 2018.

Rosen, S., 1974. Hedonic prices and implicit markets: product differentiation in pure competition. Journal of political economy, 82(1), pp.34-55.

Simmons, K. M., \& Sutter, D. (2007). Tornado shelters and the housing market. Construction Management and Economics, 25(11), 1119-1126.

Sirmans, G. S., MacDonald, L., Macpherson, D. A., \& Zietz, E. N. (2006). The value of housing characteristics: a meta analysis. The Journal of Real Estate Finance and Economics, 33(3), 215-240.

Sirmans, S., Macpherson, D., \& Zietz, E. (2005). The composition of hedonic pricing models. Journal of real estate literature, 13(1), 1-44.

Vigdor, J. (2008). The economic aftermath of Hurricane Katrina. The Journal of Economic Perspectives, 22(4), 135-154.

Wyman, D., Hutchison, N., \& Tiwari, P. (2014). Testing the Waters: A Spatial Econometric Pricing Model of Different Waterfront Views. Journal of Real Estate Research. 
TABLES

Table 2.1 Variable Definitions and Descriptive Statistics

\begin{tabular}{|c|c|c|c|c|}
\hline Variable & Description & $\mathrm{N}$ & Mean & SD \\
\hline Diffsale & Price differences of repeat sales & 5250 & $1.5 \mathrm{E}+5$ & $2.4 \mathrm{E}+5$ \\
\hline Logdiffsale & $\begin{array}{l}\text { Log of price differences of repeat } \\
\text { sales }\end{array}$ & 5250 & 11.39 & 1.14 \\
\hline Totalhit & $\begin{array}{l}\text { Total number of hurricane hits } \\
\text { (based on Saffir-Simpson Wind } \\
\text { Scale, if a home was in the path of } \\
\text { sustained wind of } 74 \text { mph or higher } \\
\text { it is considered as a hit by a } \\
\text { hurricane) }\end{array}$ & 5250 & 2.49 & 0.57 \\
\hline SFHA & $\begin{array}{l}\text { If a home was in SFHA }(1=\text { Yes, } \\
0=\text { Otherwise })\end{array}$ & 5250 & 0.11 & 0.31 \\
\hline Totalhit*SFHA & $\begin{array}{l}\text { The interaction term of Totalhit and } \\
\text { SFHA }\end{array}$ & 5250 & 0.26 & 0.78 \\
\hline Damage & $\begin{array}{l}1 \text { if a home was marked as } \\
\text { "damaged" by a hurricanes in } 2004 \\
\text { and } 2005 \text { by the property tax } \\
\text { authority, } 0 \text { otherwise }\end{array}$ & 5250 & 0.29 & 0.45 \\
\hline Bedroom & Total number of bedroom & 5250 & 2.96 & 0.79 \\
\hline Bathroom & Total number of bathroom & 5250 & 2.32 & 0.75 \\
\hline Acreage & Total acreage & 5250 & 0.37 & 0.76 \\
\hline Garage & Attached garage in sf & 4194 & 496.78 & 172.64 \\
\hline Pool & 1 if a home has pool, 0 otherwise & 5250 & 0.27 & 0.44 \\
\hline Age & Age of the structure of the home & 5250 & 32.42 & 135.00 \\
\hline Agesqr & Square of Age & 5250 & $1.9 \mathrm{E}+4$ & $2.7 \mathrm{E}+5$ \\
\hline Dock & 1 if a home has dock, 0 otherwise & 5250 & 0.06 & 0.23 \\
\hline Distance & $\begin{array}{l}\text { The shortest distance from the house } \\
\text { to the ocean shoreline in miles }\end{array}$ & 5250 & 0.11 & 0.31 \\
\hline Shutter & 1 if a home has shutter, 0 otherwise & 5250 & 0.57 & 0.49 \\
\hline Woodwall & $\begin{array}{l}1 \text { if exterior wall is made of wood, } 0 \\
\text { otherwise }\end{array}$ & 5250 & 0.14 & 0.34 \\
\hline Metalroof & $\begin{array}{l}1 \text { if roof is made of metal, } 0 \\
\text { otherwise }\end{array}$ & 5250 & 0.14 & 0.35 \\
\hline Diffyear & $\begin{array}{l}\text { The year difference between last } \\
\text { sale and first sale }\end{array}$ & 5250 & 0.14 & 0.35 \\
\hline Year 2000 & $\begin{array}{l}1 \text { if a home had a sale transaction in } \\
2000\end{array}$ & 5250 & 0.11 & 0.32 \\
\hline
\end{tabular}




\begin{tabular}{|c|c|c|c|c|}
\hline Year 2001 & $\begin{array}{l}1 \text { if a home had a sale transaction in } \\
2001\end{array}$ & 5250 & 0.11 & 0.31 \\
\hline Year 2002 & $\begin{array}{l}1 \text { if a home had a sale transaction in } \\
2002\end{array}$ & 5250 & 0.14 & 0.34 \\
\hline Year 2003 & $\begin{array}{l}1 \text { if a home had a sale transaction in } \\
2003\end{array}$ & 5250 & 0.14 & 0.35 \\
\hline Year 2004 & $\begin{array}{l}1 \text { if a home had a sale transaction in } \\
2004\end{array}$ & 5250 & 0.14 & 0.35 \\
\hline Year 2005 & $\begin{array}{l}1 \text { if a home had a sale transaction in } \\
2005\end{array}$ & 5250 & 0.11 & 0.31 \\
\hline Year 2006 & $\begin{array}{l}1 \text { if a home had a sale transaction in } \\
2006\end{array}$ & 5250 & 0.07 & 0.26 \\
\hline Year 2007 & $\begin{array}{l}1 \text { if a home had a sale transaction in } \\
2007\end{array}$ & 5250 & 0.06 & 0.23 \\
\hline Year 2008 & $\begin{array}{l}1 \text { if a home had a sale transaction in } \\
2008\end{array}$ & 5250 & 0.05 & 0.22 \\
\hline Year 2009 & $\begin{array}{l}1 \text { if a home had a sale transaction in } \\
2009\end{array}$ & 5250 & 0.04 & 0.19 \\
\hline Year 2010 & $\begin{array}{l}1 \text { if a home had a sale transaction in } \\
2010\end{array}$ & 5250 & 0.04 & 0.20 \\
\hline
\end{tabular}

Table 2.2 Spatial/temporal decomposition of sale prices in Martin County

\begin{tabular}{llllll}
\hline SFHA & 0 Hurricane & 1 Hurricane & 2 Hurricane & 3 Hurricane & Total \\
& Hits & Hits & Hits & Hits & \\
\hline In & 0 & 0 & 291 & 267 & 558 \\
Out & 61 & 10 & 2,208 & 2,413 & 4,692 \\
Total & 61 & 10 & 2,499 & 2,680 & 5,250 \\
\hline
\end{tabular}


Table 2.3 Hedonic Model Estimation of Real Estate Sales for Totalhit

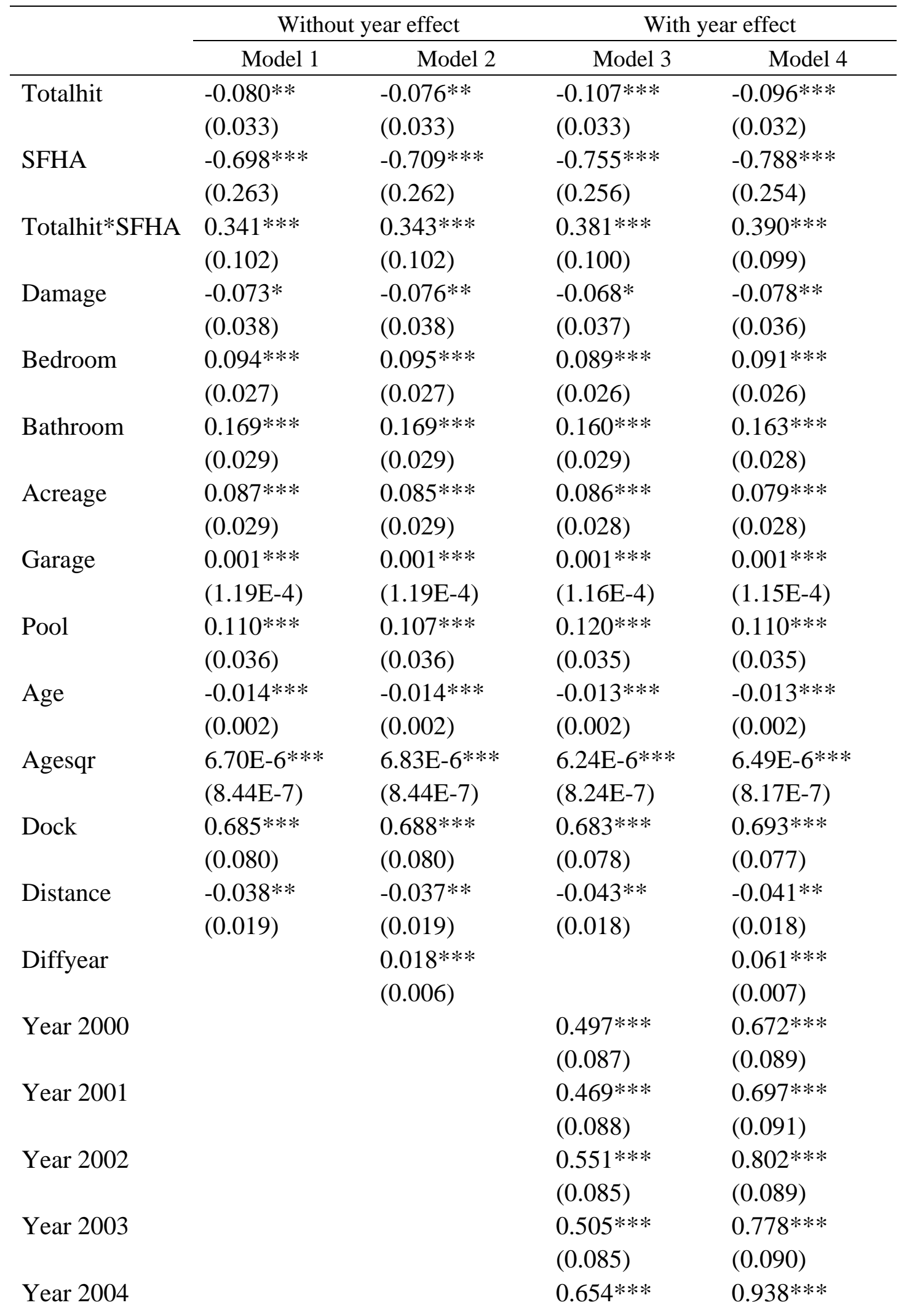


Year 2005

Year 2006

Year 2007

Year 2008

Year 2009

Constant

N

$\mathrm{R}^{2}$

$$
\text { (0.085) }
$$

$0.917 * * *$

(0.088)

$0.967 * * *$

(0.095)

$0.736 * * *$

(0.099)

$0.485 * * *$

(0.101)

$-0.064$

(0.109)

$10.719 * * *$

$10.297 * * *$

(0.153)

4194

$$
\text { (0.138) }
$$

4194

0.155
(0.141)

4194

0.157
(0.090)

1.177 ***

(0.092)

$1.188 * * *$

(0.098)

$0.916 * * *$

(0.101)

$0.581 * * *$

(0.101)

$-0.003$

(0.108)

$9.822 * * *$

(0.161)

4194

0.215

Notes: $* * *, * *, *$ imply significance at $1 \%, 5 \%, 10 \%$ levels respectively; numbers in the parenthesis are robust standard errors.

Table 2.4 Variations in Property Values for Totalhit

\begin{tabular}{lllll}
\hline & \multicolumn{1}{c}{ Model 1 } & \multicolumn{1}{c}{ Model 2 } & \multicolumn{1}{c}{ Model 3 } & \multicolumn{1}{c}{ Model 4 } \\
\hline Totalhit & $-7.73 \%$ & $-7.31 \%$ & $-10.19 \%$ & $-9.17 \%$ \\
SFHA & $-50.23 \%$ & $-50.80 \%$ & $-52.98 \%$ & $-54.53 \%$ \\
Damage & $-7.03 \%$ & $-7.33 \%$ & $-6.62 \%$ & $-7.54 \%$ \\
Bedroom & $9.83 \%$ & $10.00 \%$ & $9.26 \%$ & $9.49 \%$ \\
Bathroom & $18.37 \%$ & $18.46 \%$ & $17.30 \%$ & $17.70 \%$ \\
Acreage & $9.09 \%$ & $8.88 \%$ & $8.96 \%$ & $8.20 \%$ \\
Garage & $0.08 \%$ & $0.08 \%$ & $0.08 \%$ & $0.08 \%$ \\
Pool & $11.61 \%$ & $11.29 \%$ & $12.73 \%$ & $11.62 \%$ \\
Age & $-1.38 \%$ & $-1.41 \%$ & $-1.28 \%$ & $-1.33 \%$ \\
Dock & $98.41 \%$ & $99.00 \%$ & $97.94 \%$ & $99.93 \%$ \\
Distance & $-3.75 \%$ & $-3.68 \%$ & $-4.24 \%$ & $-4.04 \%$ \\
Diffyear & & $1.82 \%$ & & $6.33 \%$ \\
\hline
\end{tabular}

Notes: Estimated from log and exponential transformation to obtain the variation of property value appreciation. 
Table 2.5 Hedonic Model Estimation of Real Estate Sales for Totalhit with Hurricane Mitigation

\begin{tabular}{|c|c|c|c|c|}
\hline & \multicolumn{2}{|c|}{ Without year effect } & \multicolumn{2}{|c|}{ With year effect } \\
\hline & Model 1 & Model 2 & Model 3 & Model 4 \\
\hline \multirow[t]{2}{*}{ Totalhit } & $-0.075 * *$ & $-0.071 * *$ & $-0.101 * * *$ & $-0.090 * * *$ \\
\hline & $(0.033)$ & $(0.033)$ & $(0.033)$ & $(0.032)$ \\
\hline \multirow[t]{2}{*}{ SFHA } & $-0.724 * * *$ & $-0.735^{* * *}$ & $-0.781 * * *$ & $-0.817 * * *$ \\
\hline & $(0.262)$ & $(0.262)$ & $(0.255)$ & $(0.253)$ \\
\hline \multirow[t]{2}{*}{ Totalhit*SFHA } & $0.347 * * *$ & $0.349 * * *$ & $0.386 * * *$ & $0.396 * * *$ \\
\hline & $(0.102)$ & $(0.102)$ & $(0.100)$ & $(0.099)$ \\
\hline \multirow[t]{2}{*}{ Damage } & $-0.066^{*}$ & $-0.069 *$ & $-0.061 *$ & $-0.071 * *$ \\
\hline & $(0.038)$ & $(0.038)$ & $(0.037)$ & $(0.036)$ \\
\hline \multirow[t]{2}{*}{ Bedroom } & $0.089 * * *$ & $0.091 * * *$ & $0.083 * * *$ & $0.086 * * *$ \\
\hline & $(0.027)$ & $(0.027)$ & $(0.026)$ & $(0.026)$ \\
\hline \multirow[t]{2}{*}{ Bathroom } & $0.172 * * *$ & $0.172 * * *$ & $0.164 * * *$ & $0.166 * * *$ \\
\hline & $(0.029)$ & $(0.029)$ & $(0.029)$ & $(0.028)$ \\
\hline \multirow[t]{2}{*}{ Acreage } & $0.086^{* * * *}$ & $0.084 * * *$ & $0.083 * * *$ & $0.075^{* * *} *$ \\
\hline & $(0.029)$ & $(0.029)$ & $(0.028)$ & $(0.028)$ \\
\hline \multirow[t]{2}{*}{ Garage } & $0.001 * * *$ & $0.001 * * *$ & $0.001 * * *$ & $0.001 * * *$ \\
\hline & $(1.19 \mathrm{E}-4)$ & $(1.19 \mathrm{E}-4)$ & $(1.16 \mathrm{E}-4)$ & $(1.15 \mathrm{E}-4)$ \\
\hline \multirow[t]{2}{*}{ Pool } & $0.115^{* * *}$ & $0.112 * * *$ & $0.126^{* * *}$ & $0.117 * * *$ \\
\hline & $(0.036)$ & $(0.036)$ & $(0.035)$ & $(0.035)$ \\
\hline \multirow[t]{2}{*}{ Age } & $-0.012 * * *$ & $-0.013 * * *$ & $-0.011^{* * *}$ & $-0.012 * * *$ \\
\hline & $(0.002)$ & $(0.002)$ & $(0.002)$ & $(0.002)$ \\
\hline \multirow[t]{2}{*}{ Agesqr } & $5.99 \mathrm{E}-6 * * *$ & $6.14 \mathrm{E}-6 * * *$ & $5.50 \mathrm{E}-6 * * *$ & $5.81 \mathrm{E}-6 * * *$ \\
\hline & $(8.65 \mathrm{E}-7)$ & $(8.66 \mathrm{E}-7)$ & (8.44E-7) & $(8.37 \mathrm{E}-7)$ \\
\hline \multirow[t]{2}{*}{ Dock } & $0.673^{* * *}$ & $0.676^{* * *}$ & $0.669 * * *$ & $0.68 * * *$ \\
\hline & $(0.080)$ & $(0.08)$ & $(0.078)$ & $(0.077)$ \\
\hline \multirow[t]{2}{*}{ Distance } & $-0.035^{*}$ & $-0.034 *$ & $-0.038^{* *}$ & $-0.036^{*}$ \\
\hline & $(0.019)$ & $(0.019)$ & $(0.019)$ & $(0.018)$ \\
\hline \multirow[t]{2}{*}{ Diffyear } & & $0.017^{* * *}$ & & $0.061 * * *$ \\
\hline & & $(0.006)$ & & $(0.007)$ \\
\hline \multirow[t]{2}{*}{ Shutter } & $0.070^{* *}$ & $0.063^{*}$ & $0.081^{* *}$ & $0.063^{*}$ \\
\hline & $(0.034)$ & $(0.034)$ & $(0.033)$ & $(0.033)$ \\
\hline \multirow[t]{2}{*}{ Woodwall } & $-0.146^{* *}$ & $-0.149 * * *$ & $-0.134 * *$ & $-0.142 * *$ \\
\hline & $(0.058)$ & $(0.058)$ & $(0.056)$ & $(0.056)$ \\
\hline \multirow[t]{2}{*}{ Metalroof } & $0.105^{* *}$ & $0.103^{* *}$ & $0.140 * * *$ & $0.139 * * *$ \\
\hline & $(0.049)$ & $(0.049)$ & $(0.048)$ & $(0.047)$ \\
\hline \multirow[t]{2}{*}{ Year 2000} & & & $0.517 * * *$ & $0.689 * * *$ \\
\hline & & & $(0.087)$ & $(0.089)$ \\
\hline
\end{tabular}




\begin{tabular}{|c|c|c|c|c|}
\hline \multicolumn{3}{|l|}{ Year 2001} & $\begin{array}{l}0.479 * * * \\
(0.088)\end{array}$ & $\begin{array}{l}0.702 * * * \\
(0.091)\end{array}$ \\
\hline \multirow{2}{*}{\multicolumn{3}{|c|}{ Year 2002}} & $0.562 * * *$ & $0.809 * * *$ \\
\hline & & & $(0.085)$ & $(0.089)$ \\
\hline \multirow{2}{*}{\multicolumn{3}{|c|}{ Year 2003}} & $0.514 * * *$ & $0.784 * * *$ \\
\hline & & & $(0.085)$ & $(0.090)$ \\
\hline \multirow{2}{*}{\multicolumn{3}{|c|}{ Year 2004}} & $0.664 * * *$ & $0.944 * * *$ \\
\hline & & & $(0.085)$ & $(0.090)$ \\
\hline \multirow{2}{*}{\multicolumn{3}{|c|}{ Year 2005}} & $0.935 * * *$ & $1.191 * * *$ \\
\hline & & & $(0.088)$ & $(0.092)$ \\
\hline \multirow{2}{*}{\multicolumn{3}{|c|}{ Year 2006}} & $0.974 * * *$ & $1.193 * * *$ \\
\hline & & & $(0.095)$ & $(0.097)$ \\
\hline \multirow{2}{*}{\multicolumn{3}{|c|}{ Year 2007}} & $0.744 * * *$ & $0.92 * * *$ \\
\hline & & & $(0.099)$ & $(0.100)$ \\
\hline \multirow{2}{*}{\multicolumn{3}{|c|}{ Year 2008}} & $0.487 * * *$ & $0.583 * * *$ \\
\hline & & & $(0.101)$ & $(0.100)$ \\
\hline \multirow{2}{*}{\multicolumn{3}{|c|}{ Year 2009}} & -0.06 & $3.26 \mathrm{E}-5$ \\
\hline & & & $(0.108)$ & $(0.108)$ \\
\hline \multirow[t]{2}{*}{ Constant } & $10.715^{* * * *}$ & $10.646 * * *$ & $10.188 * * *$ & $9.733 * * *$ \\
\hline & $(0.141)$ & $(0.143)$ & $(0.155)$ & $(0.163)$ \\
\hline $\mathrm{N}$ & 4193 & 4193 & 4193 & 4193 \\
\hline $\mathrm{R}^{2}$ & 0.158 & 0.159 & 0.204 & 0.218 \\
\hline
\end{tabular}


Table 2.6 Variations in Property Values for Totalhit with Hurricane Mitigation

\begin{tabular}{lllll}
\hline & \multicolumn{1}{c}{ Model 1 } & \multicolumn{1}{c}{ Model 2 } & \multicolumn{1}{c}{ Model 3 } & \multicolumn{1}{c}{ Model 4 } \\
\hline Totalhit & $-7.26 \%$ & $-6.85 \%$ & $-9.65 \%$ & $-8.60 \%$ \\
SFHA & $-51.51 \%$ & $-52.06 \%$ & $-54.21 \%$ & $-55.80 \%$ \\
Damage & $-6.40 \%$ & $-6.71 \%$ & $-5.90 \%$ & $-6.90 \%$ \\
Bedroom & $9.33 \%$ & $9.53 \%$ & $8.66 \%$ & $8.97 \%$ \\
Bathroom & $18.73 \%$ & $18.79 \%$ & $17.79 \%$ & $18.10 \%$ \\
Acreage & $8.97 \%$ & $8.76 \%$ & $8.60 \%$ & $7.79 \%$ \\
Garage & $0.08 \%$ & $0.08 \%$ & $0.08 \%$ & $0.08 \%$ \\
Pool & $12.16 \%$ & $11.86 \%$ & $13.47 \%$ & $12.40 \%$ \\
Age & $-1.24 \%$ & $-1.27 \%$ & $-1.13 \%$ & $-1.19 \%$ \\
Dock & $95.93 \%$ & $96.58 \%$ & $95.22 \%$ & $97.37 \%$ \\
Distance & $-3.45 \%$ & $-3.38 \%$ & $-3.74 \%$ & $-3.51 \%$ \\
Diffyear & & $1.74 \%$ & & $6.25 \%$ \\
Shutter & $7.23 \%$ & $6.49 \%$ & $8.46 \%$ & $6.51 \%$ \\
Woodwall & $-13.59 \%$ & $-13.88 \%$ & $-12.55 \%$ & $-13.26 \%$ \\
Metalroof & $11.09 \%$ & $10.88 \%$ & $15.03 \%$ & $14.89 \%$ \\
\hline
\end{tabular}




\section{FIGURES}

Figure 2.1 Percentages of Total Sales with Property Value Appreciation from the Year 2000-2010 in Martin County

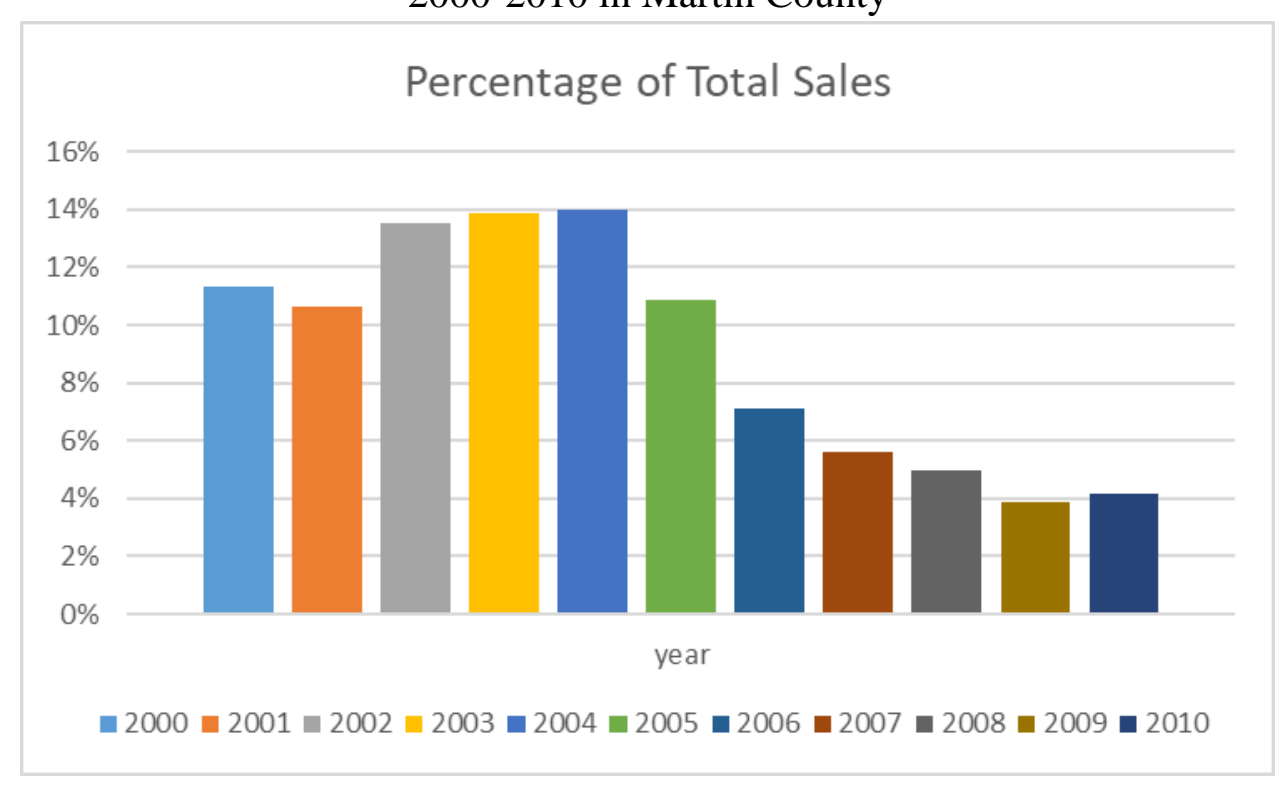


Figure 2.2 Location of St. Lucie, Martin and Palm Beach County with Hurricane Tracks of Wilma, Jeanne, and Frances

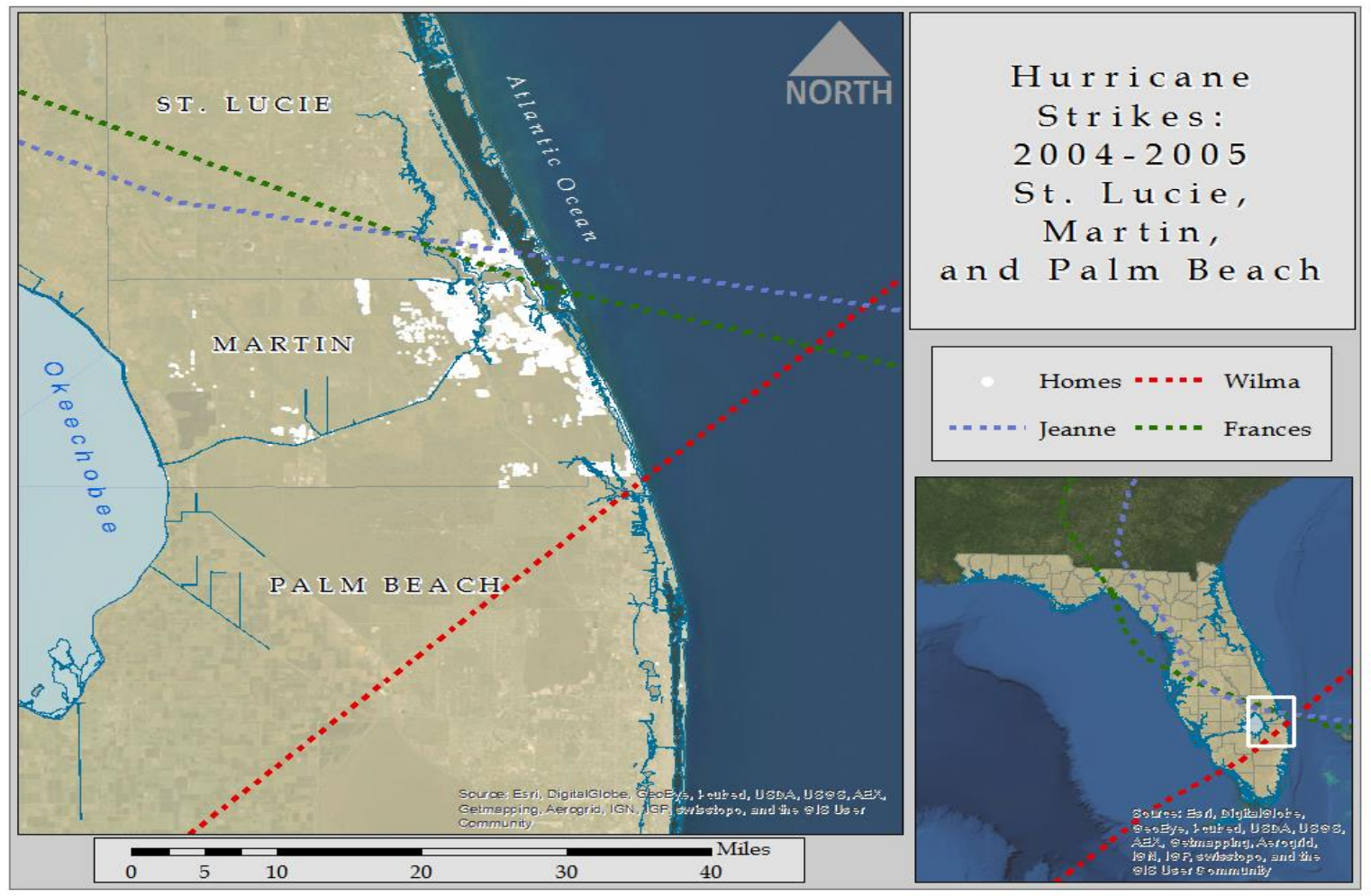


Figure 2.3 Variations in Property Values for Totalhit and Other Characteristics

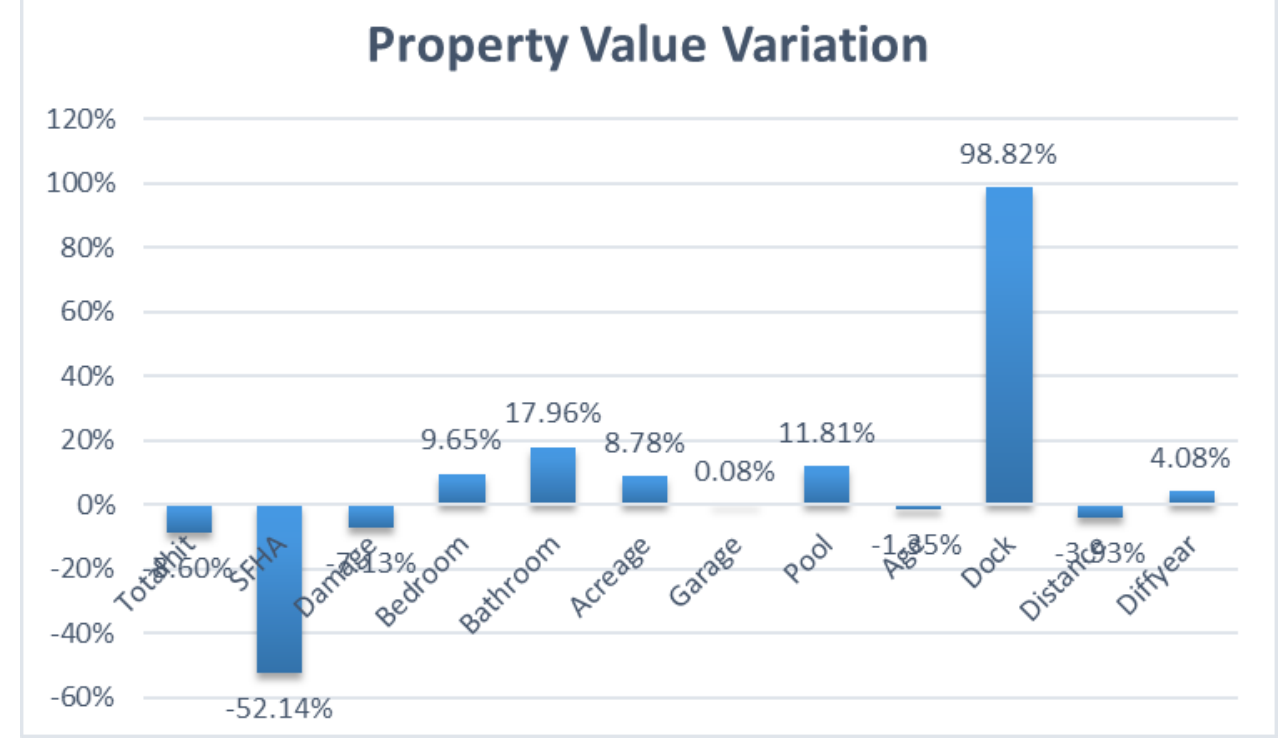

Figure 2.4 Variations in Property Values for Totalhit with Hurricane Mitigation and Other Characteristics

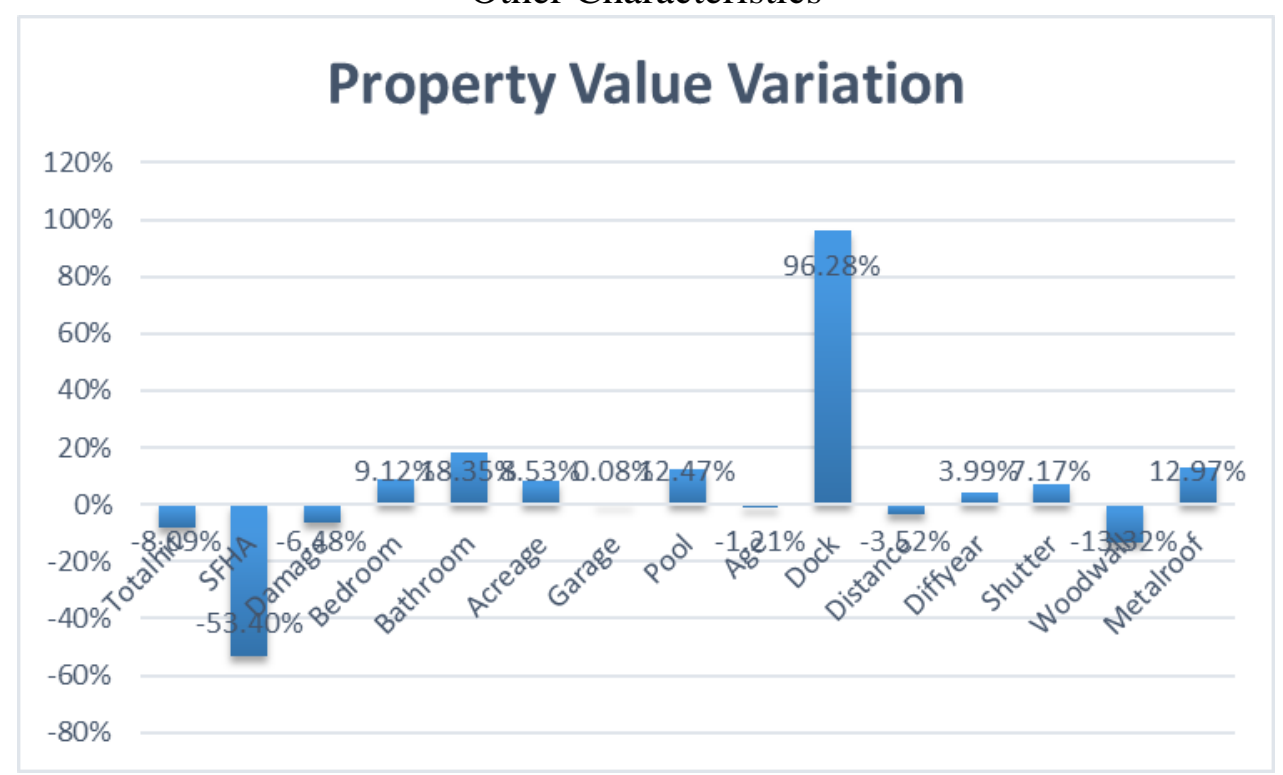




\section{CHAPTER 3}

\section{TIME PREFERENCE AND THE DYNAMICS OF EVACUATION BEHAVIOR: EVIDENCE FROM HURRICANE IKE AND HURRICANE SANDY}

\subsection{Introduction}

In the past few decades, hurricanes have become one of the deadliest natural disasters affecting coastal areas of the US (Yang 2008); they caused an average of 74 fatalities and USD $\$ 31$ billion in damages per year worldwide (NOAA 2018). It has been demonstrated that evacuation is an effective option to reduce hurricane-related deaths and property damage. However, hurricane evacuations are becoming an increasingly complicated activity since a large number of people need to evacuate quickly and efficiently during a hurricane event. Mass hurricane evacuations lead to high traffic congestion and possible damage to road networks (Barrett et al., 2000). It is essential for social scientists and community planners to understand people's hurricane evacuation behavior to devise an effective evacuation plan for coastal residents.

Many papers have studied hurricane evacuation behavior. However, very few studies have examined the evacuation timing decisions. Dash and Gladwin (2007) found that household characteristics such as age, the presence of children, gender, race, ethnicity, income, previous hurricane experience, and location play a vital role in the hurricane evacuation decision-making process. Sarwar (2016) reported that coastal flooding, vehicle, household size, children, senior, owner, education, mobile house, 
voluntary order and mandatory order play an essential role in deciding the time of hurricane evacuation. Lindell et al. (2007) reported how previous hurricane experience affects drivers' evacuation route decisions but not the timing of evacuation.

The present study contributes to the literature on households' evacuation timing decisions and investigates the factors influencing earlier versus later evacuation. I used two datasets from households who experienced Hurricane Ike and Hurricane Sandy. The data were collected by a telephone survey. I developed Heckman selection models to identify what factors affect people's evacuation timing decisions. In this paper, I combine hurricane evacuation datasets from different locations, the Atlantic and Gulf coast areas, to analyze various factors that influence travel time decision for hurricane evacuation. Both empirical analyses indicate that respondents who have prior experience with hurricane evacuation evacuated earlier. Households who own their houses chose to leave earlier in both cases. I also find that people who evacuated earlier traveled longer.

\subsection{Literature Review}

Hurricane evacuations are often a complicated issue, as they involve a large population moving along the Atlantic and Gulf coasts. Lindell et al. (2005) argued that traffic congestion could cause 10 to 20 hours of delays if the evacuation process is not managed correctly. Franklin et al. (2006) revealed that a portion of the Interstate 10 bridge system over Pensacola Bay was heavily damaged and US Highway 90 was also severely damaged during Hurricane Ivan. Furthermore, if the evacuation routes run parallel to 
surge-prone bays and rivers, storm surge and inland flooding could cause massive loss of life among the evacuees trapped in the traffic congestion (Sarwar, 2016). To avoid loss of life and heavy damage to property, it becomes increasingly important for emergency management planners to design an efficient and safe evacuation plan. Households may exhibit different evacuation behaviors, which can be driven by the different levels of risk perception, social network, and characteristics under the same emergency situation. It is necessary to understand what factors influence their decisions to evacuate and deciding what time to evacuate.

Considerable research on hurricane evacuation has been conducted; however, a limited number of studies have contributed to behavioral modeling. Researchers have found that evacuation decisions depend on factors such as the household risk perception, the decisions of influential people (neighbors, family or friends), the characteristics of the hurricane, hurricane warning and information systems, and the characteristics of households (Baker, 1991; Gladwin et al., 2001; Petrolia and Bhattacharjee, 2010; Lindell et al., 2011). Mesa-Arango et al. (2012) indicated that factors such as household location, socioeconomic characteristics, and previous experience affect the type of destination following evacuation. Irwin et al. (1995) found that the perception of risk, type of dwelling, gender, and age significantly influenced the probability of evacuation during Hurricane Andrew. 
Lindell and Prater (2007) conducted a detailed review of evacuation timing. Sorenson (1991) investigated evacuation timing behavior by using path analysis. Fu (2004) found that evacuation order, flood, the mobile home will influence people's decision regarding the timing of evacuation. Fu and Wilmot (2004) developed a sequential logit model to analyze people's evacuation decision; later, they developed a hazard-based model (Fu and Wilmot, 2006). Hasan et al. (2013) also developed a model of evacuation timing behavior using a hazard-based modeling approach.

Previous studies have indicated that hurricane experience and past hurricane experience affect people's evacuation behavior and risk preference (Raid and Norris 1998, Whitehead et al. 2000). Negative experience from a previous hurricane evacuation reduces the likelihood of evacuation for future hurricanes (Dow and Cutter 1998). Dash and Gladwin (2007) argued that risk perception is more important than a negative hurricane evacuation experience. Riad et al. (1998) claimed that previous evacuation experience significantly predicted future evacuation behavior, whereas, prior disaster experience did not. Moreover, Riad et al. (1999) concluded that prior evacuation experience was the single best predictor of evacuation during Hurricanes Hugo and Andrew. Dash and Morrow (2000) stated that people who experienced traffic delays in returning after a hurricane evacuation are less likely to evacuate for a future hurricane. Huang et al. (2007) indicated that hurricane experiences positively affect evacuation 
decisions, and unnecessary evacuation experience was positively correlated with perceived evacuation impediments.

Although previous studies have reported that hurricane experiences play an important role in people's decision making and risk preference, few studies focused on how experience affects people's timing in the context of the hurricane evacuation. In the valuation literature on environmental economics, experience with public good has been used to predict consumers' preference and their WTP (Boyle et al., 1993; Adamowicz, 1994; Whitehead et al., 1995; Cameron et al., 1997; Breffle et al., 2000; Ferrini et al., 2007; Hanley et al., 2009). However, the relationship between experience with public good and preference usually cannot be tested since markets for public goods are often incomplete (Carson and Czajkowski, 2014).

In the previous economic literature, the time preference was analyzed using the discounted utility model (DUM), which was introduced by Samuelson in 1937 . The DUM assumes that an individual's time preference can be obtained by a single discount rate (Cassar et al., 2017). However, studies have argued that a potential measurement error exists in estimating DUM (Frederick et al., 2002). For instance, there are substantial overestimates for how impatient people are if failing to account for risk aversion (Andersen et al., 2008). In fact, the two main focuses in behavioral economics are the time and risk preferences. A few studies attempted to estimate the rate of time preference and the coefficient of risk aversion at the same time (Ida and Goto, 2009). 
Most of the previous literature measured time and risk preferences separately; however, time preference parameters regarding delay and probability discounting need to be measured together. A few papers have attempted to measure the time and risk preferences together (Rachlin et al. 1991, Keren and Roelofsma 1995, Anderhub et al. 2001, and Yi et al. 2006). In this study, I simultaneously estimate the rate of time preference and the coefficient of risk aversion using reference-dependent utility models. Reference-dependent preference utility incorporates loss aversion that explains an individual's decisions based on the potential value of losses rather than the outcome (Tversky and Kahneman 1979). Using the Heckman selection approach, I analyze the relationship between hurricane evacuation and time and risk preferences simultaneously. The empirical models estimate the individual's time and risk preference under different reference points (with hurricane experience and without hurricane experience).

\subsection{Background and Data Description}

On Sept 13, 2008, Hurricane Ike made landfall on Galveston Island, Texas, with sustained winds of $110 \mathrm{mph}$, a 22-foot storm surge, and widespread coastal flooding. Hurricane Ike affected mostly Texas, Louisiana, and Arkansas and caused at least 84 deaths in these three states; other affected regions included Florida and the Ohio Valley. Insured damage was estimated to be approximately USD $\$ 19.3$ billion in those three states. The total damage caused by Ike was estimated at USD $\$ 24.9$ billion, which made it the third costliest of any Atlantic hurricane. To understand the factors that influence the evacuation timing 
decisions, researchers at Florida International University conducted a survey in which researchers phone interviewed 1,099 households located in Harris and Galveston Counties in Texas. The questionnaire asked the residents to report the behaviors they adopted to lower their risk during Hurricane Ike's impact on the coast of Texas. Respondents who evacuated due to Ike were asked when they evacuated. Respondents were also asked to report their evacuation experience if they had previously evacuated for a hurricane.

More recently, in the 2012 Atlantic hurricane season, most residents of the eastern coastal area experienced the highly destructive Hurricane Sandy, which was marked as the second most costly natural disaster ever to affect the United States (Blake et al., 2013). The damage of Hurricane Sandy (estimates as of June 2013) reached nearly USD\$68 billion, surpassed by only Hurricane Katrina. At least 287 people in seven counties lost their lives due to this catastrophe (Sullivan, 2012). Hurricane Sandy affected 24 states, which included the whole eastern coastal area from Florida to Maine and the western path to Michigan and Wisconsin. New York and New Jersey were particularly severely affected among 24 stricken states. The total property damage due to Hurricane Sandy was approximately USD\$65 billion in the United States (Herring, 2013). In 2003, researchers at Florida International University conducted a phone-based survey and collected the survey data from respondents who lived in the Hurricane Sandy influence area. 


\subsection{Motivation and Objective}

Figures 3.1 and 3.2 indicate that approximately $59 \%$ of respondents had past hurricane evacuation experience during Hurricane Ike; this number for Hurricane Sandy was only $6 \%$. Figures 3.3, 3.4, and 3.5 reveal that most of the evacuees chose to evacuate two days or one day before the hurricane hit during Hurricane Ike. Conversely, $90 \%$ of Hurricane Sandy evacuees departed home one day before or on the day the hurricane made landfall. These preliminary descriptive statistics indicate that people who have past evacuation experience evacuated earlier than those who did not have a similar experience. In the empirical analysis section, I investigate whether the respondents with hurricane evacuation experience evacuated sooner rather than later.

\subsection{Analytical Framework and Empirical Modeling}

This section describes a theoretical framework of people's evacuation timing decision associated with an individual's experience of avoiding hurricane risks. The theoretical framework is based on a model of reference-dependent preferences (Tversky and Kahneman 1991). Köszegi and Rabin (2006) extended the models of reference-dependent preferences and loss aversion. Reference-dependent preferences depend on utility comparisons to relevant reference levels. The reference-dependent utility theory explains people's decisions based on the potential value of losses rather than on the outcome (Tversky and Kahneman 1979). Loss aversion is one of the crucial properties of reference-dependent preferences, which indicates that people dislike losses to the 
reference point more than they like same-sized gains. Much literature on reference-dependent preferences has previously been published in the domain of behavioral economics. Hardie et al. (1993) developed a model of loss aversion and reference dependence effects on brand choice. Kahneman et al. (1990) reported experimental tests of the endowment effect and loss aversion.

However, the empirical analysis of reference-dependent models has not been conducted in the context of a natural disaster, particularly for hurricane evacuation decision making. In this study, I assume that people have two reference points when making hurricane evacuation decision: 1) with prior hurricane experience and 2) with no prior hurricane experience (Figure 3.6). People who stayed at home during a hurricane event and who chose not to evacuate can expect to live their normal lives, provided that they are not affected by the hurricane. Conversely, evacuating (compared with staying home) entails a sense of loss of normal life. People who decide to stay will enjoy a normal life, and evacuees will spend money for travel, food, and lodging and disrupt their normal lives. Conversely, people who choose to stay can suffer major discomfort (due to utility disruption, etc.) and risk their lives if they are hit by the hurricane. In that case, evacuees will enjoy the benefit of avoiding the risk to their lives and the discomfort.

In accordance with Kőszegi and Rabin's (2006) models of reference-dependent preferences, I formulate the total reference-dependent utility of an individual based on two reference-dependent points (Figure 3.6): 


$$
\begin{aligned}
& V_{h}=\lambda U_{h}^{e}\left(x_{h}^{e}-r_{h}\right)+(1-\lambda) U_{h}^{s}\left(x_{h}^{s}-r_{h}\right) \\
& V_{n}=\lambda U_{n}^{e}\left(x_{n}^{e}-r_{n}\right)+(1-\lambda) U_{n}^{s}\left(x_{n}^{s}-r_{n}\right)
\end{aligned}
$$

where $V_{h}$ is the total utility of an individual who had prior hurricane experience and $V_{n}$ is the total utility of an individual with no hurricane experience. $U_{h}^{e}$ is the utility of evacuees who had hurricane experience, and $U_{n}^{e}$ is the utility of evacuees who had no hurricane evacuation experience and $\lambda$ is the probability of hurricane evacuation. $U_{h}^{s}$ is the utility of an individual who chose to stay with hurricane experience, and $U_{n}^{s}$ is the utility of an individual who chose to stay without experience; $x^{e}$ is the time that evacuees chose to leave, and $x^{s}$ is the time residents chose to stay; $r_{h}$ is the reference point of the individual who had the hurricane experience, and $r_{n}$ is for the reference point of the individual with no experience. I assume that the utility of the individual who chose to evacuate with hurricane experience is greater than the utility of the individual who evacuated without experience, which is $U_{h}^{e}>U_{n}^{e}$ (due to the preference for loss aversion).

I use the Heckman selection model (Heckman 1976) since, in this case, people choose to evacuate first and then decide when to evacuate. Cameron et al. (2010) and Greene (2012) extended the Heckman selection model and provided the steps for its implementation. Heckman (1979) provided a two-stage estimation procedure using the inverse Mills ratio to address the selection bias. In the first step, a probit model is estimated to observe a positive outcome of the dependent variable (Equation 3.3). The estimated 
parameters are used to calculate the inverse Mills ratio, which is then included as an additional explanatory variable in the OLS estimation (Equation 3.4).

$y_{1 i}=\alpha z_{i}+\delta \quad$ Selection equation

$y_{2 i}=\beta_{0}+\beta_{1} x_{i}+\sigma \rho_{\varepsilon \sigma} \lambda\left(T-\alpha z_{i}\right)+\sigma^{\prime} \varepsilon^{\prime} \quad$ Regression equation

where $y_{1 i}$ is the dichotomous dependent variable (Evacuation decision) and $y_{2 i}$ is the dependent variable of interest (Evacuation timing decision). $x_{i}$ and $z_{i}$ represent matrices of covariates including the individual and household characteristics and the respondents' attitudes regarding hurricane; $\alpha$ and $\beta_{1}$ are the conformable vectors of coefficients to be estimated.

In the regression equation, the value of $y_{2 i}$ is observed when $y_{1 i}$ is greater than a threshold $\mathrm{T}$, and it is omitted if $y_{1 i} \leq T$. The estimation of regression equation by simply regressing $\mathrm{Y}$ on $\mathrm{X}$ will be biased, which represents the omitted variable. In this model, I select $z_{i}$ first in explaining the evacuation decision; I then retain $z_{i}$ in the full regression if $y_{2 i}$ is omitted (Puhani 2000). I also include a set of household characteristics and risk perception variables.

Usually, the assumption in OLS regression is that the dependent variable is continuous. Our interest dependent variable $y_{1 i}$ is the discrete variable in the regression equation, however, Xu et al. (2017) introduced how the Heckman selection model handles discrete/continuous modeling issue and developed an empirical study on transportation. When dependent variables are discrete, there are a number of alternatives to OLS such as 
Poisson, multinomial, switching, survival and ordered probit model. I use the Poisson and the generalized linear latent and mixed models to check the robustness of the findings.

\subsection{Results}

Table 3.1 and Table 3.2 show the definitions and descriptive statistics of variables involved in the matrix of covariates for analyzing evacuation behavior. First, I summarize the information about the two dependent variables EVACUATE (the evacuation decision) and TIME (the evacuation timing decision). I also use the variable EXPERIENCE (had prior hurricane evacuation experience), whether the respondent evacuated for a hurricane before. Following Whitehead (2005a), the binary indicators VOLUNTARY (receive a voluntary evacuation order) and MANDATORY (receive a mandatory evacuation order) are included as an indicator of location-specific hurricane risk. Household and respondent characteristics (age, household size, education, owner, race, and gender) are also included to control for potential heterogeneity across individuals and their households. The binary indicators IMPSURGE (if the respondents considered the possibility of flooding to be important), and IMPCRIME (if the respondents considered that being able to protect the home from crime is important) are included to control for attitudes that can affect household averting behaviors implemented to cope with hurricane risks. Finally, the binary indicators WINDOWPREP (if the respondent was prepared to protect windows against hurricanes) is included because it could be expected that risk averting measures 
implemented before the hurricane season can also affect evacuation choices (Solís et al., 2010).

Table 3.1 displays the descriptive statistics for Hurricane Ike. On average, the respondents evacuated two days before Hurricane Ike made landfall. Approximately 59\% of respondents had prior hurricane evacuation experience. Approximately $88 \%$ of respondents lived in their housing unit, with an average household size of 2.7 members. Approximately $52 \%$ of respondents had a college degree. Most respondents identified themselves as white $(77.1 \%)$, less than $16 \%$ were black, and $6.9 \%$ had a racial background other than white and black. More than $51 \%$ of respondents reported that they prepared to protect the windows of their housing units against hurricanes in 2008 (when Ike hit Texas). Approximately $26 \%$ of respondents received a voluntary order to evacuate, and $30 \%$ of respondents received a mandatory order to evacuate when Ike hit their localities. Approximately $10 \%$ of respondents were laid off from work because of Hurricane Ike. Only $13 \%$ of respondents said their neighbors affected their evacuation decision.

Table 3.2 shows the descriptive statistics for Hurricane Sandy. On average, the respondents evacuated one day before Hurricane Sandy landfall (i.e., left later than Ike's evacuees on average). Approximately $6 \%$ of respondents had prior hurricane evacuation experience, which is lower than the respondents affected by Hurricane Ike (59\%). Approximately $78 \%$ of respondents lived in their housing unit, with an average household size of approximately 2.5 members. The majority of respondents identified themselves as 
white (80\%), and nearly $40 \%$ were male. More than $13 \%$ of respondents were living in the flood zone, and almost 59\% reported they had an insurance policy to cover storm-induced damages. Only $8 \%$ of respondents were told by a government agency (police or fire official) or news broadcast to evacuate when Hurricane Sandy hit the area where they lived in 2012. Approximately $22 \%$ of respondents made the necessary preparations to leave their home to go somewhere safer in the event of a hurricane. The average age of respondents was 53, and the average number of seniors in the households was 2.5.

Table 3.3 and Table 3.5 present the Heckman selection models estimated for Hurricane Ike and Hurricane Sandy, respectively, to explore which factors will influence people's evacuation decision and evacuation timing decision. First, I focus on the selection equations and investigate which factors should affect the evacuation decision. All models in both tables reveal that people with past evacuation experience are more likely to evacuate, which is consistent with the previous literature (Dash and Gladwin 2007, Hasan, et al. 2010). Models 1, 2, 3, and 4 in Table 3.3 indicate that respondents who received a mandatory or voluntary order have a probability to evacuate, which is also consistent with the previous research (Mozumder 2008, Whitehead 2005).

Race and gender also affect evacuation behavior. People who identified as white are less likely to evacuate. Females are also less likely to evacuate. People who believe a storm surge is extremely important are more likely to evacuate. People who believe protecting their home from crime is extremely important are less likely to evacuate. Models 1, 2, 3, 
and 4 in Table 3.5 reveal that households with more seniors and those who made the necessary preparations to leave their home to go somewhere safer in the event of a hurricane are more likely to evacuate. People who were told by a government agency (police or fire official) or news broadcast to evacuate their home when Hurricane Sandy hit the area were more likely to evacuate. Respondents who live in the flood zone have a higher probability to leave, which is consistent with Whitehead (2010).

For both datasets, I find that respondents who have past hurricane evacuation experience are more likely to evacuate and evacuate sooner. The coefficient of experience for Sandy is larger than that for Ike, as the proportion of respondents who had evacuation experience was smaller in the Sandy survey than in the Ike survey. Households who owned their house chose to leave earlier for both hurricanes. The coefficients of days are positive and statistically significant for both hurricane events, which is logical since people who evacuated earlier may have traveled greater distances and stayed away for a longer duration.

The empirical estimations of both datasets reveal that people who identified themselves as white chose to evacuate later than did those of other races. I find specific characteristics that influence people's evacuation time decision from Hurricane Ike's estimations. People who were influenced by neighbors' decisions evacuated later than did others, and those who believed evacuation orders given by the government agency are extremely important departed earlier. In Table 3.5, I find that responders with larger 
families evacuated later. Respondents who had a home insurance policy to cover damages from a storm (when Hurricane Sandy hit) chose to leave later. Respondents who made the necessary preparations to leave their home departed earlier.

Table 3.4 and Table 3.6 present the robustness analysis for Hurricane Ike and Hurricane Sandy. The results from the Poisson and the generalized linear latent and mixed models are consistent with that from Heckman selection models. For both datasets, I still find that respondents who have past hurricane evacuation experience evacuated sooner. Respondents who departed earlier stayed away for a longer duration since the coefficients of days are positive and statistically significant for both hurricane events. For Hurricane Ike, people who believed evacuation orders given by the government agency are extremely important evacuated earlier. For Hurricane Sandy, households who owned their house chose to leave earlier and responders with larger families evacuated later.

\subsection{Discussions and Conclusions}

In this paper, I develop a Heckman selection model for analyzing the evacuation timing decision of households during a hurricane event and predict their evacuation behavior for future planning purposes. I use respondents' evacuation timing and a set of explanatory variables to estimate which factors play the key role in determining the timing of evacuation. I find that prior hurricane evacuation experience, ownership of property and race influence people to determine when to evacuate in both datasets. Hurricane Ike's 
results illustrate that respondents who care about the government's evacuation order chose to evacuate early. People evacuated later if their decision needed to depend on their neighbor's activity. Moreover, regarding Hurricane Sandy's evacuation, people with a large household size evacuated earlier, and respondents who had an insurance policy to cover hurricane damage chose to leave later.

In closing, this study used data on evacuation timing decisions from Hurricane Ike and Hurricane Sandy. The findings from the Heckman selection models have identified five primary set of determinants of evacuation timing decisions: 1) hurricane experience;2) characteristics of households, such as ownership of house, household size, race, income; 3) decisions of influential people, such as neighbors; 4) household risk perception, such as insurance and flood; and 5) hurricane warning and information, such as evacuation orders.

In this research, I analyze the hurricane evacuation timing decision using survey data from residents who experienced Hurricane Ike and Sandy. I use a different model from previous evacuation behavior studies; Heckman selection models help us to predict more precisely what factors influence household evacuation time. The Atlantic and Gulf coast areas have different geographic and demographic characteristics, and it is essential to apply the empirical analysis across different locations to check the robustness of the findings. Finally, I believe that the findings of this paper will be useful for community planners in coastal areas that are exposed to hurricane threats. The empirical estimation performed in this paper provides insight into households' timing preferences in making 
evacuation decisions and can be applied to other hurricane events across different locations.

\section{REFERENCES}

Adamowicz, W.L., 1994. Habit formation and variety seeking in a discrete choice model of recreation demand. Journal of Agricultural and Resource Economics, pp.19-31.

Anderhub, V., Güth, W., Gneezy, U. and Sonsino, D., 2001. On the interaction of risk and time preferences: An experimental study. German Economic Review, 2(3), pp.239-253.

Andersen, S., Harrison, G.W., Lau, M.I. and Rutström, E.E., 2008. Eliciting risk and time preferences. Econometrica, 76(3), pp.583-618.

Baker, E.J., 1991. Hurricane evacuation behavior. International Journal of Mass Emergencies and Disasters, 9(2), pp.287-310.

Barrett, B., Ran, B. and Pillai, R., 2000. Developing a dynamic traffic management modeling framework for hurricane evacuation. Transportation Research Record: Journal of the Transportation Research Board, (1733), pp.115-121.

Blake, E.S., Kimberlain, T.B., Berg, R.J., John, P.C. and Beven II, J.L., 2013. Hurricane Sandy: October 22-29, 2012. Tropical Cyclone Rep.

Boyle, K.J., Welsh, M.P. and Bishop, R.C., 1993. The role of question order and respondent experience in contingent-valuation studies. Journal of Environmental Economics and Management, 25(1), pp. S80-S99.

Breffle, W.S. and Morey, E.R., 2000. Investigating preference heterogeneity in a repeated discrete-choice recreation demand model of Atlantic salmon fishing. Marine Resource Economics, 15(1), pp.1-20.

Cameron, T.A. and Englin, J., 1997. Respondent experience and contingent valuation of environmental goods. Journal of Environmental Economics and management, 33(3), pp.296-313. 
Cameron, A.C. and Trivedi, P.K., 2010. Microeconometrics using stata.

Carson, R. and Czajkowski, M., 2014. The discrete choice experiment approach to environmental contingent valuation (Doctoral dissertation, Edward Elgar Publishing).

Cassar, A., Healy, A. and Von Kessler, C., 2017. Trust, risk, and time preferences after a natural disaster: experimental evidence from Thailand. World Development, 94, pp.90-105.

Czajkowski, J., 2011. Is It Time to Go Yet? Understanding Household Hurricane Evacuation Decisions from a Dynamic Perspective. Natural Hazards Review, 12(2): $72-84$.

Czajkowski, M., Hanley, N. and LaRiviere, J., 2014. The effects of experience on preferences: theory and empirics for environmental public goods. American Journal of Agricultural Economics, p.aau 087.

Dash, N. and Gladwin, H., 2007. Evacuation decision making and behavioral responses: Individual and household. Natural Hazards Review, 8(3), pp.69-77.

Ferrini, S. and Scarpa, R., 2007. Designs with a priori information for nonmarket valuation with choice experiments: A Monte Carlo study. Journal of environmental economics and management, 53(3), pp.342-363.

$\mathrm{Fu}$, H., 2004. Development of dynamic travel demand models for hurricane evacuation (Doctoral dissertation, Louisiana State University).

Fu, H. and Wilmot, C., 2004. Sequential logit dynamic travel demand model for hurricane evacuation. Transportation Research Record: Journal of the Transportation Research Board, (1882), pp.19-26.

Fu, H. and Wilmot, C., 2006. Survival analysis-based dynamic travel demand models for hurricane evacuation. Transportation Research Record: Journal of the Transportation Research Board, (1964), pp.211-218.

Franklin, J.L., Pasch, R.J., Avila, L.A., Beven, J.L., Lawrence, M.B., Stewart, S.R. and Blake, E.S., 2006. Atlantic hurricane season of 2004. Monthly Weather Review, 134(3), pp.981-1025. 
Frederick, S., Loewenstein, G. and O'donoghue, T., 2002. Time discounting and time preference: A critical review. Journal of economic literature, 40(2), pp.351-401.

Gladwin, C.H., Gladwin, H. and Peacock, W.G., 2001. Modeling hurricane evacuation decisions with ethnographic methods. International Journal of Mass Emergencies and Disasters, 19(2), pp.117-143.

Greene, W. H., 2012. Econometric Analysis. 7th ed. Upper Saddle River, NJ: Prentice Hall.

Hanley, N., Kriström, B. and Shogren, J.F., 2009. Coherent arbitrariness: on value uncertainty for environmental goods. Land Economics, 85(1), pp.41-50.

Hardie, B.G., Johnson, E.J. and Fader, P.S., 1993. Modeling loss aversion and reference dependence effects on brand choice. Marketing science,12(4), pp.378-394.

Hasan, S., Ukkusuri, S., Gladwin, H. and Murray-Tuite, P., 2010. Behavioral model to understand household-level hurricane evacuation decision making. Journal of Transportation Engineering, 137(5), pp.341-348.

Hasan, S., Mesa-Arango, R. and Ukkusuri, S., 2013. A random-parameter hazard-based model to understand household evacuation timing behavior. Transportation research part C: emerging technologies, 27, pp.108-116.

Heckman, J.J., 1976. The common structure of statistical models of truncation, sample selection and limited dependent variables and a simple estimator for such models. In Annals of Economic and Social Measurement, Volume 5, number 4 (pp. 475-492). NBER.

Heckman, J.J., 1979. Sample selection bias as a specification error. Econometrica: Journal of the econometric society, pp.153-161.

Herring, D., 2013. "Billion-Dollar Weather/Climate Disasters". National Climatic Data Center. National Oceanic and Atmospheric Administration. 2013. Retrieved June 13, 2013.

Huang, S.K., Lindell, M.K., Prater, C.S., Wu, H.C. and Siebeneck, L.K., 2012. Household evacuation decision making in response to Hurricane Ike. Natural Hazards Review, 13(4), pp.283-296. 
Ida, T. and Goto, R., 2009. Simultaneous measurement of time and risk preferences: stated preference discrete choice modeling analysis depending on smoking behavior. International Economic Review, 50(4), pp.1169-1182.

Irwin, M.D. and Hurlbert, J.S., 1995. A behavioral analysis of hurricane preparedness and evacuation in southwestern Louisiana. Louisiana Population Data Center, Louisiana State Univ., Baton Rouge, La.

Kahneman, D. and Tversky, A., 1979. Prospect theory: An analysis of decision under risk. Econometrica: Journal of the Econometric Society, pp.263-291.

Kahneman, D., Knetsch, J.L. and Thaler, R.H., 1990. Experimental tests of the endowment effect and the Coase theorem. Journal of political Economy, pp.1325-1348.

Keren, G. and Roelofsma, P., 1995. Immediacy and certainty in intertemporal choice. Organizational Behavior and Human Decision Processes, 63(3), pp.287-297.

Köszegi, B. and Rabin, M., 2006. A model of reference-dependent preferences. The Quarterly Journal of Economics, pp.1133-1165.

Lindell, M.K., Lu, J.C. and Prater, C.S., 2005. Household decision making and evacuation in response to Hurricane Lili. Natural Hazards Review.

Lindell, M.K. and Prater, C.S., 2007. Critical behavioral assumptions in evacuation time estimate analysis for private vehicles: Examples from hurricane research and planning. Journal of Urban Planning and Development.

Lindell, M.K., Kang, J.E. and Prater, C.S., 2011. The logistics of household hurricane evacuation. Natural hazards, 58(3), pp.1093-1109.

Maiolo, J., Delia, A., Whitehead, J.C., Edwards, B., Wilson, K., Van Willigen, M., Williams, C. and Meekins, M., 1999. A socioeconomic hurricane evacuation impact analysis and a hurricane evacuation impact assessment tool methodology for coastal North Carolina: A case study of Hurricane Bonnie. Rep. to the Department of Emergency Management.

Mesa-Arango, R., Hasan, S., Ukkusuri, S.V. and Murray-Tuite, P., 2012. Household-level model for hurricane evacuation destination type choice using hurricane Ivan data. Natural hazards review, 14(1), pp.11-20. 
Mozumder, P., Raheem, N., Talberth, J. and Berrens, R.P., 2008. Investigating intended evacuation from wildfires in the wildland-urban interface: application of a bivariate probit model. Forest Policy and Economics, 10(6), pp.415-423.

Nelson, P., 1970. Information and consumer behavior. Journal of political economy, 78(2), pp.311-329.

Nelson, P., 1974. Advertising as information. Journal of political economy, 82(4), pp.729-754.

Petrolia, D.R. and Bhattacharjee, S., 2010. Why don't coastal residents choose to evacuate for hurricanes? Coastal Management, 38(2), pp.97-112.

Puhani, P., 2000. The Heckman correction for sample selection and its critique. Journal of economic surveys, 14(1), pp.53-68.

Rachlin, H. and Siegel, E., 1994. Temporal patterning in probabilistic choice. Organizational Behavior and Human Decision Processes, 59(2), pp.161-176.

Riad, J.K. and Norris, F.H., 1998. Hurricane threat and evacuation intentions: An analysis of risk perception, preparedness, social influence, and resources.

Riad, J.K., Norris, F.H. and Ruback, R.B., 1999. Predicting evacuation in two major disasters: risk perception, social influence, and access to Resources1. Journal of Applied Social Psychology, 29(5), pp.918-934.

Sarwar, M.T., Anastasopoulos, P.C., Ukkusuri, S.V., Murray-Tuite, P. and Mannering, F.L., 2016. A statistical analysis of the dynamics of household hurricane-evacuation decisions. Transportation, pp.1-20. Solís, D., Thomas, M. and Letson, D., 2010. An empirical evaluation of the determinants of household hurricane evacuation choice. Journal of Development and Agricultural Economics, 2(3), pp.188-196.

Sullivan, D., 2012. "Sandy Brings Hurricane-Force Gusts After New Jersey Landfall". Washington Post. Retrieved 2012-10-30.

Whitehead, J.C., Blomquist, G.C., Hoban, T.J. and Clifford, W.B., 1995. Assessing the validity and reliability of contingent values: a comparison of on-site users, off-site users, and non-users. Journal of Environmental Economics and Management, 29(2), pp.238-251. 
Whitehead, J.C., 2003. One million dollars per mile? The opportunity costs of hurricane evacuation. Ocean and Coastal Management 46(11-12): 1069-1083.

Whitehead, J.C., Edwards, B., Van Willigen, M., Maiolo, J.R., Wilson, K. and Smith, K.T., 2000. Heading for higher ground: factors affecting real and hypothetical hurricane evacuation behavior. Global Environmental Change Part B: Environmental Hazards, 2(4), pp.133-142.

Xu, X., Wong, S.C., Zhu, F., Pei, X., Huang, H. and Liu, Y., 2017. A Heckman selection model for the safety analysis of signalized intersections. PloS one, 12(7), p.e0181544.

Yang, D., 2008. Coping with disaster: The impact of hurricanes on international financial flows, 1970-2002. The BE Journal of Economic Analysis \& Policy, 8(1)

Yi, R., de la Piedad, X. and Bickel, W.K., 2006. The combined effects of delay and probability in discounting. Behavioural Processes, 73(2), pp.149-155. 


\section{TABLES}

Table 3.1 Variable Definitions and Descriptive Statistics for Analyzing Evacuation Behavior during Hurricane Ike

\begin{tabular}{|c|c|c|c|c|}
\hline Variable & Description & $\mathrm{N}$ & Mean & SD \\
\hline EVAC & $\begin{array}{l}\text { If the respondent evacuated for Hurricane } \\
\text { Ike } \\
(1=\text { Yes, } 0=\text { Otherwise })\end{array}$ & 1052 & 0.48 & 0.50 \\
\hline TIME & $\begin{array}{l}\text { When the respondent evacuated for } \\
\text { Hurricane Ike } \\
(0=\text { the day Ike hit ....6=6 days before Ike } \\
\text { hit })\end{array}$ & 509 & 1.82 & 0.98 \\
\hline INDEXP & Mean evacuation expenditures of individual & 678 & 324.72 & 770.13 \\
\hline INCOME & $\begin{array}{l}\text { Households' annual income in intervals of } \\
\text { USD } \$ 10,000(1=\mathrm{USD} \$ 10,000 \text { or less } \ldots . \\
11=\text { over USD } \$ 100,000)\end{array}$ & 603 & 6.33 & 3.52 \\
\hline VOLUNTARY & $\begin{array}{l}\text { If the respondent received a voluntary order } \\
\text { to evacuate }(1=\text { Yes, } 0=\text { Otherwise })\end{array}$ & 949 & 0.26 & 0.44 \\
\hline MANDATORY & $\begin{array}{l}\text { If the respondent received a mandatory } \\
\text { order to evacuate ( } 1=\text { Yes, } 0=\text { Otherwise })\end{array}$ & 949 & 0.30 & 0.46 \\
\hline EXPERIENCE & $\begin{array}{l}\text { If the respondent evacuated for the } \\
\text { hurricane before ( } 1=\text { Yes, } 0=\text { Otherwise) }\end{array}$ & 869 & 0.59 & 0.49 \\
\hline HHSIZE & $\begin{array}{l}\text { The number of individuals lived in the } \\
\text { respondent's household }\end{array}$ & 1021 & 2.66 & 1.56 \\
\hline$E D U C$ & $\begin{array}{l}\text { If the respondent had a college degree } \\
(1=\text { Yes, } 0=\text { Otherwise })\end{array}$ & 979 & 0.52 & 0.50 \\
\hline$A G E$ & The respondent's age (in years) & 996 & 58.84 & 15.67 \\
\hline OWNER & $\begin{array}{l}\text { If the respondent owned the house }(1=\text { Yes, } \\
0=\text { Otherwise })\end{array}$ & 1015 & 0.88 & 0.33 \\
\hline IMPSURGE & $\begin{array}{l}\text { If the respondents considered the possibility } \\
\text { of flooding to be important ( } 1=\text { Yes, } \\
0=\text { Otherwise) }\end{array}$ & 794 & 0.37 & 0.48 \\
\hline IMPCRIME & $\begin{array}{l}\text { If the respondent thought protecting home } \\
\text { from crime and looting is important ( } 1=\text { Yes, } \\
0=\text { Otherwise) }\end{array}$ & 793 & 0.42 & 0.49 \\
\hline GENDER & 1 if male, 0 if female & 1055 & 0.33 & 0.47 \\
\hline$D A Y S$ & $\begin{array}{l}\text { The number of days was the respondent } \\
\text { away from home when they evacuated }\end{array}$ & 492 & 9.22 & 18.42 \\
\hline IMORDER & If the respondent thought the evacuation & 790 & 0.36 & 0.48 \\
\hline
\end{tabular}


orders given by the government is important

( $1=$ Yes, $0=$ Otherwise)

\begin{tabular}{|c|c|c|c|c|}
\hline IMPETS & $\begin{array}{l}\text { If the respondent thought the needs of pets } \\
\text { or animals is important }(1=\text { Yes, } \\
0=\text { Otherwise })\end{array}$ & 721 & 0.36 & 0.48 \\
\hline LAIDOFF & $\begin{array}{l}\text { If the respondent was laid off from work } \\
\text { because of Hurricane Ike ( } 1=\text { Yes, } \\
0=\text { Otherwise })\end{array}$ & 758 & 0.10 & 0.30 \\
\hline$R A C E$ & $\begin{array}{l}\text { If the respondents identified themselves as } \\
\text { the white }(1=\text { Yes, } 0=\text { Otherwise })\end{array}$ & 986 & 0.77 & 0.37 \\
\hline CHILDREN & $\begin{array}{l}\text { If the respondent had children } \\
(1=\text { Yes, } 0=\text { Otherwise })\end{array}$ & 1053 & 0.17 & 0.37 \\
\hline MOBILE & $\begin{array}{l}\text { If the respondent's home was a mobile } \\
\text { home ( } 1=\text { Yes, } 0=\text { Otherwise })\end{array}$ & 1013 & 0.90 & 0.29 \\
\hline NEIGHBOR & $\begin{array}{l}\text { If the respondent's neighbors influenced } \\
\text { their evacuation decisions ( } 1=\text { Yes, } \\
0=\text { Otherwise) }\end{array}$ & 1025 & 0.13 & 0.33 \\
\hline WINDOWPREP & $\begin{array}{l}\text { if the respondent was prepared to protect } \\
\text { windows against hurricanes }(1=\text { Yes, } \\
0=\text { Otherwise) }\end{array}$ & 1017 & 0.51 & 0.50 \\
\hline
\end{tabular}


Table 3.2 Variable Definitions and Descriptive Statistics for Analyzing Evacuation Behavior during Hurricane Sandy

\begin{tabular}{|c|c|c|c|c|}
\hline Variable & Description & $\mathrm{N}$ & Mean & SD \\
\hline$E V A C$ & $\begin{array}{l}\text { If the respondent evacuated for Hurricane } \\
\text { Sandy } \\
(1=\text { Yes, } 0=\text { Otherwise) }\end{array}$ & 1212 & 0.08 & 0.26 \\
\hline$T I M E$ & $\begin{array}{l}\text { When the respondent evacuated for } \\
\text { Hurricane Sandy }(0=\text { the day Sandy hit } \\
\ldots .6=6 \text { days before Sandy hit })\end{array}$ & 91 & 1.07 & 3.54 \\
\hline EXPERIENCE & $\begin{array}{l}\text { If the respondent evacuated for a hurricane } \\
\text { before ( } 1=\text { Yes, } 0=\text { Otherwise) }\end{array}$ & 1212 & 0.06 & 0.24 \\
\hline HHSIZE & $\begin{array}{l}\text { The number of individuals lived in the } \\
\text { respondent's household }\end{array}$ & 1212 & 2.49 & 1.28 \\
\hline$R A C E$ & $\begin{array}{l}\text { If the respondents identified themselves as } \\
\text { the white ( } 1=\text { Yes, } 0=\text { Otherwise) }\end{array}$ & 1212 & 0.80 & 0.40 \\
\hline OWNER & $\begin{array}{l}\text { If the respondent owned the house }(1=\text { Yes, } \\
0=\text { Otherwise })\end{array}$ & 1212 & 0.78 & 0.41 \\
\hline$D A Y S$ & $\begin{array}{l}\text { The number of days was the respondent } \\
\text { away from home when they evacuated }\end{array}$ & 1212 & 1.64 & 2.41 \\
\hline INSURANCE & $\begin{array}{l}\text { If the respondent had an insurance policy } \\
\text { that paid for damages to their home from a } \\
\text { storm or hurricane ( } 1=\text { Yes, } 0=\text { Otherwise) }\end{array}$ & 1212 & 0.59 & 0.49 \\
\hline SMOKE & $\begin{array}{l}\text { If the respondent smoke }(1=\text { Yes, } \\
0=\text { Otherwise })\end{array}$ & 1212 & 0.10 & 0.29 \\
\hline SENIOR & $\begin{array}{l}\text { The number of seniors in the respondent's } \\
\text { household }\end{array}$ & 1212 & 2.47 & 0.77 \\
\hline VEHICLES & $\begin{array}{l}\text { The number of vehicles in the respondent's } \\
\text { household }\end{array}$ & 1212 & 3.87 & 1.18 \\
\hline$H E A D$ & $\begin{array}{l}\text { If the respondent was the head of their } \\
\text { household ( } 1=\text { Yes, } 0=\text { Otherwise) }\end{array}$ & 1212 & 0.87 & 0.34 \\
\hline LIVED & $\begin{array}{l}\text { The number of years had the respondent } \\
\text { lived }\end{array}$ & 1212 & 23.85 & 19.17 \\
\hline PLAN & $\begin{array}{l}\text { If the respondent's household had a } \\
\text { hurricane evacuation plan } \\
\text { (1=Yes, } 0=\text { Otherwise) }\end{array}$ & 1212 & 0.34 & 0.47 \\
\hline PREPARE & $\begin{array}{l}\text { If the respondent's household made the } \\
\text { necessary preparations to leave their home } \\
\text { to go someplace safer in the event of a } \\
\text { hurricane this year ( } 1=\text { Yes, } 0=\text { Otherwise) }\end{array}$ & 1212 & 0.28 & 0.45 \\
\hline
\end{tabular}




\begin{tabular}{|c|c|c|c|c|}
\hline FLOOD & $\begin{array}{l}\text { If the respondent's household lived in flood } \\
\text { zone }\end{array}$ & 1212 & 0.13 & 0.34 \\
\hline $\begin{array}{l}\text { INFORMATIO } \\
N\end{array}$ & $\begin{array}{l}\text { If the respondent's household told by a } \\
\text { government or news broadcast to evacuate } \\
\text { their home when Hurricane Sandy hit }\end{array}$ & 1212 & 0.08 & 0.27 \\
\hline$A G E$ & The respondent's age (in years) & 1212 & 52.91 & 15.43 \\
\hline GENDER & 1 if male, 0 if female & 1212 & 0.40 & 0.49 \\
\hline WINDOW & $\begin{array}{l}\text { If the respondent's home had any window } \\
\text { protection ( } 1=\text { Yes, } 0=\text { Otherwise) }\end{array}$ & 1212 & 0.05 & 0.23 \\
\hline DISABLES & $\begin{array}{l}\text { The number of disables in the respondent's } \\
\text { household }\end{array}$ & 1212 & 2.17 & 0.54 \\
\hline
\end{tabular}


Table 3.3 Selection Models of Evacuation Time Decision for Hurricane Ike

\begin{tabular}{|c|c|c|c|c|}
\hline TIME & Model 1 & Model 2 & Model 3 & Model 4 \\
\hline EXPERIENCE & $\begin{array}{l}0.391(0.157) \\
* *\end{array}$ & $\begin{array}{l}0.471(0.224) \\
* *\end{array}$ & $0.414(0.216) *$ & $0.471(0.214) * *$ \\
\hline IMORDER & $\begin{array}{l}0.393(0.122) \\
* * *\end{array}$ & $\begin{array}{l}0.294(0.178) \\
*\end{array}$ & $0.37(0.167) * *$ & $0.293(0.177) *$ \\
\hline$R A C E$ & $\begin{array}{l}-0.277(0.137) \\
* *\end{array}$ & $\begin{array}{l}-0.583(0.216) \\
* * *\end{array}$ & $-0.568(0.214) * * *$ & $-0.582(0.208) * * *$ \\
\hline NEIGHBOR & $\begin{array}{l}-0.47(0.184) \\
* *\end{array}$ & $\begin{array}{l}-0.533(0.254) \\
* *\end{array}$ & $-0.488(0.247) * *$ & $-0.539(0.255) * *$ \\
\hline$D A Y S$ & $\begin{array}{l}0.031(0.008) \\
* * *\end{array}$ & $\begin{array}{l}0.046(0.011) \\
* * *\end{array}$ & $0.047(0.011) * * *$ & $0.046(0.011) * * *$ \\
\hline OWNER & $\begin{array}{l}0.436(0.187) \\
* *\end{array}$ & $0.51(0.292) *$ & $0.591(0.269) * *$ & $0.531(0.305) *$ \\
\hline INDEXP & $\begin{array}{l}-0.00004(0) \\
* * *\end{array}$ & $-0.001(0) * * *$ & $-0.001(0) * * *$ & $-0.001(0) * * *$ \\
\hline IMPCRIME & & $-0.086(0.192)$ & $-0.043(0.188)$ & $-0.093(0.193)$ \\
\hline IMPSURGE & & $0.146(0.232)$ & $0.045(0.216)$ & $0.155(0.232)$ \\
\hline VOLEVACOR & & $-0.018(0.315)$ & $-0.063(0.312)$ & $-0.016(0.294)$ \\
\hline MANEVACOR & & $0.453(0.543)$ & $0.313(0.532)$ & $0.465(0.503)$ \\
\hline INCOME & & $0.001(0.028)$ & $0.009(0.027)$ & $0.001(0.028)$ \\
\hline HHSIZE & & $0.006(0.067)$ & $-0.01(0.055)$ & $0.005(0.067)$ \\
\hline$E D U C$ & & $-0.058(0.163)$ & $-0.048(0.161)$ & $-0.059(0.163)$ \\
\hline GENDER & & $0.052(0.193)$ & $0.089(0.188)$ & $0.044(0.195)$ \\
\hline IMPPETS & & $-0.124(0.183)$ & $-0.09(0.173)$ & $-0.125(0.184)$ \\
\hline WINDOWPRE & & $0.064(0.156)$ & & $0.083(0.164)$ \\
\hline \multicolumn{5}{|l|}{$P$} \\
\hline$A G E$ & & $-0.004(0.007)$ & & $-0.004(0.007)$ \\
\hline CHILDREN & & $-0.212(0.197)$ & & $-0.204(0.199)$ \\
\hline MOBILE & & $0.195(0.327)$ & & $0.161(0.317)$ \\
\hline Constant & $\begin{array}{l}2.117(0.245) \\
* * *\end{array}$ & $\begin{array}{l}1.898(0.912) \\
* *\end{array}$ & $1.903(0.734) * *$ & $1.882(0.861) * *$ \\
\hline \multicolumn{5}{|l|}{$E V A C$} \\
\hline EXPERIENCE & $\begin{array}{l}0.409(0.194) \\
* *\end{array}$ & $\begin{array}{l}0.501(0.236) \\
* *\end{array}$ & $0.498(0.236) * *$ & $0.473(0.242) *$ \\
\hline VOLEVACOR & $\begin{array}{l}0.936(0.202) \\
* * *\end{array}$ & $\begin{array}{l}0.817(0.246) \\
* * *\end{array}$ & $0.83(0.245) * * *$ & $0.816(0.251) * * *$ \\
\hline MANEVACOR & $\begin{array}{l}2.008(0.24) \\
* * *\end{array}$ & $\begin{array}{l}2.106(0.284) \\
* * *\end{array}$ & $2.098(0.282) * * *$ & $2.074(0.288) * * *$ \\
\hline
\end{tabular}




\begin{tabular}{|c|c|c|c|c|}
\hline$R A C E$ & $\begin{array}{l}-0.662(0.239) \\
* * *\end{array}$ & $\begin{array}{l}-0.801(0.304) \\
* * *\end{array}$ & $-0.776(0.298) * * *$ & $-0.757(0.308) * *$ \\
\hline LAIDOFF & $\begin{array}{l}-0.599(0.278) \\
* *\end{array}$ & $\begin{array}{l}-0.796(0.354) \\
* *\end{array}$ & $-0.799(0.356) * *$ & $-0.88(0.37) * *$ \\
\hline IMPCRIME & $-0.355(0.19) *$ & $\begin{array}{l}-0.463(0.241) \\
*\end{array}$ & $-0.461(0.241) *$ & $-0.453(0.243) *$ \\
\hline IMPSURGE & $\begin{array}{l}0.533(0.186) \\
* * *\end{array}$ & $\begin{array}{l}0.799(0.262) \\
* * *\end{array}$ & $0.799(0.262) * * *$ & $0.806(0.262) * * *$ \\
\hline OWNER & $0.519(0.271) *$ & $0.586(0.336)$ & $0.615(0.33) *$ & $0.821(0.41) * *$ \\
\hline INDEXP & $-0.001(0) * * *$ & $-0.001(0) *$ & $-0.001(0) *$ & $-0.001(0) *$ \\
\hline GENDER & $\begin{array}{l}-0.449(0.187) \\
* *\end{array}$ & $\begin{array}{l}-0.476(0.224) \\
* *\end{array}$ & $-0.477(0.224) * *$ & $-0.525(0.231) * *$ \\
\hline NEIGHBOR & & $-0.432(0.346)$ & $-0.43(0.346)$ & $-0.485(0.354)$ \\
\hline HHSIZE & & $-0.03(0.09)$ & $-0.047(0.082)$ & $-0.059(0.107)$ \\
\hline$E D U C$ & $0.028(0.179)$ & $-0.109(0.219)$ & $-0.111(0.218)$ & $-0.074(0.221)$ \\
\hline IMPPETS & & $-0.352(0.249)$ & $-0.348(0.248)$ & $-0.337(0.255)$ \\
\hline $\begin{array}{l}\text { WINDOWPRE } \\
P\end{array}$ & & & & $0.252(0.226)$ \\
\hline$A G E$ & & $0.004(0.01)$ & & $0.004(0.01)$ \\
\hline CHILDREN & & & & $0.141(0.322)$ \\
\hline MOBILE & & & & $-0.452(0.46)$ \\
\hline Constant & $\begin{array}{l}-0.683(0.341) \\
* *\end{array}$ & $-0.907(0.727)$ & $-0.664(0.506)$ & $-0.785(0.745)$ \\
\hline$\rho$ & $-0.095(0.147)$ & $0.163(0.453)$ & $0.049(0.437)$ & $0.182(0.43)$ \\
\hline$\sigma$ & -0.132 & 0.251 & 0.075 & 0.278 \\
\hline$\lambda$ & 0.714 & 0.650 & 0.648 & 0.652 \\
\hline$N$ & 320 & 249 & 250 & 246 \\
\hline $\operatorname{Wald}\left(\chi^{2}\right)$ & $46.39 * * *$ & $57.75 * * *$ & $55.09 * * *$ & $58.61 * * *$ \\
\hline
\end{tabular}

Notes: $* * *, * *, *$ imply significance at $1 \%, 5 \%$, and $10 \%$ levels respectively; numbers in parentheses are corresponding standard errors. 
Table 3.4 Robustness Analysis for Hurricane Ike

\begin{tabular}{lll}
\hline TIME & Poisson Model & $\begin{array}{c}\text { Generalized Linear } \\
\text { Latent and Mixed } \\
\text { Model }\end{array}$ \\
\hline EXPERIENCE & $0.293(0.169) *$ & $0.278(0.167) *$ \\
IMORDER & $0.231(0.139) *$ & $0.243(0.135) *$ \\
DAYS & $0.014(0.007) *$ & $0.014(0.007) *$ \\
RACE & $-0.14(0.155)$ & $-0.136(0.153)$ \\
NEIGHBOR & $-0.097(0.197)$ & $-0.104(0.19)$ \\
OWNER & $0.173(0.254)$ & $0.275(0.21)$ \\
INDEXP & $-0.001(0)$ & $0(0)$ \\
IMPCRIME & $-0.053(0.132)$ & $-0.054(0.131)$ \\
IMPSURGE & $0.015(0.139)$ & $0.012(0.136)$ \\
HHSIZE & $-0.014(0.052)$ & $-0.004(0.047)$ \\
GENDER & $0.082(0.129)$ & $0.082(0.128)$ \\
IMPPETS & $0.012(0.143)$ & $-0.011(0.138)$ \\
LAIDOFF & $0.004(0.253)$ & $-0.035(0.249)$ \\
WINDOWPREP & $-0.041(0.125)$ & $-0.02(0.123)$ \\
AGE & $-0.002(0.006)$ & $-0.002(0.006)$ \\
CHILDREN & $0.038(0.183)$ & \\
MOBILE & $0.242(0.321)$ & \\
Constant & $0.063(0.477)$ & $0.186(0.432)$ \\
\hline
\end{tabular}


Table 3.5 Selection Models of Evacuation Time Decision for Hurricane Sandy

\begin{tabular}{|c|c|c|c|c|}
\hline TIME & Model 1 & Model 2 & Model 3 & Model 4 \\
\hline EXPERIENCE & $2.831(1.076) * * *$ & *3.802(1.812) ** & $3.48(1.62) * *$ & $3.638(1.74) * *$ \\
\hline OWNER & $2.13(0.73) * * *$ & $2.114(0.769) * * *$ & $2.085(0.761) * * *$ & $* 2.111(0.758) * * *$ \\
\hline INDEX & $0.002(0.001) * * *$ & $*^{*} 0.002(0.001) * * *$ & $0.002(0.001) * * *$ & $* 0.002(0.001) * * *$ \\
\hline HHSIZE & $-0.556(0.28) * *$ & $-0.73(0.392) *$ & $-0.707(0.366) *$ & $-0.68(0.378) *$ \\
\hline INSURANCE & $-1.442(0.632) * *$ & $-1.429(0.814) *$ & $-1.485(0.749) * *$ & $-1.487(0.786) *$ \\
\hline$R A C E$ & $-1.903(0.792) * *$ & $-2.223(1.025) * *$ & $-2.096(0.908) * *$ & $-2.087(1.001) * *$ \\
\hline$D A Y S$ & $0.196(0.09) * *$ & $0.189(0.085) * *$ & $0.194(0.088) * *$ & $0.199(0.086) * *$ \\
\hline SMOKE & $3.553(1.089) * * *$ & *3.02(1.531)** & $3.093(1.389) * *$ & $3.317(1.487) * *$ \\
\hline PREPARE & $2.127(1.1) *$ & $2.956(1.633) *$ & $2.634(1.489) *$ & $2.765(1.544) *$ \\
\hline FLOOD & & $0.896(1.198)$ & $0.657(1.1)$ & $0.831(1.145)$ \\
\hline INFORMATION & $3.122(2.13)$ & $5.689(3.836)$ & $4.668(3.33)$ & $5.298(3.643)$ \\
\hline VEHICLES & & $0.126(0.39)$ & $0.112(0.354)$ & $0.113(0.375)$ \\
\hline$H E A D$ & & $-0.983(1.369)$ & $-0.588(1.154)$ & $-0.936(1.327)$ \\
\hline LIVED & $-0.016(0.014)$ & $-0.015(0.019)$ & $-0.012(0.018)$ & $-0.015(0.019)$ \\
\hline PLAN & $-1.455(0.8)$ & $-1.038(1.062)$ & $-1.291(0.838)$ & $-0.995(1.025)$ \\
\hline$A G E$ & & $0.016(0.022)$ & & $0.018(0.022)$ \\
\hline GENDER & & $-0.576(0.784)$ & & $-0.558(0.757)$ \\
\hline DISABLES & & & & $-0.698(0.722)$ \\
\hline Constant & $-4.922(4.113)$ & $-10.665(7.367)$ & $-8.212(6.369)$ & $-8.674(6.931)$ \\
\hline \multicolumn{5}{|l|}{$E V A C$} \\
\hline EXPERIENCE & $0.58(0.197) * * *$ & $0.574(0.198) * * *$ & $0.581(0.197) * * *$ & $* 0.58(0.2) * * *$ \\
\hline SENIOR & $0.164(0.081) * *$ & $0.163(0.083) * * *$ & $0.164(0.083) * *$ & $0.172(0.084) * *$ \\
\hline PREPARE & $0.536(0.129) * * *$ & ${ }^{*} 0.488(0.163) * * *$ & $0.535(0.13) * * *$ & $0.488(0.163) * * *$ \\
\hline FLOOD & $0.326(0.164) * *$ & $0.319(0.166) *$ & $0.325(0.165) * *$ & $0.323(0.166) * *$ \\
\hline INFORMATION & $1.409(0.176) * * *$ & * $1.403(0.177)$ *** & $* 1.41(0.176) * * *$ & $1.401(0.177) * * *$ \\
\hline$H E A D$ & $-0.3(0.172) *$ & $-0.304(0.173) *$ & $-0.299(0.172) *$ & $-0.314(0.174) *$ \\
\hline HHSIZE & $-0.081(0.051)$ & $-0.078(0.056)$ & $-0.078(0.055)$ & $-0.076(0.056)$ \\
\hline$R A C E$ & $-0.167(0.154)$ & $-0.17(0.157)$ & $-0.165(0.157)$ & $-0.17(0.157)$ \\
\hline INSURANCE & & $-0.001(0.137)$ & $0.002(0.137)$ & $-0.007(0.138)$ \\
\hline SMOKE & $-0.31(0.236)$ & $-0.316(0.237)$ & $-0.313(0.237)$ & $-0.294(0.241)$ \\
\hline VEHICLES & & $-0.008(0.063)$ & $-0.007(0.063)$ & $-0.009(0.063)$ \\
\hline LIVED & & $0(0.003)$ & $0(0.003)$ & $0(0.003)$ \\
\hline PLAN & & $0.08(0.164)$ & & $0.089(0.165)$ \\
\hline
\end{tabular}




\begin{tabular}{|c|c|c|c|c|}
\hline GENDER & & $0.023(0.13)$ & & $0.023(0.131)$ \\
\hline WINDOW & & & & $-0.01(0.253)$ \\
\hline DISABLES & & & & $-0.075(0.125)$ \\
\hline$\rho$ & $2.322(1.827)$ & $4.959(3.57)$ & $3.991(3.172)$ & $4.576(3.402)$ \\
\hline$\sigma$ & 0.710 & 1.000 & 0.934 & 0.982 \\
\hline$\lambda$ & 3.269 & 4.959 & 4.275 & 4.660 \\
\hline$N$ & 1211 & 1211 & 1211 & 1211 \\
\hline $\operatorname{Wald}(\chi 2)$ & $61.95^{* * *}$ & $47.73^{* * *}$ & $52.50 * * *$ & $50.87 * * *$ \\
\hline
\end{tabular}


Table 3.6 Robustness Analysis for Hurricane Sandy

\begin{tabular}{lll}
\hline TIME & Poisson Model & $\begin{array}{l}\text { Generalized Linear } \\
\text { Latent and Mixed } \\
\text { Model }\end{array}$ \\
\hline EXPERIENCE & $0.532(0.27) * *$ & $0.499(0.268) *$ \\
OWNER & $1.026(0.333) * * *$ & $1.211(0.317) * * *$ \\
HHSIZE & $-0.323(0.137) * *$ & $-0.444(0.124) * * *$ \\
INSURANCE & $-0.903(0.265) * * *$ & $-0.915(0.267) * * *$ \\
RACE & $-0.636(0.262) * *$ & $-0.791(0.242) * * *$ \\
DAYS & $0.184(0.051) * * *$ & $0.219(0.048) * * *$ \\
PREPARE & $0.444(0.266) *$ & $0.518(0.263) * *$ \\
HEAD & $-0.361(0.337)$ & $-0.526(0.313) *$ \\
INDEX & $0(0) *$ & \\
Constant & $-1.517(0.836) *$ & $-1.487(0.826)^{*}$ \\
\hline
\end{tabular}




\section{FIGURES}

Figure 3.1 Respondents who have hurricane experience before for Ike

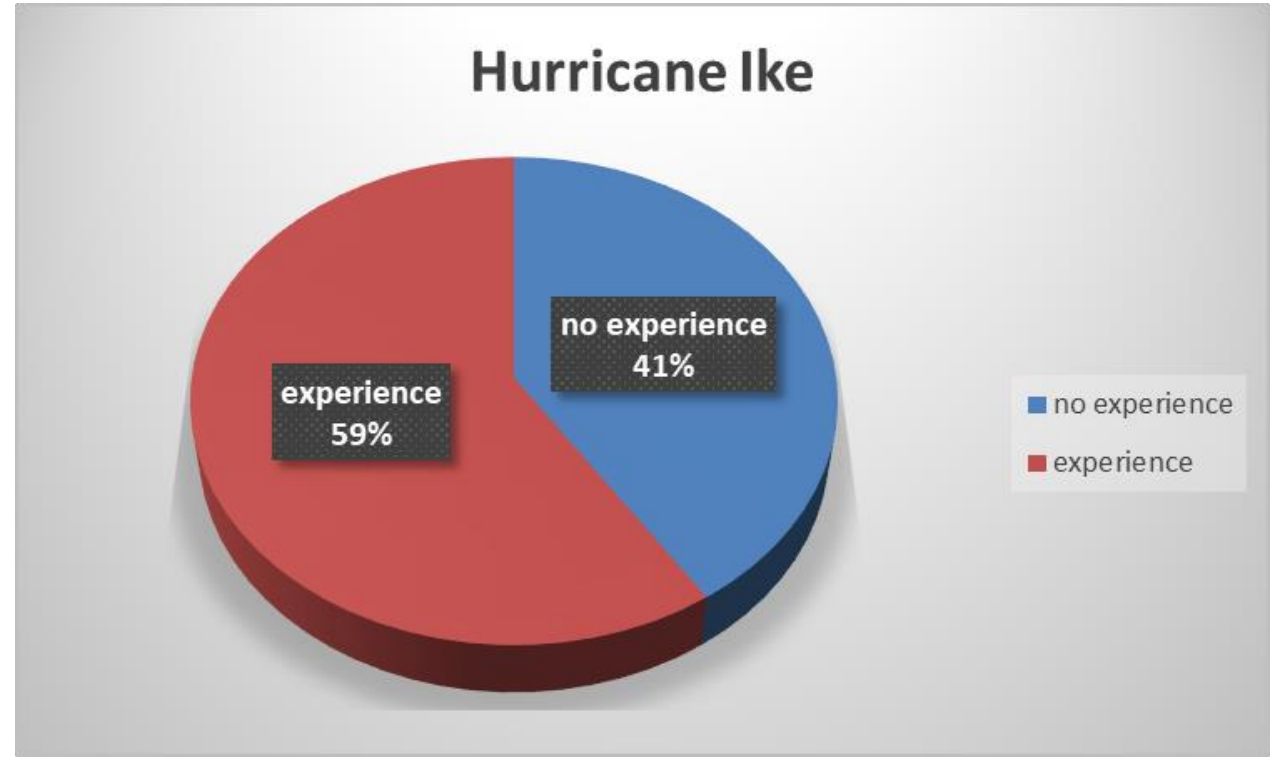

Figure 3.2 Respondents who have hurricane experience before for Sandy

\section{Hurricane Sandy}

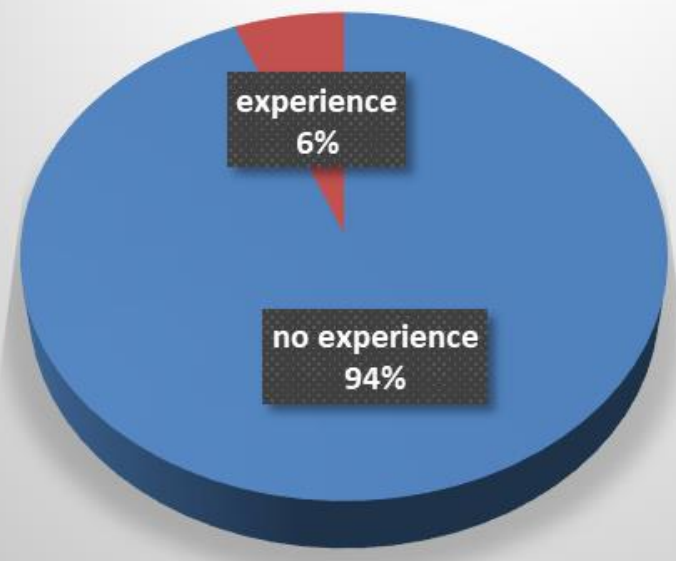

n no experience

axperience 
Figure 3.3 Hurricane Ike Evacuation Time Interval

\section{Percent of Evacuees at Different Time Intervals for Hurricane Ike}

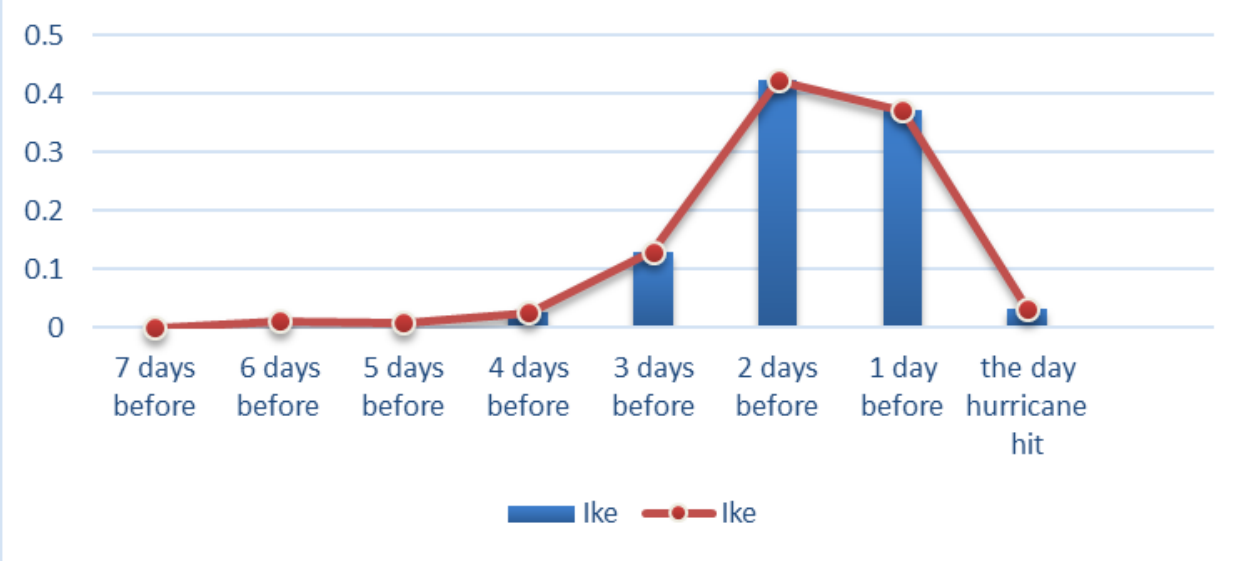

Figure 3.4 Hurricane Sanday Evacuation Time Interval

\section{Percent of Evacuees at Different Time Intervals for Hurricane Sandy}

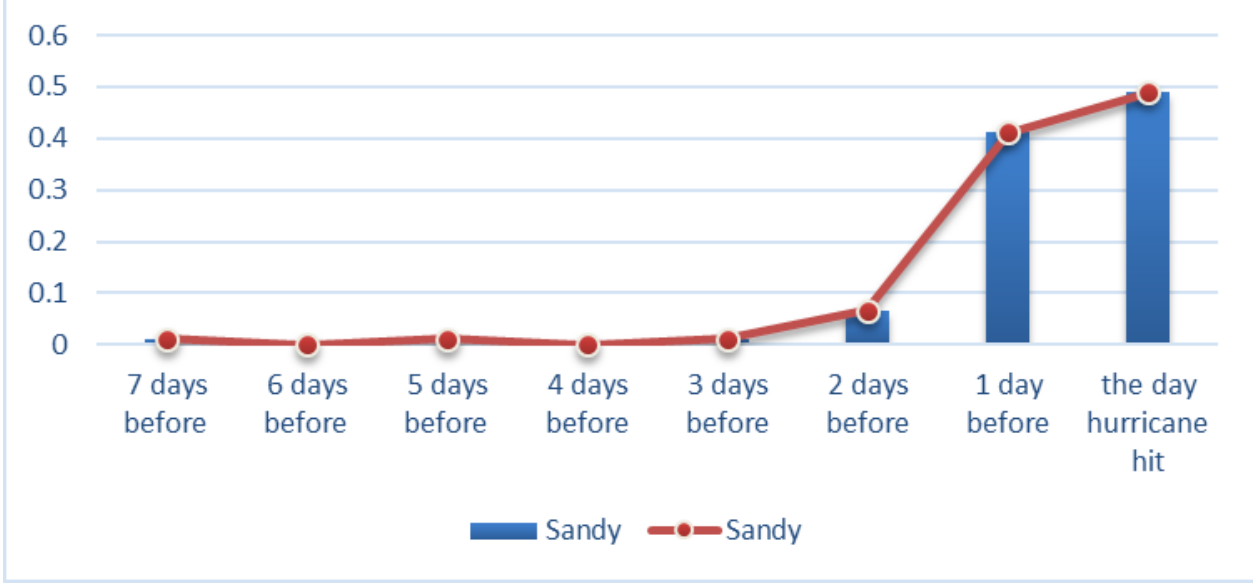


Figure 3.5 Hurricane Evacution Time Interval

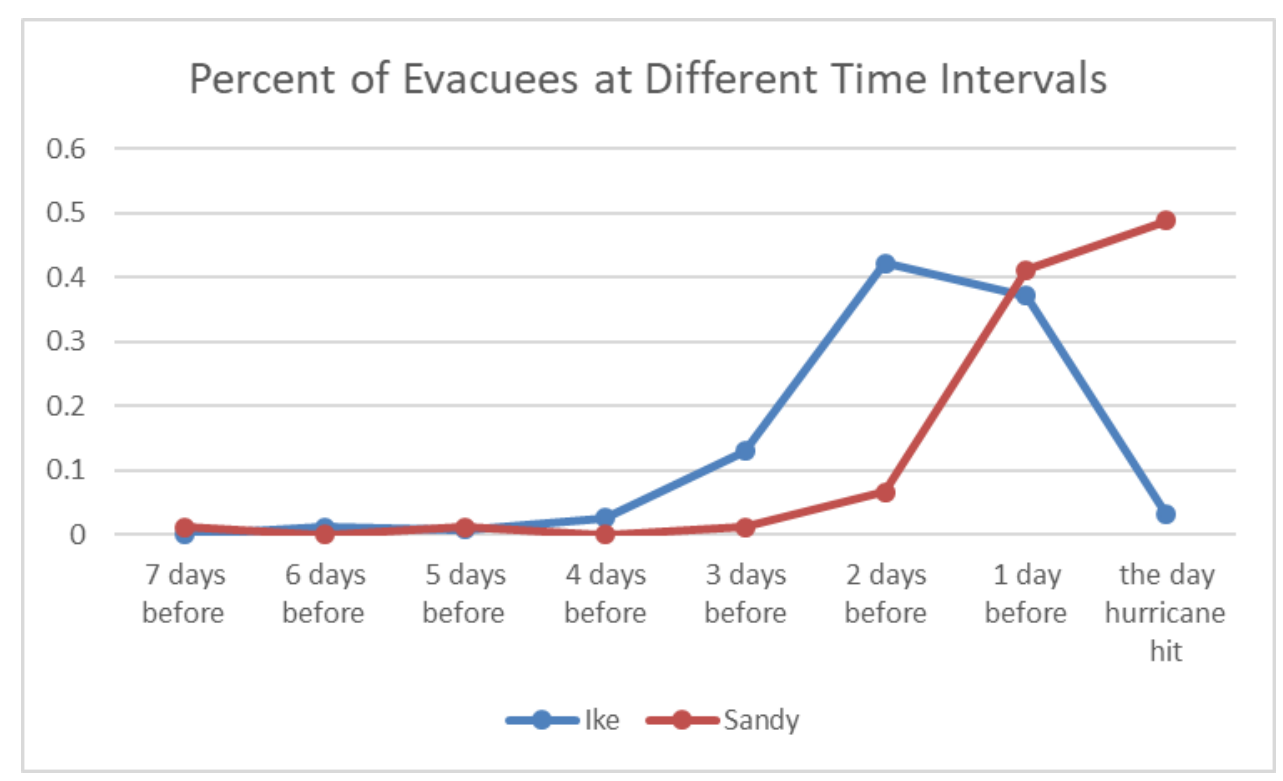


Figure 3.6 Reference Point with Hurricane Experience

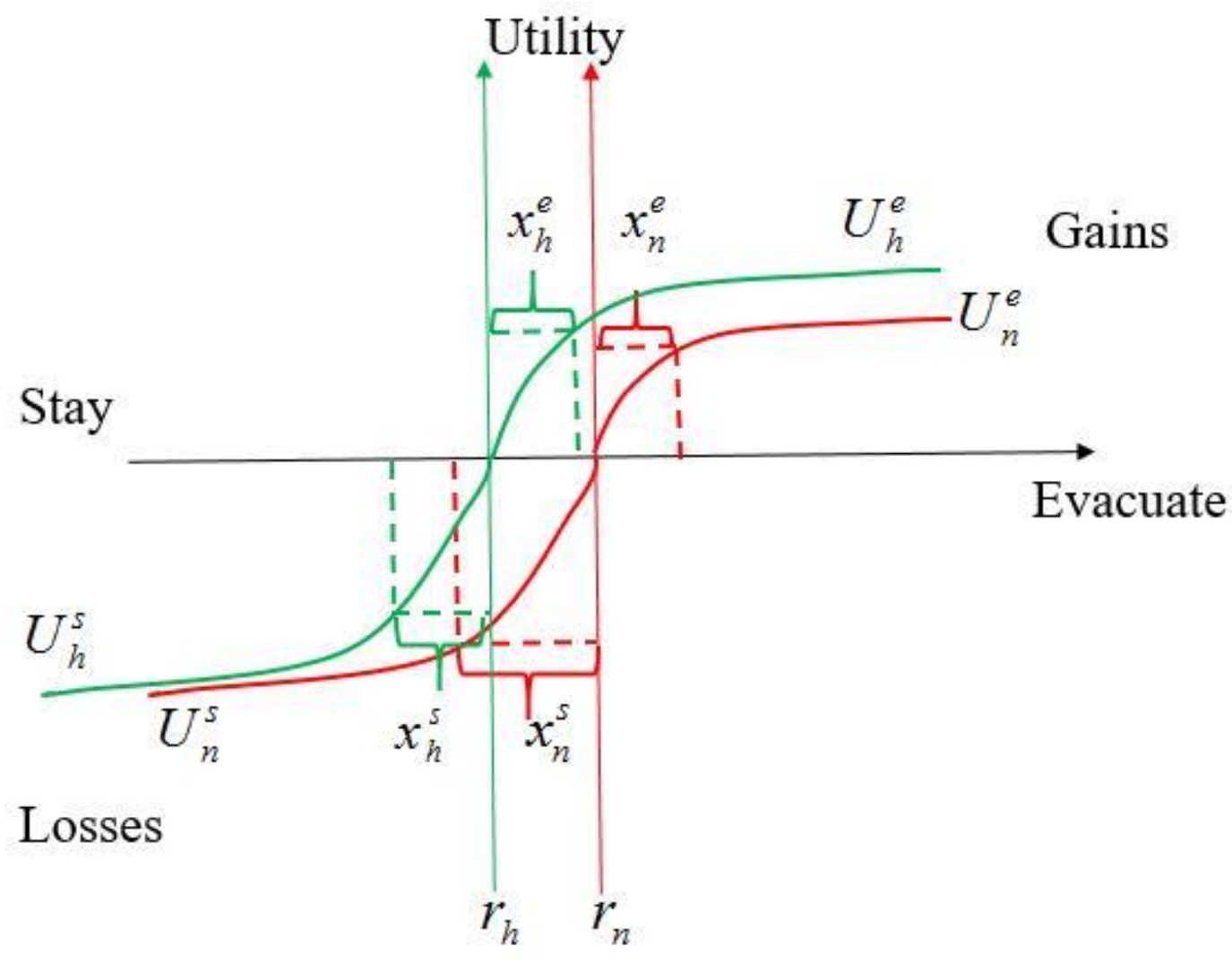

Reference Point

1

$1 U_{h}$ is the utility of people who have the hurricane experience before and $U_{n}$ is for no hurricane experience. $\lambda$ is the probability of hurricane evacuation. $U^{e}$ is the utility of hurricane evacuees and $U^{s}$ is the utility of people who chose to stay. $x^{e}$ is the days that evacuees chose to leave and $x^{s}$ is the days residents chose to stay. $r_{h}$ is the reference level of people who have the hurricane experience and $r_{n}$ is for no experience. 
Figure 3.7 Hurricane Ike Track

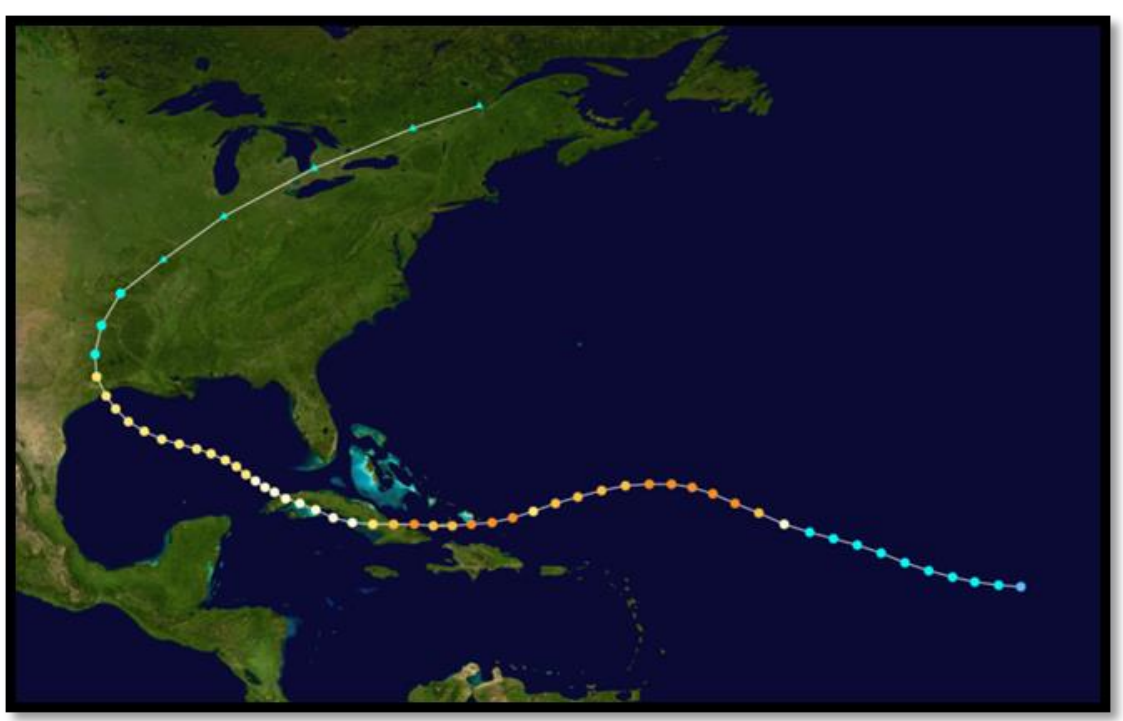

Figure 3.8 Hurricane Sandy Track

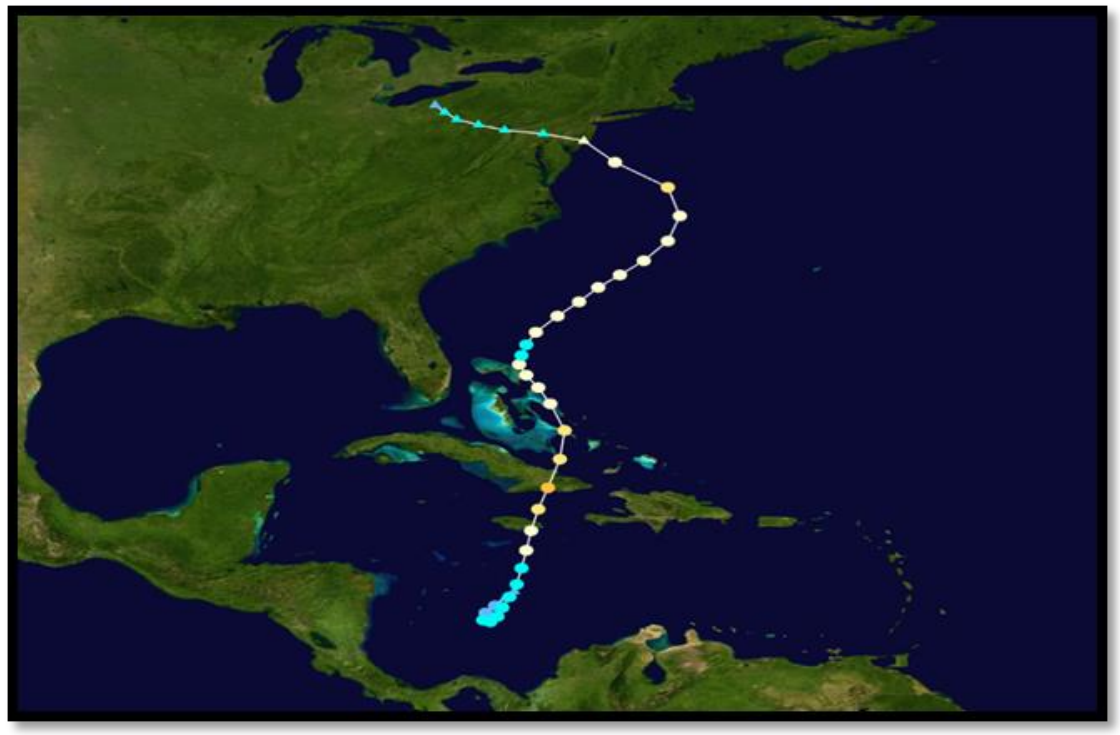




\section{CHAPTER 4}

\section{CONCLUSION}

\subsection{Summary of the Dissertation}

In this dissertation, I concentrate on three core areas of research. First, I have lived in Miami for six years and experienced hurricane seasons each year. I have seen that people always feel panic and do not know when and where to go when a hurricane is approaching. I have worked with hurricane survey data for the last few years and found that effective hurricane preparation and evacuation plans can save human lives and minimize property loss. In Chapter 1, I use revealed preference (RP) data and stated preference (SP) data on the evacuation cost and evacuation decision during Hurricane Ike. I estimate individuals' willingness to pay (WTP) for an evacuation to mitigate hurricane risks and calculate the associated value of a statistical life (VSL).

Second, in each hurricane season, I have seen severe property damage due to the massive rain and intense winds. Hurricanes cause extensive property damage and negatively affect home values. People tends to adopt hurricane mitigation measures (e.g., putting on shutters) to reduce property loss. I am interested in understanding the market response to hurricane exposures and the value of hurricane mitigation. I use repeat sales data and estimate a hedonic price model with a semi-log transformation approach. I utilize a set of regression models to predict the marginal effects of a set of hurricane-related variables and other pertinent factors on property values. 
Finally, I did evacuate from Miami for Hurricane Matthew and Hurricane Irma. I experienced high traffic congestion and damage to road networks. I have observed that many people, mostly those with a lack of hurricane evacuation experience, struggle to decide on an evacuation time and destination. In Chapter 3, I investigate the evacuation timing decisions made by households during a hurricane event and predict the time preferences associated with their evacuation behaviors. I use data on evacuation timing decisions from Hurricane Ike and Hurricane Sandy and identify the significant factors that affect individuals' evacuation timing decisions.

\subsection{Discussion}

\subsubsection{Contribution of This Dissertation}

Individuals are affected by hurricanes in various ways, and the cost of evacuation captures only the out-of-pocket expenses that individuals pay when they evacuate. Individuals always encounter the tradeoff between potential expenses and hurricane risk. In Chapter 1, the empirical approaches analyze the values associated with evacuation (for reducing mortality and morbidity risks) and other risk reduction measures, which are often missing. The findings not only indicate the primary set of determinants of evacuation decisions but also reveal that more lives could be saved if governments would have issued a mandatory evacuation order instead of a voluntary evacuation order. This research provides useful information for emergency management agencies and community planners in Texas and beyond. 
Florida is one of the states most vulnerable to hurricane exposure. Hurricane exposures affect property values in the real estate market of Florida. In recent hurricane seasons, Florida has encountered more than one hurricane hit, and understanding the real estate market responses to multiple hurricane exposures is essential for robust economic analysis. The results in Chapter 2 indicate that sets of hurricane-related variables, location-related variables, and home characteristics influence property value appreciation. Moreover, the analysis includes useful information regarding hurricane mitigation measures adopted by homeowners. This piece of research provides valuable insights regarding the benefits of hurricane mitigation for Florida residents and beyond.

Hurricane evacuation is an effective option to reduce hurricane-related deaths and property damage. However, the effectiveness of a hurricane evacuation decision is highly time sensitive. In Chapter 3, I utilize a Heckman selection model for investigating the evacuation timing decision of households during a hurricane event and predict their time preferences for future evacuation planning purposes. The results indicate that prior hurricane evacuation experience, ownership of property and race/ethnicity influence the time to evacuate. The findings from this research provide useful information for community planners in coastal areas to manage hurricane-related emergency situations. The findings may be also helpful for household planning in making more effective evacuation decisions. 


\subsubsection{Limitations and Scope for Future Research}

It is worth noting some of the limitations of this dissertation research. In Chapter 1, I use a data set obtained only from Texas. To make a more generalizable conclusion, I need to utilize more data sets from other hurricane-prone areas of the U.S. and elsewhere. By collecting the data from other hurricane events across different locations, I can predict individuals' WTP for avoiding hurricane risks under both voluntary and mandatory evacuation orders and the associated VSL with more confidence.

In Chapter 2, I use repeat sales data from the real estate market in Florida for the period 2000-2010 and estimate the factors that significantly affect the appreciation of property values. The limitation is that I use data only from Martin County and mainly focus on properties that appreciated in value after the 2004-2005 hurricane seasons. In future research, I can extend this analysis to include properties with depreciated values. I can also extend the repeat sales analysis to study the impacts of property values in other states that are frequently affected by hurricanes.

In Chapter 3, I use the cross-sectional evacuation data sets from Hurricane Ike and Sandy. The limitation is that the Atlantic and Gulf coast areas have different geographic and demographic characteristics, and the respondents have different hurricane evacuation experiences. It is important to build and analyze longitudinal data sets across different locations to check the robustness of the findings. 


\subsection{Conclusion}

Hurricanes are becoming the most destructive natural disasters affecting coastal areas. They cause severe property damage and fatalities due to the massive rain and intense winds. Against this backdrop, this dissertation focuses on different components of hurricane risk management. Hurricane evacuation is an effective option to reduce hurricane-related deaths and property damage. However, hurricane evacuations are becoming an increasingly complicated activity since a large number of people need to be evacuated in a timely and efficient manner. Understanding hurricane evacuation behavior is part of the planning puzzle for building sustainable coastal communities. The findings can help social scientists and community planners to understand people's hurricane evacuation behavior in order to devise more effective evacuation plans for coastal residents. The findings from the hedonic model not only provide reliable estimates of hurricane impacts on property values but also offer insights on the value of hurricane risk mitigation for both homebuyers and sellers in coastal areas. 


\section{VITA}

\section{FAN JIANG}

2010

2013

2015

2015-2018

2011-2018

2018

B.S., Mathematics Applied Mathematics

Anhui University

Hefei, China

M.S., Statistics

Florida International University

Miami, FL

M.A., Economics

Florida International University

Miami, FL

Doctoral Candidate in Economics

Florida International University

Miami, FL

Teaching Assistant

Florida International University

Miami, FL

Joins faculty in September

Shanghai University of International Business and Economics

Shanghai, China

\section{PUBLICATIONS}

Chatterjee, C., Flugman, E., Jiang, F., Mozumder, P., Chowdhury, A. (2018). The Role of Information and Incentives in Hurricane Risk Mitigation: Insights from a Stated Preference Experiment of Florida Residents. Under review in Natural Hazards Review. 